
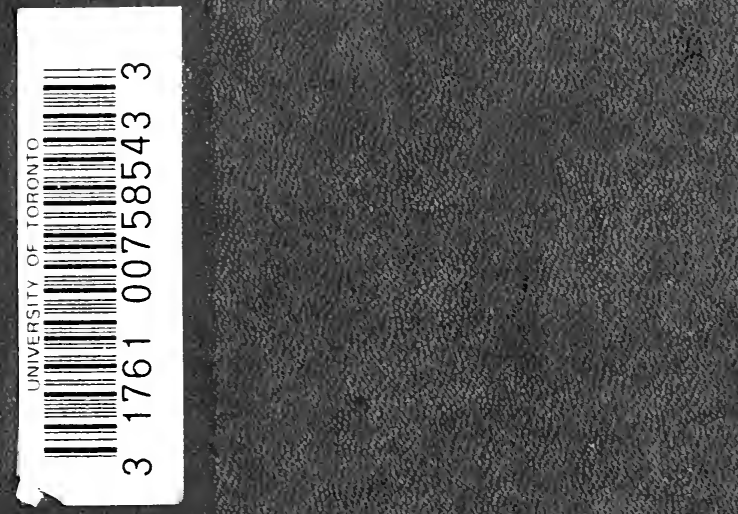


Digitized by the Internet Archive in 2007 with funding from Microsoft Corporation 
varrel

\title{
AN ENQUIRY
}

\author{
CONCERNING
}

\section{HUMAN UNDERSTANDING}

AND SELECTIONS FROM

A TREATISE OF HUMAN NATURE

\author{
$B Y$ \\ DAVID HUME
}

WITH HUME'S AUTOBIOGRAPHY AND

A LETTER FROM ADAM SMITH

LA SALLE

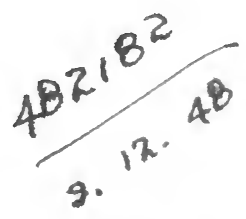

THE OPEN COURT PUBLISHING CO. 


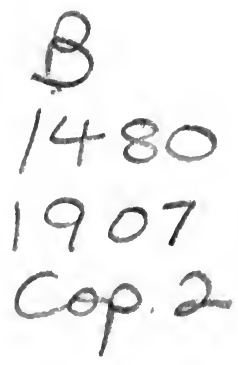

Printed in the United States of America By Paquin Painters, Chicago 


\section{$-i$ \\ PUBLISHERS' PREFACE.}

THE present volume is the second of the series of Philosophical Classics which The Open Court Publishing Company purposes issuing in cheap form for the convenience and instruction of the general reading public. It is an unannotated reprint, merely, of the Enquiry Concerning Human Unaierstanding, made from the posthumous edition of 1777 , together with Hume's charming autobiography and the eulogistic letter of Adam Smith, usually prefixed to the History of England. These additions, with the portrait by Ramsay, which forms the frontispiece to the volume, render the picture of Hume's life complete, and leave but a word to be said concerning his philosophical importance.

With the great public, Hume's fame has always rested upon his History of England,-a work now antiquated as history and remarkable only for the signal elegance and symmetry of its style. But this once prevalent opinion, our age has reversed, and, as has been well remarked,* "Hume, the spiritual father of Kant, now takes precedence over Hume, the rival of Robertson and Gibbon." It is precisely here, in fact, that Hume's significance for the history of thought lies. With him modern philosophy entered upon its Kantian phase, became critical and positivistic, became a theory of knowledge. For the old "false and adulterate" metaphysics he sought to substitute a "true" metaphysics, based on the firm foundations of reason and experience. His scepticism,- -and of scepticism he has since been made the standard-bearer,-was directed against the old ontology only, and not against science proper (inclusive of philosophy). "Had Hume been an absolute sceptic he could never have produced an Immanuel Kant. ... The spirit of the theoretical philosophy of Hume and Kant, the fundamental conception of their investigations, and the goal at which they aim, are perfectly identical. Theirs

-Alfred Weber, History of Philosophy, New York, 1896. 
is the critical spirit, and positive knowledge the goal at which they aim. To claim for Kant the sole honor of having founded criticism is an error which a closer study of British philosophy tends to refute." $\dagger$

To this reprint of Hume's Enquiry Concerning Human Understanding has been added a supplement containing selections from his earlier and longer philosophical work, the Treatise on Human Understanding, referred to in the "Author's Advertisement" to the Enquiry (page xxvirr., this edition). In spite of Hume's deprecatory reference to the Treatise, it remains the completest expression of his philosophical doctrine. The selected portions of the Treatise comprise (I) certain sections on causality which amplify the causal doctrine of the Enquiry and may profitably be read after Section VII. of the latter work; and (2) those sections which embody the essential features of Hume's constructive philosophy, his conception of matter and of self of spirit. Nothing in the Enquiry, with the exception of a few paragraphs of Section XII., corresponds to these sections of the Treatise. They should be read before, or in place of, the comparatively irrelevant sections, IX-XI., of the Enquiry.

The first part of this book, pages I to I74, has been edited by Mr. Thomas J. McCormack of La Salle, Ill., now principal of the La Salle Township High School. The remainder, pages 175 to 263 , has been edited by Prof. Mary Whiton Calkins, of Wellesley College, Wellesley, Mass.

THE OPEN COURT PUBLISHING CO.

March, 1907.

t Weber, loc. cit., pp. 419-420. 


\title{
THE LIFE OF DAVID HUME, ESQ.
}

\author{
WRIT TEN BY HIMSELF.
}

MY OWN LIFE.

$\Gamma^{T}$ is difficult for a man to speak long of himself I without vanity; therefore I shall be short. It may be thought an instance of vanity that I pretend at all to write my life; but this narrative shall contain little more than the history of my writings; as, indeed, al most all my life has been spent in literary pursuits and occupations. The first success of most of my writings was not such as to be an object of vanity. .

I was born the twenty-sixth of April, I7II, old style, at Edinburgh. I was of a good family, both by father and mother: my father's family is a branch of the earl of Home's, or Hume's; and my ancestors had been proprietors of the estate which my brother possesses, for several generations. My mother was daughter of.Sir David Falconer, president of the col. lege of justice; the title of Lord Halkerton carne by succession to her brother.

My family, however, was not rich ; and being myself a younger brother, my patrimony, according to the mode of my country, was of course very slender. 
My father, who passed for a man of parts, died wher I was an infant, leaving me, with an elder brother and a sister. under the care of our mother, a woman of singular merit,. who, though young and handsome, devoted herself entirely to the rearing and educating of her children. I passed through the ordinary course of education with success, and was seized very early with a passion for literature, which has been the ruling passion of my life, and the great source of my enjoyments. My studious disposition, my sobriety, and my industry, gave my family a notion that the law was a proper profession for me; but I found an insurmountable aversion to every thing but the pursuits of philosophy and general learning; and while they fancied I was poring upon Voet and Vinnius, Cicero and Virgil were the authors which I was secretly devouring.

My very slender fortune, however, being unsuitable to this plan of life, and my health being a little broken by my ardent application, I was tempted, or rather forced, to make a very feeble trial for entering into a more active scene of life. In I734, I went to Bristol, with some recommendations to several eminent merchants; but in a few months found that scene totally unsuitable to me. I went over to France, with a view of prosecuting my studies in a country retreat; and I there laid that plan of life which I have steadily and successfully pursued. I resoived to make a very rigid frugality supply my deficiency of fortune, to maintain 
unimpaired my independency, and to regard every object as contemptible, except the improvements of my talents in literature.

During my retreat in France, first at Rheims, but ;hiefly at La Flèche, in Anjou, I composed my Treaise of Human Natr e. After passing three years very agreeably in that country, I came over to London in 1737. In the end of 1738 , I published my Treatise, and immediately went down to my mother and my brother, who lived at his country house, and was employing himself very judiciously and successfully in the improvement of his fortune.

Never literary attempt was more unfortunate than my Treatise of Human Nature. It fell dead-born from the press, without reaching such distinction as even to excite a murmur among the zealots. But being naturally of a cheerfil and sanguine temper, I very soon recovered the blow, and prosecuted with great ardor my studies in the country. In 1742 , I printed at Edinburgh the first part of my Essays. The work was favorably received, and soon made me entirely forget my former disappointment. I continued with my mother and brother in the country, and in that time recovered the knowledge of the Greek language, which I had too much neglected in my early youth.

In 1745 , I received a letter from the marquis of Annandale, inviting me to come and live with him in England; I found also that the friends and family of that young nobleman were desirous of putting him 
under my care and direction, for the state of his mind and health required it. I lived with him a twelvemonth. My appointments during that time made a considerable accession to my small forture. I then received an invitation from General St. Clair to attend him as a secretary to his expedition, which was at first meant against Canada, but ended in an incursion on the coast of France. Next year, to wit, I747, I received an invitation from the general to attend him in the same station in his military embassy to the courts of Vienna and Turin. I then wore the uniform of an officer, and was introduced at these courts as aid-decamp to the general, along with Sir Harry Erskine and Captain Grant, now General Grant. These two years were almost the only interruptions which my studies have received during the course of my life: I passed them agreeably, and in good company; and my ap. pointments, with my frugality, had made me reach a fortune which I called independent, though most of my friends were inclined to smile when I said so: in short, I was now master of near a thousand pounds.

I had always entertained a notion, that my want of success in publishing the Treatise of Human Nature had proceeded more from the manner than the matter, and that I had been guilty of a very usual indiscretion, in going to the press too early. I, therefore, cast the first part of that work anew in th Inquiry concerning Human Understanding, which was published while I was at Turin. But this piece was 
at irrst little more successful than the Treatise on Human Nature. On my return from Italy, I had the mortification to find all England in a ferment, on account of Dr. Middleton's Free Inquiry, while my performance was entirely overlooked and neglected. A new edition, which had been published at London, of my Essays, moral and political, met not with a much better reception.

Such is the force of natural temper, that these disappointments made little or no impression on me. I went down, in 1749, and lived two years with my brother at his country house, for my mother was now dead. I there composed the second part of my Essay, which I called Political Discourses, and also my Inquiry concerning the Principles of Morals, which is another part of my Treatise that I cast anew. Meanwhile, my bookseller, A. Millar, informed me, that my former publications (all but the unfortunate Treatise) were beginning to be the subject of conversation; that the sale of them was gradually increasing, and that new editions were demanded. Answers by reverends and right reverends came out two or three in a year; and I found, by Dr. Warburton's railing, that the books were beginning to be esteemed in good company. However, I had fixed a resolution, which I inflexibly maintained, never to reply to any body; and not being very irascible in my temper, I have easily kept myself clear of all literary squabbles. These symptoms of a rising reputation gave me encourage- 
ment, as I was ever more disposed to see the favorab!e than unfavorable side of things; a turn of mind which it is more happy to possess, than to be born to an estate of ten thousand a year.

In $175 \mathrm{I}$, I removed from the country to the town, the true scene for a man of letters. In I752 were published at Edinburgh, where I then lived, my Political Discourses, the only work of mine that was successful on the first publication. It was well received at home and abroad. In the same year was published, at London, my Inquiry concerning the Principles of Morals; which, in my own opinion, (who ought not to judge on that subject, ) is, of all my writings, historical, philosophical, or literary, incomparably the best. It came unnoticed and unobserved into the world.

In 1752, the Faculty of Advocates chose me their librarian, an office from which I received little or no emolument, but which gave me the command of a large library. I then formed the plan of writing the History of England; but being frightened with the notion of continuing a narrative through a period of seventeen hundred years, I commenced with the accession of the house of Stuart, an epoch when, I thought, the misrepresentations of faction began chiefly to take place. I was, I own, sanguine in my expectations of the success of this work. I thought that I was the only historian that had at once neglected present power, interest and authority, and the cry of popular 
prejudices; and as the subject was suited to every capacity, I expected proportional applause. But miserable was my disappointment; I was assailed by one cry of reproach, disapprobation, and even detestation; English, Scotch, and Irish, whig and tory, churchman and sectary, freethinker and religionist, patriot and courtier, united in their rage against the man who had presumed to shed a generous tear for the fate of Charles I. and the earl of Strafford; and after the first ebullitions of their fury were over, what was still more mortifying, the book seemed to sink. into oblivion. Mr. Millar told me that in a twelvemonth he sold only forty-five copies of it. I scarcely, indeed, heard of one man in the three kingdoms, considerable for rank or letters, that could endure the book. 1 must only except the primate of England, Dr. Herring, and the primate of Ireland, Dr. Stone, which seem two odd exceptions. These dignified prelates separately sent me messages not to be discouraged.

I was, however, I confess, discouraged; and had not the war been at that time breaking out between France and England, I had certainly retired to some provincial town of the former kingdom, have changed my name, and never more have returned to my native country. But as this scheme was not now practicable, and the subsequent volume was considerabiy advanced, I resolved to pick up courage and to persevere.

In this interval, I published, at London, my Natu- 
ral History of Religion, along with some other small pieces. Its public entry was rather obscure, except only that Dr. Hurd wrote a pamphlet against it, with all the illiberal petulance, arrogance, and scurrility, which distinguish the Warburtonian school. This pamphlet gave me some consolation fcr the otherwise indifferent reception of my performance.

In 1756 , two years after the fall of the first volume, was published the second volume of my history, containing the period from the death of Charles I. till the revolution. This performance happened to give less displeasure to the whigs, and was better received. It not only rose itself, but helped to buoy up its unfortunate brother.

But though I had been taught by experience that the whig party were in possession of bestowing all places, both in the state and in literature, I was so little inclined to yield to their senseless clamor, that in above a hundred alterations, which further study, reading, or reflection engaged me to make in the reigns of the two first Stuarts, I have made all of them invariably to the tory side. It is ridiculous to consider the English constitution before that period as a regular plan of liberty.

In I759, I published my history of the house of Tudor. The clamor against this performance was almost equal to that against the history of the two first Stuarts. The reign of Elizabeth was particularly obnoxious. But I was now callous against the im 
pressions of public folly, and continued very peaceabiy and contentedly, in my retreat at Edinburgh, to finish, in two volumes, the more early part of the English history, which I gave to the public in $176 \mathrm{I}$, with tolerable, and but tolerable, success.

But, notwithstanding this variety of winds and seasons, to which my writings had been exposed, they had still been making such advances, that the copymoney given me by the booksellers much exceeded any thing formerly known in England; I was become not only independent, but opulent. I retired to my native country of Scotland, determined never more to set my foot out of it; and retaining the satisfaction of never having preferred a request to one great man, or even making advances of friendship to any of them. As I was now turned of fifty, I thought of passing all the rest of my life in this philosophical manner : when I received, in $\mathrm{I}_{7} 6_{3}$, an invitation from the earl of Hertford, with whom I was not in the least acquainted, to attend him on his embassy to Paris, with a near prospect of being appointed secretary to the embassy; and, in the mean while, of performing the functions of that office. This offer, however inviting, I at first declined; both because I was reluctant to begin connections with the great, and because I was afraid that the civilities and gay company of Paris would prove disagreeable to a person of my age and humor; but on his lordship's repeating the invitation, I accepted of it. I have every reason, both of pleasure and interest, to 
think myself happy in my connexions with that nobleman, as well as afterwards with his brother, General Conway.

Those who have not seen the strange effects of modes, will never imagine the reception I met with at Paris, from men and women of all ranks and stations. The more I resiled from their excessive civilities, the more I was loaded with them. There is, however, a real satisfaction in living at Paris, from the great number of sensible, knowing, and polite company with which that city abounds above all places in the universe. I thought once of settling there for life.

I was appointed secretary to the embassy; and, in summer, $\mathrm{I} 765$, Lord Hertford left me, being appointed lord lieutenant of Ireland. I was charge d'affaires till the arrival of the duke of Richmond, towards the end of the year. In the beginning of 1766 , I left Paris, and next summer went to Edinburgh, with the same view as formerly, of burying myself in a philosophical retreat. I returned to that place, not richer, but with much more money, and a much larger income, by means of Lord Hertford's friendship, than I left it; and 1 was desirous of trying what superfluity could roduce, as I had formerly made an experiment of a competency. But in 1767 , I received from Mr. Conway an invitation to be under-secretary; and this invitation, both the character of the person, and $\mathrm{mv}$ connexions with Lord Hertford, prevented me from declining. I returned to Edinburgh in I769, very 
opulent, (for I possessed a revenue of one thousanc pounds a year,) healthy, and though somewhat stricker. in years. with the prospect of enjoying long my ease, and of seeing the increase of my reputation.

In spring, 1775 , I was struck with a disorder in my bowels, which at first gave me no alarm, but has since, as $\mathrm{I}$ apprehend it, become mortal and incurable. I row reckon upon a speedy dissolution. I have suffered vary little pain from my disorder; and what is more strunge, have, notwithstanding the great decline of my pexson, never suffered a moment's abatement of my spirits; insomuch, that were I to name a period of my life which I should most choose to pass over again, I migt t be tempted to point to this later period. 1 possess the same ardor as ever in study, and the same gayety in company. I consider, besides, that a man of sixty-five, by dying, cuts off only a few years of infirmities; and though I see many symptoms of my literary reputatirn's breaking out at last with additional lustre, I kyow that I could have but few years to enjoy it. It is difficult to be more detached from life than $I$ am at present.

To conclude historically with my own character: I am, or rather was, (for that is the style I must now use in speaking of myself, which emboldens me the more to speak my sentiments;) I was, I say, a man of mild disposition, of command of temper, of an open social, and cheerful humor, capable of attachment, but little susceptible of enmitv. and of great moderation 
in all my passions. Even my love of literary fame, my ruling passion, never soured my temper, notwithstanding my frequent disappointments. My company was not unacceptable to the young and careless, as well as to the studious and literary; and as I took a particular pleasure in the company of modest women, I had no reason to be displeased with the reception I met with from them. In a word, though most men, anywise eminent, have found reason to complain of Calumny, I never was touched, or even attacked, by her baleful tooth; and though I wantonly exposed myself to the rage of both civil and religious factions, they seemed to be disarmed in my behalf of their wonted fury. My friends never had occasion to vindicate any onè circumstance of my character and conduct; not but that the zealots, we may well suppose, would have been glad to invent and propagate any story to my disadvantage, but they could never find any which they thought would wear the face of probability. I cannot say there is no vanity in making this funeral oration of myself, but I hope it is not a misplaced one; and this is a matter of fact which is easily cleared and ascertained.

April 18, 1776. 
LETTER FROM ADAM SMITH LL. D.

TO WILLIAM STRAHAN, ESQ.

Kirkaldy, Fifeshire, Nov. 9, I776.

DeAR Sir,

[] is with a real, though a very melancholy pleasure, I that I sit down to give you some account of the behaviour of our late excellent friend, Mr. Hume, during his last illness.

Though, in his own judgement, his disease was mortal and incurable, yet he allowed nimself to be prevailed upon, by the entreaty of his friends, to try what might be the effects of a long journey. A few days before he set out, he wrote that account of his own life, which, together with his other papers, he has left to your care. My account, therefore, shall begin where his ends.

He set out for London towards the end of April, and at Morpeth met with Mr. John Home and myself, who had both come down from London on purpose to see him, expecting to have found him at Edinburgh. Mr. Home returned with him, and attended him during the whole of his stay in England, with that care and attention which might be expected from a temper 
so perfectly friendly and affectionate As I had written to my mother that she might expect me in Scotland, I was under the necessity of continuing my journey. His disease seemed to yield to exercise and change of air; and when he arrived in London, he was apparently in much better health than when he left Edinburgh. $\mathrm{He}$ was advised to go to Bath to drink the waters, which appeared for some time to have so good an effect upon $\dot{h}$ im, that even he himself began to entertain, what he was not apt to do, a better opinion of his own health. His symptoms, however, soon returned with their usual violence; and from that moment he gave up all thoughts of recovery, but submitted with the utmost cheerfulness, and the most perfect complaتency and resignation. Upon his return to Edinburgh, though he tüund himself much weaker, yet his cheerfulness never abated, and he continued to divert himself, as usual, with correcting his own works for a new edicior, with reading books of amusement, with the conversation of his friends; and, sometimes in the evening: with a party at his favorite game of whist His cheerfulness was so great, and his conversation and amusements ran so much in their usual strain, that, notwithstanding all bad symptoms, many people could not believe he was dying. "I shall tell your friend, Colonel Edmonstone," said Dr. Dundas to him one day, "that I left you much better, and in a fair way of recovery." "Doctor," said he, "as I believe you would not chocse to tell any thing but the truth, 
you had better tell him that I am dying as fast as my enemies, if I have any, could wish, and as easily and cheerfully as my best friends could desire." Colonel Edmonstone soon afterwards came to see him, and take leave of him; and on his way home he could not forbear writing him a letter, bidding him once more an eternal adieu, and applying to him, as to a dying man, the beautiful French verses in which the Abbé Chaulieu, in expectation of his own death, laments his approaching separation from his friend the Marquis de la Fare. Mr. Hume's magnanimity and firmness were such, that his most affectionate friends knew that they hazarded nothing in talking or writing to him as to a dying man, and that so far from being hurt by this frankness, he was rather pleased and flattered by it. I happened to come into his room while he was reading this letter, which he had just received, and which he immediately showed me. I told him, that though I was sensible how very much he was weakened, and that appearances were in many respects very bad, yet his cheerfulness was still so great, the spirit of life seemed still to be so very strong in him, that I could not help entertaining some faint hopes. He answered, "Your hopes are groundless. An habitual diarrhœe of more than a year's standing, would be a very bad disease at any age; at my age it is a mortal one. When I lie down in the evening, I feel myself weaker than when I rose in the morning; and when I rise in the morning. weaker than when I lay 
down in the evening. I am sensible, besides, that some of my vital parts are affected, so that I must soon die." "Well," said I, "if it must be so, you have at least the satisfaction of leaving all your friends, your brother's family in particular, in great prosperity." He said that he felt that satisfaction so sensibly, that when he was reading, a few days before, Lucian's Dialogues of the Dead, among all the excuses which are alleged to Charon for not entering readily into his boat, he could not find one that fitted him: he had no house to finish, he had no daughter to provide for, he had no enemies upon whom he wished to revenge himself. "I could not well imagine," said he, "what excuse I could make to Charon in order to obtain a little delay. I have done every thing of consequence which I ever meant to do; and I could at no time expect to leave my relations and friends in a better situation than that in which I am now likely to leave them: I, therefore, have all reason to die contented." $\mathrm{He}$ then diverted himself with inventing several jocular excuses, which he supposed he might make to Charon, and with imagining the very surly answers which it might suit the character of Charon to return to them. "Upon further consideration," said he, "I thought I might say to him, "Good Charon, I have been correcting my works for a new edition. Allow me a little time, that I may see how the public receives the alterations.' But Charon would answer, 'When you have seen the effect of these, you will be for making other 
alterations. There will be no end of such excuses; so, honest friend, please step into the boat.' But I might still urge, 'Have a little patience, good Charon: I have been endeavouring to open the eyes of the public. If I live a few years longer, I may have the satisfaction of seeing the downfall of some of the prevailing systems of superstition.' But Charon would then lose all temper and decency. "You loitering rogue, that will not happen these many hundred years. Do you fancy I will grant you a lease for so long a term ? Get into the boat this instant, you lazy, loitering rogue.' "

But, though Mr. Hume always talked of his approaching dissolution with great cheerfulness, he never affected to make any parade of his magnanimity. He never mentioned the subject but when the conversation naturally led to it, and never dwelt longer upon it than the course of the conversation happened to require; it was a subject indeed which occurred pretty frequently, in consequence of the inquiries which his friends, who came to see him, naturally made concerning the state of his health. The conversation which I mentioned above, and which passed on Thursday the eighth of August, was the last, except one, that I ever had with him. He had now become so very weak, that the company of his most intimate friends fatigued him; for his cheerfulness was still so great, his complaisance and social disposition were still so entire, that when any friend was with him, he could not help talking more, and with greater exertion, than 
suited the weakness of his body. At his own desire, therefore, I agreed to leave Edinburgh, where I was staying partly upon his account and returned to my mother's house here at Kirkaldy, upon condition that he would send for me whenever he wished to see me; the physician who saw him most frequently, Dr. Black, undertaking, in the mean time, to write me occasion ally an account of the state of his health.

On the twenty-second of August, the doctor wrote me the following letter:-

"Since my last, Mr. Hume has passed his time pretty easily, but is much weaker. He sits up, goes down stairs once a day, and amuses himself with reading, but seldom sees any body. He finds that even the conversation of his most intinate friends fatigues and oppresses him; and it is happy that he does not need it, for he is quite free from anxiety, impatience, or low spirits, and passes his time very weli with the assistance of amusing books."

I received, the day after, a letter from Mr. Hume himself, of which the following is an extract :-

\section{“Edinburgh, 23d August, i776.}

“My Dearest Friend,

"I am obliged to make use of my nephew's hand in writing to you, as I do not rise to-day.

“I go very fast to decline, and last night had a small fever, which I hoped might put a quicker period 
to this tedious illness; but unluckily it ras, in a great measure, gone off. I cannot submit to your coming over here on my account, as it is possible for me to see you so small a part of the day; but Dr. Black can better inform you concerning the degree of strength which may from time to time remain with me. Adieu, etc."

Three days atter, 1 recelved the following ielter trom Dr. Black :--

"Edingurgh, Monday, 26th August, $1770 ̈$.

"DEar Sir,

"Yesterday, about four o'clock, afternoon. Mr. Hume expired. The near approach of his death became evident in the night between Ihursday and Friday, when his disease became excessive, and soon weakened him so much, that he could no longer rise out of his bed. He continued to the last perfectly sensible, and free from much pain or feelings of distress. He never dropped the smallest expression of impatience; but when he had occasion to speak to the people about him, always did it with affection and tenderness. I thought it improper to write to bring you over, especially as I heard that he had dictated a letter to you, desiring you not to come. When he became very weak, it cost him an effort to speak; and he died in such a happy composure of mind. that nothing could exceed it.' 
Thus died our most excellent and never to be forgotten friend; concerning whose philosophical opinions men will, no doubt, judge variously, every one approving or condemning them, according as they happen to coincide or disagree with his own, but concerning whose character and conduct there can scarce be a difference of opinion. His temper, indeed, seemed to be more happily balanced, if I may be allowed such an expression, than that perhaps of any other man I have ever known. Even in the lowest state of his fortune, his great and necessary frugality never hindered him from exercising, upon proper occasions, acts both of charity and generosity. It was a frugality founded not upon avarice, but upon the love of independency. The extreme gentleness of his nature never weakened either the firmness of his mind or the steadiness of his resolutions. His constant pleasantry was the genuine effusion of good nature and good humour, tempered with delicacy and modesty, and without even the slightest tincture of malignity, so frequently the disagreeable source of what is called wit in other men. It never was the meaning of his raillery to mortify; and therefore, far from offending, it seldom failed to please and delight, even those who were frequently the objects of it ; there was not perhaps any one of all his great and amiable qualities which contributed more to endear his conversation. And that gayety of temper, so agreeable in society, but which is so often accompanied with frivolous and 
superficial qualities, was in him certainly attended with the most severe application, the most extensive learning, the greatest depth of thought, and a capacity in every respect the most comprehensive. Upon the whole, I have always considered him, both in his lifetime and since his death, as approaching as nearly to the idea of a perfectly wise and virtuous man as perhaps the nature of human frailty will permit.

I ever am, dear sir,
Most affectionally yours,

Adam SMith. 


\section{CONTENTS.}

Publishers' Preface . . . . . . . . . . . . iii

Autobiography . . . . . . . . . . . . . . v

Letter from Adam Smith to William Strahan . . . . xvii Author's Advertisement . . . . . . . . . . xxviii

An Enquiry Concerning Human Understanding-

Of the Different Species of Philosophy . . . . . 1

Of the Origin of Ideas . . . . . . . . . . . 14

$\checkmark$ Of the Association of Ideas . . . . . . . . . 21

Sceptical Doubts Concerning the Operations of the

Understanding . . . . . . . . . . . 23

Sceptical Solution of these Doubts . . . . . 40

Of Probability . . . . . . . . . . . . 57

Of the Idea of Necessary Connexion . . . . . . 61

- Of Liberty and Necessity . . . . . . . . 82

Of the Reason of Animals . . . . . . . . . 109

Of Miracles . . . . . . . . . . . . . . . 114

Of a Particular Providence and of a Future State . . 139

Of the Academical or Sceptical Philosophy . . . . 158

Selections from A Treatise of Human Nature-

The Doctrine of Causality.

Book I. Part III.

Section I. Of Knowledge . . . . . . . . 185

Section II. Of Probability; and of the Idea of Cause

and Effect . . . . . . . . 190

Section III. Why a Cause Is Always Necessary . . 197

Section XIV. Of the Idea of Necessary Connexion . . 202

The Doctrine of Substance.

Book I. Part I.

Section VI. Of Modes and Substances . . . . . 227

Book I. Part II.

Section VI. Of the Idea of Existence and of External

Existence . . . . . . . . 229

Book I. Part IV.

Section II. Of Scepticism with regard to the Senses 232

Section VI. Of Personal Identity . . . . . . 245

Appendix . . . . . . . . . . . 260 


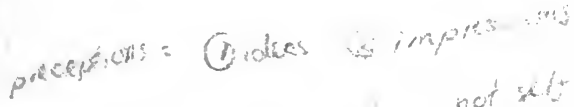

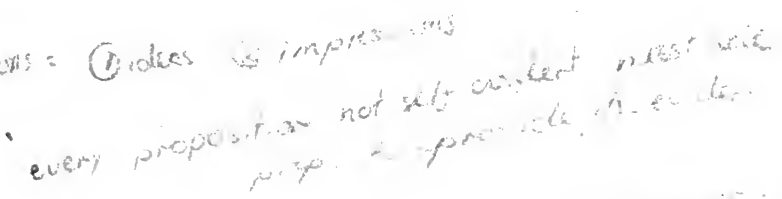

hindintich of cae

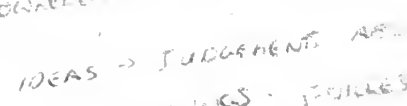

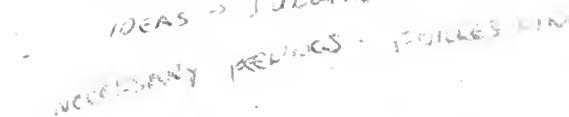

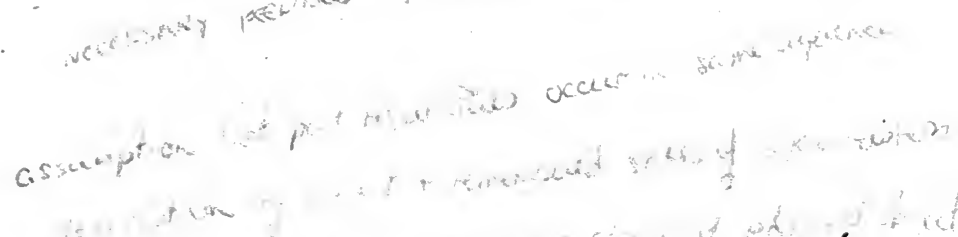

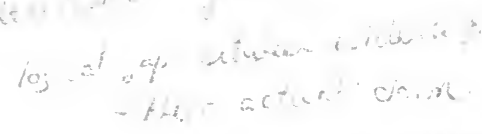

D,, VT

$\begin{array}{lll}14 & 940 & 86 \\ (7) & (16) & (20)\end{array}$ 


\section{AUTHOR'S ADVERTISEMENT.}

Most of the principles, and reasonings, contained in this volume, ${ }^{1}$ were published in a work in three volumes, called $A$ Treatise of Human Nature: A work which the Author had projected before he left College, and which he wrote and published not long after. But not finding it successful, he was sensible of his error in going to the press too early, and he cast the whole anew in the following pieces, where some negligences in his former reasoning and more in the expression, are, he hopes, corrected. Yet several writers who bave honoured the Author's Philosophy with answers, have taken care to direct all their batteries against that juvenile work, which the author never acknowledged, and have affected to triumph in any advantages, which, they imagined, they had obtained over it: A practice very contrary to all rules of candour and fair-dealing, and a strong instance of those polemical artifices which a bigotted zeal thinks itself authorized to employ. Henceforth, the Author desires, that the following Pieces may alone be regarded as containing his philosophical sentiments and principles.

1 Volume II. of the posthumous edition of Hume's works published in 1777 and containing, besides the present Enquiry, $A$ Dissertation on the Pas sions, and An Enquiry Concerning the Principles of Morals. A reprint of the latter treatise has already appeared in the Religion of Science Library (No. 46), published by The Open Court Publishing Co.-Editor. 


\section{SECTION I.}

\section{OF THE DIFFERENT SPECIES OF PHILOSOPHY.}

MORAL philosophy, or the science of human na$\mathrm{I}$ ture, may be treated after two different manners; each of which has its peculiar merit, and may contribute to the entertainment, instruction, and reformation of mankind. The one considers man chiefly as born for action; and as influenced in his measures by taste and sentiment; pursuing one object, and avoiding another, according to the value which these objects seem to possess, and according to the light in which they present themselves. As virtue, of all objects, is allowed to be the most valuable, this species of philosophers paint her in the most amiable colours; borrowing all helps from poetry and eloquence, and treating their subject in an easy and obvious manner, and such as is best fitted to please the imagination, and engage the affections. They select the most striking observations and instances from common life; place opposite characters in a proper contrast; and alluring us into the paths of virtue by the views of glory and happiness, direct our steps in these paths by the soundest precepts and most illustrious examples. They make us feel the difference between vice and virtue; they excite and regulate our sentiments; and so they can but bend our hearts to the love of probity and true honour, they think, that they have fully attained the end of all their labours. 
The other species of philosophers consider man in the light of a reasonable rather than an active being, and endeavour to form his understanding more than cultivate his manners. They regard human nature as a subject of speculation; and with a narrow scrutiny examine it, in order to find those principles, which regulate our understanding, excite our sentiments, and make us to approve or blame any particular object, action, or behaviour. They think it a reproach to all literature, that philosophy should not yet have fixed, beyond controversy, the foundation of morals, reasoning, and criticism; and should for ever talk of truth and falsehood, vice and virtue, beauty and deformity, without being able to determine the source of these distinctions. While they attempt this arduous task, they are deterred by no difficulties; but proceeding - from particular instances to general principles, they still push on their enquiries to principles more gen. eral, and rest not satisfied till they arrive at those original principles, by which, in every science, all human curiosity must be bounded. Though their speculations seem abstract, and even unintelligible to common read. ers, they aim at the approbation of the learned and the wise; and think themselves sufficiently compensated for the labour of their whole lives, if they can discover some hidden truths, which may contribute to the instruction of posterity.

It is certain that the easy and obvious philosophy will always, with the generality of mankind, have the preference above the accurate and abstruse; and by many will be recommended, not only as more agree. able, but more useful than the other. It enters more into common life; moulds the heart and affections; and, by touching those principles which actuate men, 
.eforms their conduct, and brings them nearer to that model of perfection which it describes. On the contrary, the abstruse philosophy, being founded on a iurn of mind, which cannot enter into business and action, vanishes when the philosopher leaves the shade, and comes into open day; nor can its principles easily retain any influence over our conduct and behaviour. The feelings of our heart, the agitation of our passions, the vehemence of our affections, dissipate all its conclusions, and reduce the profound philosopher to a mere plebeian

This also must be confessed, that the most durable, as well as justest fame, has been acquired by the easy philosophy, and that abstract reasoners seem hitherto to have enjoyed only a momentary reputation, from the caprice or ignorance of their own age, but have not been able to support their renown with more equitable posterity. It is easy for a profound philosopher to commit a mistake in his subtile reasonings; and one mistake is the necessary parent of another, while he pushes on his consequences, and is not deterred from embracing any conclusion, by its unusual appearance, or its contradiction to popular opinion. But a philosopher, who purposes only to represent the common sense of mankind in more beautiful and more engaging colours, if by accident he falls into error, goes no farther; but renewing his appeal to common sense, and the natural sentiments of the mind, returns into the right path, and secures himself from any dangerous illusions. The fame of Cicero flourishes at present; but that of Aristotle is utterly decayed. La Bruyere passes the seas, and still maintains his reputation: But the glory of Malebranche is confined to his own nation, and to his own age. And Addison. 
perhaps, will be read with pleasure, when Locke shall be entirely forgotten.

The mere philosopher is a character, which is commonly but little acceptable in the world, as being supposed to contribute nothing either to the advantage or pleasure of society; while he lives remote from communication with mankind, and is wrapped up in principles and notions equally remote from their comprehension. On the other hand, the mere ignorant is still more despised; nor is any thing deemed a surer sign of an illiberal genius in an age and nation where the sciences flourish, than to be entirely destitute of all relish for those noble entertainments. The most perfect character is supposed to lie between those extremes; retaining an equal ability and taste for books, company, and business; preserving in conversation that discernment and delicacy which arise from polite letters; and in business, that probity and accuracy which are the natural result of a just philosophy. In order to diffuse and cultivate so accomplished a character, nothing can be more useful than compositions of the easy style and manner, which draw not too much from life, require no deep application or retreat to be comprehended, and send back the student among mankind full of noble sentiments and wise precepts, applicable to every exigence of human life. By means of such compositions, virtue becomes amiable, science agreeable, company instructive, and retirement entertaining.

Man is a reasonable being; and as such, receives from science his proper food and nourishment: But so narrow are the bounds of human understanding, that little satisfaction can be hoped for in this particular, either from the extent or security of his acquisi- 
tions. Man is a sociable, no less than seasonable being: But neither can he always enjoy company agreeable and amusing, or preserve the proper relish for them. Man is also an active being; and from that disposition, as well as from the various necessities of human life, must submit to business and occupation: But the mind requires some relaxation, and cannot always support its bent to care and industry. It seems, then, that nature has pointed out a mixed kind of life as most suitable to the human race, and secretly admonished them to allow none of these biasses to draze too much, so as to incapacitate them for other occupations and entertainments. Indulge your passion for science, says she, but let your science be human, and such as may have a direct reference to action and society. Abstruse thought and profound researches I prohibit, and will severely punish, by the pensive melancholy which they introduce, by the endless uncertainty in which they involve you, and by the cold reception which your pretended discoveries shall meet with, when communicated. Be a philosopher; but, amidst all your philosophy, be still a man.

Were the generality of mankind contented to prefer the easy philosophy to the abstract and profound, without throwing any blame or contempt on the latter, it might not be improper, perhaps, to comply with this general opinion, and allow every man to enjoy, without opposition, his own taste and sentiment. But as the matter is often carried farther, even to the absolute rejecting of all profound reasonings, or what is commonly called metaphysics, we shall now proceed to consider what can reasonably be pleaded in their behalf.

We may begin with observing, that one considerble advantage, which results from the accurate and 
abstract philosophy, is, its subserviency to the easy and humane, which, without the former, can never attain a sufficient degree of exactness in its sentiments, precepts, or reasonings. All polite letters are nothing but pictures of human life in various attitudes and situations; and inspire us with different sentiments. of praise or blame, admiration or ridicule, according to the qualities of the object, which they set before us. An artist must be better qualified to succeed in this undertaking. who, besides a delicate taste and a quick apprehension, possesses an accurate knowledge of the internal fabric, the operations of the understanding, the workings of the passions, and the various species of sentiment which discriminate vice and virtue. How painful soever this inward search or enquiry may appear, it becomes, in some measure, requisite to those, who would describe with success the obvious and outward appearances of life and manners. The anatomist presents to the eye the most hideous and disagreeable objects; but his science is useful to the painter in delineating even a Venus or an Helen. While the latter employs all the richest colours of his art, and gives his figures the most graceful and engaging airs; he nuust still carry his attention to the inward structure of the human body, the position of the muscles, the fabric of the bones, and the use and figure of every part or organ. Accuracy is, in every case, advantageous to beauty, and just reasoning to delicate sentiment. In vain would we exalt the one by depreciating the other.

Besides, we may observe, in every art or profession, even those which most concern life or action, that a spirit of accuracy, however acquired, carries all of them nearer their perfection, and renders then: 
more subservient to the interests of society. And though a philosopher may live remote from business, the genius of philosophy, if carefully cultivated by several, must gradually diffuse itself throughout the whole society, and bestow a similar correctness on every art and calling. The politician will acquire greater foresight and subtility, in the subdividing and balancing of power; the lawyer more method and finer principles in his reasonings; and the general more regularity in his discipline, and more caution in his plans and operations. The stability of modern governments above the ancient, and the accuracy of modern philosophy, have irnproved, and probably will still improve, by similar gradations.

Were there no advantage to be reaped from these studies, beyond the gratification of an innocent curiosity, yet ought not even this to be despised; as being one accession to those few safe and harmless pleasures, which are bestowed on the human race. The sweetest and most inoffensive path of life leads through the avenues of science and learning; and whoever can either remove any obstructions in this way, or open up any new prospect, ought so far to be esteemed a benefactor to mankind. And though these researches may appear painful and fatiguing, it is with some minds as with some bodies, which being endowed with vigorous and florid health, require severe exercise, and reap a pleasure from what, to the generality of mankind, may seem burdensome and laborious. Obscurity, indeed, is painful to the mind as well as to the eye; but to bring light from obscurity, by whatever labour, must needs be delightful and rejoicing.

But this obscurity in the profound and abstract philosophy, is objected to, not only as painful and 
fatiguing, but as the inevitable source of uncertainty and error. Here indeed lies the justest and most plausible objection against a considerable part of metaphysics, that they are not properly a science; but arise either from the fruitless efforts of human vanity, which would penetrate into subjects utterly inaccessible to the understanding, or from the craft of popular superstitions, which, being unable to defend themselves on fair ground, raise these intangling brambles to cover and protect their weakness. Chaced from the open country, these robbers fly into the forest, and lie in wait to break in upon every unguarded avenue of the mind, and overwhelm it with religious fears and prejudices. The stoutest antagonist, if he remit his watch a moment, is oppressed. And many, through cowardice and folly, open the gates to the enemies, and willingly receive them with reverence and submission, as their legal sovereigns.

But is this a sufficient reason, why philosophers should desist from such researches, and leave superstition still in possession of her retreat? Is it not proper to draw an opposite conclusion, and perceive the necessity of carrying the war into the most secret recesses of the enemy? In vain do we hope, that men, from frequent disappointment, will at last abandon such airy sciences, and discover the proper province of human reason. For, besides, that many persons find too sensible an interest in perpetually recalling such topics; besides this, I say, the motive of blind despair can never reasonably have place in the sciences; since, however unsuccessful former attempts may have proved, there is still room to hope, that the industry, good fortune, or improved sagacity of succeeding generations may reach discoveries unknown 
to former ages. Each adventurous genius will leap at the arduous prize, and find himself stimulated, rather than discouraged, by the failures of his predecessors; while he hopes that the glory of achieving so hard an adventure is reserved for him alone. The only method of freeing learning, at once, from these abstruse questions, is to enquire seriously into the nature of human understanding, and show, from an exact analysis of its powers and capacity, that it is by no means fitted for such remote and abstruse subjects. We must submit to this fatigue, in order to live at ease ever after: And must cultivate true metaphysics with some care, in order to destroy the false and adulterate. Indolence, which, to some persons, affords a safeguard against this deceitful philosophy, is, with others, overbalanced by curiosity; and despair, which, at some moments, prevails, may give place afterwards to sanguine hopes and expectations. Accurate and just reasoning is the only catholic remedy, fitted for all persons and all dispositions; and is alone able to subvert that abstruse philosophy and metaphysical jargon, which, being mixed up with popular superstition, renders it in a manner impenetrable to careless reasoners, and gives it the air of science and wisdom.

Besides this advantage of rejecting, after deliberate enquiry, the most uncertain and disagreeable part of learning, there are many positive advantages, which result from an accurate scrutiny into the powers and faculties of human nature. It is remarkable concerning the operations of the mind, that, though most intimately present to us, yet, whenever they become the object of reflexion, they seem involved in obscurity; nor can the eye readily find those lines and boundaries, which discriminate and distinguish them. The objects 
are too fine to remain long in the same aspect or situa. tion; and must be apprehended in an instant, by a superior penetration, derived from nature, and imiproved by habit and reflexion. It becomes, therefore. no inconsjderable part of science barely to know the different operations of the mind, to separate them from each other, to class them under their proper heads. and to correct all that seeming disorder, in which they lie involved, when made the object of reflexion and enquiry. This talk of ordering and distinguishing, which has no merit, when performed with regard to external bodies, the objects of our senses, rises in its value, when directed towards the operations of the mind, in proportion to the difficulty and labour, which we meet with in performing it. And if we can go no farther than this mental geography, or delineation of the dis tinct parts and powers of the mind, it is at least a satisfaction to go so far; and the more obvious this science may appear (and it is by no means obvious) the more contemptible still must the ignorance of it be esteemed, in all pretenders to learning and philosophy.

Nor can there remain any suspicion, that this science is uncertain and chimerical; unless we should entertain such a scepticism as is entirely subversive of all speculation, and even action. It cannot be doubted, that the mind is endowed with several powers and faculties, that these powers are distinct from each other, that what is really distinct to the immediate perception may be distinguished by reflexion; and consequently, that there is a truth and falsehood in all propositions on this subject, and a truth and falsehood, which lie not beyond the compass of human understanding. There are many obvious distinctiona 
of this kind, such as those between the will and un derstanding, the imagination and passions, which fall within the comprehension of every human creature; and the finer and more philosophical distinctions are no less real and certain, though more difficult to be comprehended. Some instances, especially late ones, of success in these enquiries, may give us a juster notion of the certainty and solidity of this branch of learning. And shall we esteem it worthy the labour of a philosopher to give us a true system of the planets, and adjust the position and order of those remote bodies; while we affect to overlook those, who, with so much success, delineate the parts of the mind, in which we are so intimately concerned?

But may we not hope, that philosophy, if cultivated with care, and encouraged by the attention of the public, may carry its researches still farther, and discover, at least in some degree, the secret springs and principles, by which the human mind is actuated in its operations? Astronomers had long contented themselves with proving, from the phaenomena, the true motions, order, and magnitude of the heavenly bodies: Till a philosopher, at last, arose, who seems, from the happiest reasoning, to have also determined the laws and forces, by which the revolutions of the planets are governed and directed. The like has been performed with regard to other parts of nature. And there is no reason to despair of equal success in our enquiries concerning the mental powers and economy, if prosecuted with equal capacity and caution. It is probable, that one operation and principle of the mind depends on another; which, again, may be resolved into one more general and universal: And how far these researches may possibly be carried, it will be 
difficult for us, before, or even after, a careful trial, exactly to determine. This is certain, that attempts of this kind are every day made even by those who philosophize the most negligently: And nothing can be more requisite than to enter upon the enterprize with thorough care and attention; that, if it lie within the compass of human understanding, it may at last be happily achieved; if not, it may, however, be rejected with some confidence and security. This last conclusion, surely, is not desirable; nor ought it to be embraced too rashly. For how much must we diminish from the beauty and value of this species of philosophy, upon such a supposition? Moralists have hitherto been accustomed, when they considered the vast multitude and diversity of those actions that excite our approbation or dislike, to search for some common principle, on which this variety of sentiments might depend. And though they have sometimes carried the matter too far, by their passion for some one general principle; it must, however, be confessed, that they are excusable in expecting to find some general principles, into which all the vices and virtues were justly to be resolved. The like has been the endeavour of critics, logicians, and even politicians: Nor have their attempts been wholly unsuccessful; though perhaps longer time, greater accuracy, and more ardent application may bring these sciences still nearer their perfection. To throw up at once all pretensions of this kind may justly be deemed more rash, precipitate, and dogmatical, than even the boldest and most affirmative philosophy, that has ever attempted to impose its crude dictates and principles on mankind.

What though these reasonings concerning human 
nature seem abstract, and of difficult comprehension? This affords no presumption of their falsehood. On the contrary, it seems impossible, that what has hitherto escaped so many wise and profound philosophers can be very obvious and easy. And whatever pains these researches may cost us, we may think ourselves sufficiently rewarded, not only in point of profit but of pleasure, if, by that means, we can make any addition to our stock of knowledge, in subjects of such unspeakable importance.

But as, after all, the abstractedness of these speculations is no recommendation, but rather a disadvantage to them, and as this difficulty may perhaps be surmounted by care and art, and the avoiding of all unnecessary detail, we have, in the following enquiry, attempted to throw some light upon subjects, from which uncertainty has hitherto deterred the wise, and obscurity the ignorant. Happy, if we can unite the boundaries of the different species of philosophy, by reconciling profound enquiry with clearness, and truth with novelty! And still more happy, if reasoning in this easy manner, we can undermine the foundations of an abstruse philosophy, which seems to have hitherto served only as a shelter to superstition, and 2 cover to absurdity and error 1 


\section{SECTION II.}

\section{OF THE ORIGIN OF IDEAS.}

LVERY one will readily allow, that these it ton1 siderable difference between the perceptions of the mind, when a man feels the pain of excesuive heat, or the pleasure of moderate warmth, and when he afterwards recalls to his memory this sensation, or anticipates it by his imagination. These faculties may mimic or copy the perceptions of the senses; but they never can entirely reach the force and vivacity of the original sentiment. The utmost we say of them, even when they operate with greatest vigour, is, that they represent their object in so lively a manner, that we could almost say we feel or see it: But, except the mind be disordered by disease or madness, they never can arrive at such a pitch of vivacity, as to render these perceptions altogether undistinguishable. All the colours of poetry, however splendid, can never paint natural objects in such a manner as to make the description be taken for a real landskip. The most lively thought is still inferior to the dullest sensation.

We may observe a like distinction to run through all the other perceptions of the mind. A man in a fit of anger, is actuated in a very different manner from one who only thinks of that emotion. If you tell me, that any person is in love, I easily understand your meaning, and form a just conception of his situation; but never can mistake that conception for the real 
disorders and agitations of the passion. When we reflect on our past sentiments and affections, our thought is a faithful mirror, and copies its objects truly; but the colours which it employs are faint and dull, in comparison of those in which our original perceptions were clothed. It requires no nice discernment or metaphysical head to mark the distinction between them.

Here therefore we may divide all the perceptions of the mind into two classes or species, which are distinguished by their different degrees of force and vivacity. The less forcible and lively are commonly denominated Thoughts or Ideas. The other species want a name in our language, and in most others; I suppose, because it was not requisite for any, but philosophical purposes, to rank them under à general term or appellation. Let us, therefore, use a little freedom, and call them Impressions; employing that word in a sense somewhat different from the usual. By the term impression, then, I mean all our more lively perceptions, when we hear, or see, or feel, or love, or hate, or desire, or will. And impressions are distinguished from ideas, which are the less lively perceptions, of which we are conscious, when we reflect on any of those sensations or movements above mentioned.

Nothing, at first view, may seem more unbounded than the thought of man, which not only escapes all human power and authority, but is not even restrained. within the limits of nature and reality. To form monsters, and join incongruous shapes and appearances, costs the imagination no more trouble than to conceive the most natural and familiar objects. And while the body is confined to one planet, along which it creeps with pain and difficulty; the thought can in an instant 
transport us into the most distant regions of the universe; or even beyond the universe, into the unbounded chaos, where nature is supposed to lie in total confusion. What never was seen, or heard of, may yet be conceived; nor is any thing beyond the power of thought, except what implies an absolute contradiction.

But though our thought seems to possess this unbounded liberty, we shall find, upon a nearer examination, that it is really confined within very narrow limits, and that all this creative power of the mind amounts to no more than the faculty of compounding transposing, augmenting, or diminishing the materials afforded us by the senses and experience. When we think of a golden mountain, we only join two consistent ideas, gold, and mountain, with which we were formerly acquainted. A virtuous horse we can conceive; because, from our own feeling, we can conceive virtue; and this we may unite to the figure and shape of a horse, which is an animal familiar to us. In short, all the materials of thinking are derived either from our outward or inward sentiment: the mixture and composition of these belongs alone to the mind and will. Or, to express myself in philosophical language, all our ideas or more feeble perceptions are copies of our impressions or more lively ones. - ]

To prove this, the two following arguments will, I hope, be sufficient. First, when we analyze our thoughts or ideas, however compounded or sublime, we always find that they resolve themselves into such simple ideas as were copied from a precedent feeling or sentiment. Even those ideas, which, at first view, seem the most wide of this origin, are found, upon a nearer scrutiny, to be derived from it. The idea of 
God, as meaning an infinitely intelligent, wise, and good Being, arises from reflecting on the operations of our own mind, and augmenting, without limit, those qualities of goodness and wisdom. We may prosecute this enquiry to what length we please; where we shall always find, that every idea which we examine is copied from a similar impression. Those who would assert that this position is not universally true nor without exception, have only one, and that an easy method of refuting it; by producing that idea, which, in their opinion, is not derived from this source. It will then be incumbent on us, if we would maintain our doctrine, to produce the impression, or lively perception, which corresponds to it.

Secondly. If it happen, from a defect of the organ, that a man is not susceptible of any species of sensation, we always find that he is as little susceptible of the correspondent ideas. A blind man can form no notion of colours; a deaf man of sounds. Restore either of them that sense in which he is deficient; by opening this new inlet for his sensations, you also open an inlet for the ideas; and he finds no difficulty in conceiving these objects. The case is the same, if the object, proper for exciting any sensation, has never been applied to the organ. A Laplander or Negro has no notion of the relish of wine. And though there are few or no instances of a like deficiency in the mind, where a person has never felt or is wholly incapable of a sentiment or passion that belongs to his species; yet we find the same observation to take place in a less degree. A man of mild manners can form no idea of inveterate revenge or cruelty; nor can a selfish heart easily conceive the heights of friendship and generosity. It is readily allowed, that other beings 
may possess many senses of which we can have no conception; because the ideas of them have never been introduced to us in the only manner by which an idea can have access to the mind, to wit, by the actual feeling and sensation.

There is, however, one contradictory phenomenon, which may prove that it is not absolutely impossible for ideas to arise, independent of their correspondent impressions. I believe it will readily be allowed, that the several distinct ideas of colour, which enter by the eye, or those of sound, which are conveyed by the ear, are really different from each other; though, at the same time, resembling. Now if this be true of different colours, it must be no less so of the different shades of the same colour; and each shade produces a distinct idea, independent of the rest. For if this should be denied, it is possible, by the continual gradation of shades, to run a colour insensibly into what is most remote from it; and if you will not allow any of the means to be different, you cannot, without absurdity, deny the extremes to be the same. Suppose, therefore, a person to have enjoyed his sight for thirty years, and to have become perfectly acquainted with colours of all kinds except one particular shade of blue, for instance, which it never has been his fortune to meet with. Let all the different shades of that colour, except that single one, be placed before him, descending gradually from the deepest to the lightest; it is plain that he will perceive a blank, where that shade is wanting, and will be sensible that there is a greater distance in that place between the contiguous colours than in any other. Now I ask, whether it be possible for him, from his own imagination, to supply this deficiency, and raise up to himself the idea of that 
particular shade, though it had never been conveyed to him by his senses? I believe there are few but will be of opinion that he can : and this may serve as a proof that the simple ideas are not always, in every instance, derived from the correspondent impressions; though this instance is so singular, that it is scarcely worth our observing, and does not merit that for it alone we should alter our general maxim.

Here, therefore, is a proposition, which not only seems, in itself, simple and intelligible; but, if a proper use were made of it, might render every dispute equally intelligible, and banish all that jargon, which has so long taken possession of metaphysical reasonings, and drawn disgrace upon them. All ideas, especially abstract ones, are naturally faint and obscure : the mind has but a slender hold of them: they are apt to be confounded with other resembling ideas ; and when we have often employed any term, though without a distinct meaning, we are apt to imagine it has a determinate idea annexed to it. On the contrary, all impressions, that is, all sensations, either outward or inward, are strong and vivid : the limits between them are more exactly determined: nor is it easy to fall into any error or mistake with regard to them. When we entertain, therefore, any suspicion that a philosophical term is employed without any meaning or idea (as is but too frequent), we need but enquire, from what impression is that supposed idea derived? And if it be impossible to assign any, this will serve to confirm our suspicion. ${ }^{1}$ By bringing

3 It is probable that no more was meant by those, who denied innate ideas, than that all ideas were copies of our impressions; though it must be confessed, that the terms, which they employed, were not chosen with such caution, nor so exactly defined, as to prevent all mistakes about their doctrine. For what is meant by innate? If innate be equivalent to natural, then 
ideas into so clear a light we may reasonably hope to remove all dispute, which may arise, concerning their nature and reality.

all the perceptions and ideas of the mind must be allowed to be innate or natural, in whatever sense we take the latter word, whether in opposition to what is uncommon, artificial, or miraculous. If by innate be meant, contem. porary to our birth, the dispute seems to be frivolous; nor is it worth while to enquire at what time thinking begins, whether before, at, or after our tirth. Again, the word idea, seems to be commonly taken in a very loose sense, by Locke and others; as standing for any of our perceptions, our sensations and passions, as well as thoughts. Now in this sense, I should desire to know, what can be meant by asserting, that self-love, or resentment of injuries, or the passion between the sexes is not innate?

But admitting these terms, impressions and ideas, in the sense above ex plained, and understanding by innate, what is original or copied from no pre cedent perception, then may we assert that all our impressions are innate and our ideas not innate.

To be ingenuous, I must own it to be my opinion, that Locke was be trayed into this question by the schoolmen, who, making use of undefined terms, draw out their disputes to a tedious length, without ever touching the point in question. A like ambiguity and circumlocution seem to run through that philosopher's reasonings on this as well as most other subjects. 


\section{SECTION III.}

OF THE ASSUCIATION OF IDEAS.

$\mathrm{T}$ is evident that there is a principle of connexion 1 between the different thoughts or ideas of the mind, and that, in their appearance to the memory or imagination, they introduce each other with a certain degree of method and regularity. In our more serious thinking or discourse this is so observable that any particular thought, which breaks in upon the regular tract or chain of ideas, is immediately remarked and rejected. And even in our wildest and most wandering reveries, nay in our very dreams, we shall find, if we refect, that the imagination ran not altogether at adventures, but that there was still a connexion upheld among the different ideas, which succeeded each. other. Were the loosest and frest conversation to be transcribed, there would immediately be observed something which connected it in atl its transitions. Or where this is wanting, the person who broke the thread of discourse might still inform you, that there had secretly revolved in his mind a succession of thought, which had gradually led him from the subject of conversation. Among different languages, even where we cannot suspect the least connexion or communication, it is found, that the words, expressive of ideas, the most compounded, do yet nearly correspond to each other: a certain proof that the simple ideas, comprehender in the compound ones, were bound to- 
gether by some universal principle, which had an equal influence on all mankind.

Though it be too obvious to escape observation. that different ideas are connected together; I do not find that any philosopher has attempted to enumerate or class all the principles of association; a subject, however, that seems worthy of curiosity. To me, there appear to be only three principles of connexion among ideas, namely, Resemblance, Contiguity in time or place, and Cause or Effect.

That these principles serve to connect ideas will not, I believe, be much doubted. A picture naturally leads our thoughts to the original: ${ }^{1}$ the mention of one apartment in a building naturally introduces an. enquiry or discourse concerning the others $:^{2}$ and if we think of a wound, we can scarcely forbear reflecting on the pain which follows it. ${ }^{3}$ But that this enumeration is complete, and that there are no other 1.rinciples of association except these, may be difficult to prove to the satisfaction of the reader, or even to a man's own satisfaction. All we can do, in such cases, is to run over severaloinstances, and examine carefully the principle which binds the different thoughts to each other, never"stopping till we render the principle as general as possible. ${ }^{4}$ The more instances we examine, and the more care we employ, the more assurance shall we acquire, that the enumeration, which we form from the whole, is complete and entire.

1 Resemblance.

2 Contiguity.

3 Cause and effect.

4 For instance, Contrast or Contrariety is also a connexion among Irieas but it may, perhaps, be considered as a mixture of Causation and Resemblance. Where two objects are contrary, the one destroys the other; that is, the cause of its annihi a i $n$, and the idea of the annihilation of an object inplies the idea of its former existence. 


\section{SECTION IV.}

SCEPTICAL DOUBTS CONCERNING THE OPERATIONS OF THE UNDERSTANDING.

\section{PART I.}

$A^{\text {LL the objects of human reason or enquiry may }}$ A naturally be divided into two kinds, to wit, Relations of Ideas, and Matters of Fact. Of the first kind are the sciences of Geometry, Algebra, and Arithmetic; and in short, every affirmation which is either intuitively or demonstratively certain. That the square of the hypothenuse is equal to the squares of the two sides, is a proposition which expresses a relation between these figures. That three times five is equal to the half of thirty, expresses a relation between these numbers. Propositions of this kind are discoverable by the mere operation of thought, without dependence on what is anywhere existent in the universe. Though there never were a circle or triangle in nature, the truths demonstrated by Euclid would for ever retain their certainty and evidence.

Matters of fact, which are the second objects of human reason, are not ascertained in the same manner; nor is our evidence of their truth, however great, of a like nature with the foregoing. The contrary of every matter of fact is still possible; because it can never imply a contradiction, and is conceived by the mind with the same facility and distinctness, as if ever 
so conformable to reality. That the sun will not rise to-morrow is no less intelligible a proposition, and implies no more contradiction than the affirmation, that it zwill rise. We should in vain, therefore, attempt to demonstrate its falsehood. Were it demonstratively false, it would imply a contradiction, and could never be distinctly conceived by the mind.

It may, therefore, be a subject worthy of curiosity, to enquire what is the nature of that evidence which assures us of any real existence and matter of fact, beyond the present testimony of our senses, or the records of our memory. This part of philosophy, it is observable, has been little cultivated, either by the ancients or moderns; and therefore our doubts and errors, in the prosecution of so important an enquiry, may be the more excusable; while we march through such difficult paths without any guide or direction. They may even prove useful, by exciting curiosity, and destroying that implicit faith and security, which is the bane of all reasoning and free enquiry. The discovery of defects in the common philosophy, if any such there be, will not, I presume, be a discouragement, but rather an incitement, as is usual, to attempt something more sull and satisfactory than has yet been proposed to the public.

All reasonings concerning matter of fact seem to. be founded on the relation of Cause and Effect. By means of that relation alone we can go beyond the evidence of our memory and senses. If you were to ask a man, why he believes any matter of fact, which is absent ; for instance, that his friend is in the country, or in France; he would give you a reason; and this reason would be some other fact; as a letter received from him, or the knowledge of his former res 
ofutions and promises. A man finding a watch or any other machine in a desert island, would conclude that there had once been men in that island. All our reasonings concerning fact are of the same nature. And here it is constantly supposed that there is a connexion between the present fact and that which is inferred from it. Were there nothing to bind them together, the inference would be entirely precarious.' The hearing of an articulate voice and rational discourse in the dark assures us of the presence of some person: Why ? because these are the effects of the human make and fabric, and closely connected with it. If we anatomize all the other reasonings of this nature, we shall find that they are founded on the relation of cause and effect, and that this relation is either near or remote, direct or collateral. Heat and light are collateral effects of fire, and the one effect may justly be inferred from the other.

If we would satisfy ourselves, therefore, concerning the nature of that evidence, which assures us of matters of fact, we must enquire how we arrive at the knowledge of cause and effect.

I shall venture to affirm, as a general proposition, which admits of no exception, that the knowledge of this relation is not, in any instance, attained by reasonings a priori; but arises entirely from experience, when we find that any particular objects are constantly conjoined with each other. Let an object be presented to a man of ever so strong natural reason and abilities; if that object be entirely new to him, he will not be able, by the most accurate examination of its sensible qualities, to discover any of its causes or effects. Adam, though his rational faculties be supposed, at the very first, entirely perfect, could not have inferred 
from the fluidity and transparency of water that it would suffocate him, or from the light and warmth of fire that it would consume him. No object ever dis. covers, by the qualities which appear to the senses, either the causes which produced it, or the effects which will arise from it; nor can our reason, unassisted by experience, ever draw any inference con cerning real existence and matter of fact.

This proposition, that causes and effects are discoverable, not by reason but by experience, will readily be admitted with regard to such objects, as we remember to have once been altogether unknown to us; since we must be conscious of the utter inability, which we then lay under, of foretelling what would arise from them. Present two smooth pieces of marble to a man who has no tincture of natural philosophy; he will never discover that they will adhere together in such a manner as to require great force to separate them in a direct line, while they make so smail a resistance to a lateral pressure. Such events, as bear little analogy to the common course of nature, are also readily confessed to be known only by experience; nor does any man imagine that the explosion of gunpowder, or the attraction of a loadstone, could ever be discovered by arguments a priori. In like manner, when an effect is supposed to depend upon an intricate machinery or secret structure of parts, we make no difficulty in attributing all our knowledge of it to experience. Who will assert that he can give the ultimate reason, why milk or bread is proper nourishment for a man, not for a lion or a tiger?

But the same truth may not appear, at first sight, to have the same evidence with regard to events, which have hecome familiar to us from our first ap 
pearance in the world, which bear a close analogy to the whole course of nature, and which are supposed to depend on the simple qualities of objects, without any secret structure of parts. We are apt to imagine that we could discover these effects by the mere operation of our reason, without experience. We fancy, that were we brought on a sudden into this world, we could at first have inferred that one Billiard-ball would communicate motion to another upon impulse; and that we needed not to have waited for the event, in order to pronounce with certainty concerning it. Such is the influence of custom, that, where it is strongest, it not only covers our natural ignorance, but even conceals itself, and seems not to take place, merely because it is found in the highest degree.

But to convince us that all the laws of nature, and all the operations of bodies without exception, are known only by experience, the following reflections may, perhaps, suffice. Were any object presented to us, and were we required to pronounce concerning the effect, which will result from it, without consulting past observation; after what manner, I beseech you, must the mind proceed in this operation? It must invent or imagine some event, which it ascribes to the object as its effect; and it is plain that this invention must be entirely arbitrary. The mind can never possibly find the effect in the supposed cause, by the most accurate scrutiny and examination. For the effect is totally different from the cause, and consequently can never be discovered in it. Motion in the second Billiard-ball is a quite distinct event from motion in the first: nor is there anything in the one to suggest the smaliest hint of the other. A stone or piece of meta! raised into the air, and left without any support, im- 
mediately falls . but to consider the matter a priori, is there anything we discover in this situation which can beget the idea of a downward, rather than an upward, or any other motion, in the stone or metal?

And as the first imagination or invention of a particular effect, in all natural operations, is arbitrary, where we consult not experience; so must we also esteem the supposed tie or connexion between the cause and effect, which binds them together, and renders it impossible that any other effect could result from the operation of that cause. When I see, for instance, a Billiard-ball moving in a straight line towards another; even suppose motion in the second ball should by accident be suggested to me, as the result of their contact or impulse; may I not conceive, that a hundred different events might as well follow from that cause? May not both these balls remain at absolute rest? May not the first ball return in a straight line, or leap off from the second in any line or direction? All these suppositions are consistent and conceivable. Why then should we give the preference to one, which is no more consistent or conceivable than the rest? All our reasonings a priori will never be able to show us any foundation for this preference.

In a word, then, every effect is a distinct event from itș cause. It could not, therefore, be discovered in the cause, and the first invention or conception of it, a priori, must be entirely arbitrary. And even after it is suggested, the conjunction of it with the cause must appear equally arbitrary; since there are always many other effects, which, to reason, must seem fully as consistent and natural. In vain, therefore, should we pretend to determine any single event, or infer any 
cause or effect, without the assistance of observation and experience.

Hence we may discover the reason why no philosopher, who is rational and modest, has ever pretended to assign the ultimate cause of any natural operation, or to show distinctly the action of that power, which produces any single effect in the universe. It is confessed, that the utmost effort of human reason is to reduce the principles, productive of natural phenomena, to a greater simplicity, and to resolve the many particular effects into a few general causes, by means of reasonings from analogy, experience, and observation. But as to the causes of these general causes, we should in vain attempt their discovery; nor shall we ever be able to satisfy ourselves, by any particular explication of them. These ultimate springs and principles are totally shut up from human curiosity and enquiry. Elasticity, gravity, cohesion of parts, communication of motion by impulse; these are probably the ultimate causes and principles which we ever discover in nature; and we may esteem ourselves sufficiently happy, if, by accurate inquiry and reasoning, we can trace up the particular phenomena to, or near to, these general principles. The most perfect philosophy of the natural kind only staves off our ignorance a little longer: as perhaps the most perfect philosophy of the moral or metaphysical kind serves only to discover larger portions of it. Thus the observation of human blindness and weakness is the result of all philosophy, and meets us at every turn, in spite of our endeavours to elude or avoid it.

Nor is geometry, when taken into the assistance of natural philosophy, ever able to remedy this defect, or iead us into the knowledge of ultimate causes, by all 
that accuracy of reasoning for which it is so justly celebrated. Every part of mixed mathematics proceeds upon the supposition that certain laws are established by nature in her operations; and abstract reasonings are employed, either to assist experience in the discovery of these laws, or to determine their influence in particular instances, where it depends upon any precise degree of distance and quantity. Thus, it is a law of motion, discovered by experience, that the moment or force of any body in motion is in the compound ratio or proportion of its solid contents and its velocity; and consequently, that a small force may remove the greatest obstacle or raise the greatest weight, if, by any contrivance or machinery, we can increase the velocity of that force, so as to make it an overmatch for its antagonist. Geometry assists us in the application of this law, by giving us the just dimensions of all the parts and figures which can enter into any species of machine; but still the discovery of the law itself is owing merely to experience, and all the abstract reasonings in the world could never lead us one step towards the knowledge of it. When we reason a priori, and consider merely any object or cause, as it appears to the mind, independent of all observation, it never could suggest to us the notion of any distinct object, such as its effect ; much less, show us the inseparable and inviolable connexion between them. A man must be very sagacious who could discover by reasoning that crystal is the effect of heat, and ice of cold, without being previously acquainted with the operation of these qualities.

\section{PART II.}

But we have not yet attained any tolerable satisfaction with regard to the question first proposed. Each 
solution still gives rise to a new question as difficult as the foregoing, and leads us on to farther enquiries. When it is asked, What is the nature of all our reasonings concerning matter of fact? the proper answer seems to be, that they are founded on the relation of cause and effect. When again it is asked, What is the foundation of all our reasonings and conclusions concerning that relation? it may be replied in one word, Experience. But if we still carry on our sifting humour, and ask, What is the foundation of all conclusions from experience? this implies a new question, which may be of more difficult solution and explication. Philosophers, that give themselves airs of superior wisdom and sufficiency, have a hard task when they encounter persons of inquisitive dispositions, who push them from every corner to which they retreat, and who are sure at last to bring them to some dangerous dilemma. The best expedient to prevent this confusion, is to be modest in our pretensions; and even to discover the difficulty ourselves before it is objected to us. By this means, we may make a kind of merit of our very ignorance.

I shall content myself, in this section, with an easy task, and shall pretend only to give a negative answer to the question here proposed. I say then, that, even after we have experience of the operations of cause and effect, our conclusions from that experience are not founded on reasoning, or any process of the under. standing. This answer we must endeavour both to explain and to defend. *

It must certainly be allowed, that nature has kept us at a great distance from all her secrets, and has afforded us only the knowledge of a few superficial qualities of objects; while she conceals from us those powers and principles on which the influence of those ob- 
jects entirely depends. Our senses inform us of the colour, weight, and consistence of bread; but neither sense nor reason can ever inform us of those qualities which fit it for the nourishment and support of a human body. Sight or feeling conveys an idea of the actual motion of bodies; but as to that wonderful force or power, which would carry on a moving body for ever in a continued change of place, and which bodies never lose but by communicating it to cthers; of this we cannot form the most distant conception. But notwithstanding this ignorance of natural powers ${ }^{1}$ and principles, we always presume, when we see like sensible qualities, that they have like secret powers, and expect that effects, similar to those which we have experienced, will follow from them. If a body of like colour and consistence with that bread, which we have formerly eat, be presented to us, we make no scruple of repeating the experiment, and foresee, with certainty, like nourishment and support. Now this is a process of the mind or thought, of which I would willingly know the foundation. It is allowed on all hands that there is no known connexion between the sensible qualities and the secret powers; and consequently, that the mind $L$ is not led to form such a conclusion concerning their constant and regular conjunction, by anything which it knows of their nature. As to past Experience, it can be allowed to give direct and certain information of those precise objects only, and that precise period of time, which fell under its cognizance: but why this experi. ence should be extended to future times, and to other objects, which, for aught we know, may be only in ap-

1 The word. Power, is here used in a loose and popular sense. The more accurate explication of it wculd give additional evidence to this argumem See Sect. 7 . 
pearance similar; this is the main cuestion on which I would insist. The bread, which I formerly eat, nourished me; that is, a body of such sensible qualities was, at that time, endued with such secret powers: but does it follow, that other bread must also nourish me at another time, and that like sensible qualities must always be attended with like secret powers? The consequence seems nowise necessary. At least, it must be acknowledged that there is here a consequence drawn by the mind; that there is a certain step taken; a process of thought, and an inference, which wants to be explained. These two propositions are far from being the same, I have found that such an object has always been attended with such an effect, and I furesee, that other objects, which are, in appearance, similar, will be attended with similar cffects. I shall allow, if you please, that the one proposition may justly be inferred from the other; I know, in fact, that it always is inferred. But if you insist that the inference is made by a chain of reasoning, I desire you to produce that reasoning. The connexion between these propositions is not intuitive. There is required a medium, which may enable the mind to draw such an inference, if indeed it be drawn by reascning and argument. What that medium is, I musi confess, passes my comprehension; and it is incumbent on those to produce it, who assert that it really exists, and is the origin of all our conclusions concerning matter of fact.

This negative argument must certainly, in process of time, become altogether convincing, if many penetrating and able philosophers shall turn their enquiries this way and no one be ever able to discover any connecting proposition or intermediate step, which supports the understanding in this conclusion. But as the 
question is yet new, every reader may not trust so far to his own penetration, as to conclude, because an argument escapes his enquiry, that therefore it does not $r$ ally exist. For this reason it may be requisite to venture upon a more difficult task; and enumerating all the branches of human knowledge, endeavour to show that none of them can afford such an argument.

All reasonings may be divided into two kinds, namely, demonstrative reasoning, or that concerning relations of ideas, and [moral reasoning, or that concerning matter of fact and existence. That there are no demonstrative arguments in the case seems evident; since it implies no contradiction that the course of nature may change, and that an object, seemingly like those which we have experienced, may be attended with different or contrary effects. May I not clearly and distinctly conceive that a body, falling from the clouds, and which, in all other respects, resembles snow, has yet the taste of salt or feeling of fire? Is there any more intelligible proposition than to affirm, that all the trees will flourish in D scember and January, and decay in May and June? . Now whatever is intelligible, and can be distinctly conceived, implies no contradiction, and can never be proved false by any dem onstrative argument or abstract reasoning $\dot{a}$ priori.

If we be, therefore, engaged by arguments to put trust in past experience, and make it the standard of our future judgement, these arguments must be probable only, or such as regard matter of fact and real existence, according to the division above mentioned. But that there is no argument of this kind, must appear, if our explication of that species of reasoning be admitted as solid and satisfactory. We have said that all arguments concerning existence are founded on the 
relation of cause and effect; that our knowledge of that relation is derived entirely from experience; and that all our experimental conclusions proceed upon the supposition that the future will be conformable to the past. To endeavour, therefore, the proof of this last supposition by probable arguments, or arguments regarding existence, must be evidently going in a circle, and taking that for granted, which is the very point in question.

In reality, all arguments from experience are founded on the similarity which we discover among natural objects, and by which we are induced to expect effects similar to those which we have found to follow from such objects. And though none but a fool or madman will ever pretend to dispute the authority of experience, or to reject that great guide of human life, it may surely be allowed a philosopher to have so much curiosity at least as to examine the principle of human nature, which gives this mighty authority to experience, and makes us draw advantage from that similarity which nature has placed among different objects. From causes which appear similar we expect similar effects. This is the sum of all our experimental conclusions. Now it seems evident that, if this conclusion were formed by reason, it would be as perfect at first, and upon one instance, as after ever so long a course of experience. But the case is far otherwise. Nothing so like as eggs; yet no one, on account of this appearing similarity, expects the same taste and relish in all of them. It is only after a long course of uniform experiments in any kind, that we attain a firm reliance and security with regard to a particular event. Now where is that process of reasoning which, from one instance, draws a conclusion, so different from that 
which it infers from a hundred instances that are no. wise different from that single one? This question I propose as much for the sake of information, as with an intention of raising difficulties. I cannot find, I cannot imagine any such reasoning. But I keep my mind still open to instruction, if any one will vouchsafe to bestow it on me.

Should it be said that, from a number of uniform experiments, we infer a connexion between the sensible qualities and the secret powers; this, I must confess, seems the same difficulty, couclied in different terms. The question still recurs, on what process of argument this inference is founded? Where is the medium, the interposing ideas, which join propositions so very wide of each other? It is confessed that the colour, consistence, and other sensible qualities of bread appear not, of themselves, to have any connexion with the secret powers of nourishment and support. For otherwise we could infer these secret powers from the first appearance of these sensible qualities, without the aid of experience; contrary to the sentiment of all philosophers, and contrary to plain matter of fact. Here, then, is our natural state of ignorance with regard to the powers and influence of all objects. How is this remedied by experience? It only shows us a number of uniform effects, resulting from certain objects, and teaches us that those particular objects, at that particular time, were endowed with such powers and forces. When a new object, endowed with similar sensible qualities, is produced, we expect similar powers and forces, and look for a like effect. From a body of like colcur and consistence with bread we expect like nourishment and support. But this surely is a step or progress of the mind, which wants to be 
explained. When a man says, $I$ have found, in all past instances, such sensible qualities conjoined with such secret bowers: And when he says, Similar sensible qualities will always be conjoined with similar secret powers, he is not guilty of a tautology, nor are these propositions in iny respect the same. You say that the one proposition is an inference from the other. But you must confess that the inference is not intuitive; neither is it demonstrative: Of what nature is it, then? To say it is experimental, is begging the question. For all inferences from experience suppose, as their foundation, that the future will resemble the past, and that similar powers will be conjoined with similar sensible qualities. If there be any suspicion that the course of nature may change, and that the past may be no rule for the future, all experience becomes useless, and can give rise to no inference or conclusion. It is impossible, therefore, that any arguments from experience can prove this resemblance of the past to the future; since all these arguments are founded on the supposition of that resemblance. Let the course of things be allowed hitherto ever so regular; that alone, without some new argument or inference, proves not that, for the future, it will continue so. In vain do you pretend to have learned the nature of bodies from your past experience. Their secret nature, and consequently all their effects and influence, may change, without any change in their sensible qualities. This happens sometimes, and with regard to some objects: Why may it happen always, and with regard to all objects? What logic, what process of argument secures you against this supposition? My practice, you say, refutes my doubts. But you mistake the purport of my question. As an agent, I am quite satisfied in the point; but as a philosopher, 
who has some share of curiosity, I will not say scepticism, I want to learn the foundation of this inference. No reading, no enquiry has yet been able to remove my difficulty, or give me satisfaction in a matter of such importance. Can I do better than propose the difficulty to the public, even though, perhaps, I have small hopes of obtaining a solution? We shall, at least, by this means, be sensible of our ignorance, if we do not augment our knowledge.

I must confess that a man is guilty of unpardonable arrogance who concludes, because an argument has escaped his own investigation, that therefore it does not really exist. I must also confess that, though all the learned, for several ages, should have employed themselves in fruitless search upon any subject, it may still, perhaps, be rash to conclude positively that the subject must, therefore, pass all human comprehension. Even though we examine all the sources of our knowledge, and conclude them unfit for such a subject, there may still remain a suspicion, that the enumeration is not complete, or the examination not accurate. But with regard to the present subject, there are some considerations which seem to remove all this accusation of arrogance or suspicion of mistake.

It is certain that the most ignorant and stupid peasants-nay infants, nay even brute beasts-improve by experience, and learn the qualities of natural objects, by observing the effects which result from them. When a child has felt the sensation of pain from touching the flame of a candle, he will be careful not to put his hand near any candle; but will expect a similar effect from a cause which is similar in its sensible qualities and appearance. If you assert, therefore, that the understanding of the child is led into this conclu. 
sion by any process of argument or ratiocination, I may justly require you to produce that argument; nor have you any pretense to refuse so equitable a demand. You cannot say that the argument is abtruse, and may possibly escape your enquiry; since you confess that it is obvious to the capacity of a mere infant. If you hesitate, therefore, a moment, or if, after reflection, you produce any intricate or profound argument, you, in a manner, give up the question, and confess that it is not reasoning which engages us to suppose the past resembling the suture, and to expect similar effects from causes which are, to appearance, similar. This is the proposition which I intended to enforce in the present section. If I be right, I pretend not to have made any mighty discovery. And if I be wrong, I must acknowledge myself to be indeed a very backward scholar; since I cannot now discover an argument which, it seems, was perfectly familiar to me long before I was out of my cradle. 


\section{SECTION V.}

SCEPTICAL SOLUTION OF THESE DOUBTS.

\section{PART I.}

THE passion for philosophy, like that for religion, aims at the correction of our manners, and extirpation of our vices, it may only serve, by imprudent management, to foster a predominant inclination, and push the mind, with more determined resolution, towards that side which already drawes too much, by the bias and propensity of the natural temper. It is certain that, while we aspire to the magnanimous firmness of the philosophic sage, and endeavour to confine our pleasures altogether within our own minds, we may, at last, render our philosophy like that of Epictetus, and other Stoics, only a more refined system of selfishness, and reason ourselves out of all virtue as well as social enjoyment. While we study with attention the vanity of human life, and turn all our thoughts towards the empty and transitory nature of riches and honours, we are, perhaps, all the while flattering our natural indolence, which, hating the bustle of the world, and drudgery of business, seeks a pretence of reason to give itselt a full and uncontrolled indulgence. There is, however, one species of philosophy which seems little liable to this inconvenience, and that because it strikes in with no disorderly passion of the human 
mind, nor can mingle itself with any natural affection or propensity; and that is the Academic or Sceptical philosophy. The academics always talk of doubt and suspense of judgement, of danger in hasty determinations, of confining to very narrow bounds the enquiries of the understanding, and of renouncing al: speculations which lie not within the limits of common life and practice. Nothing, therefore, can be more contrary than such a philosophy to the supine indolence of the mind, its rash arrogance, its lofty pretensions, and its superstitious credulity. Every passion is mortified by it, except the love of truth; and that passion never is, nor can be, carried to too high a degree. It is surprising, therefore, that this philosophy, which, in almost every instance, must be harmless and innocent, should be the subject of so much groundless reproach and obloquy. But, perhaps, the very circumstance which renders it so innocent is what chiefly exposes it to the public hatred and resentment. By flattering no irregular passion, it gains few partizans: By opposing so many vices and follies, it raises to itself abundance of enemies, who stigmatize it as libertine, profane, and irreligious.

Nor need we fear that this philosophy, while it endeavours to limit our enquiries to common life, should ever undermine the reasonings of common life, and carry its doubts so far as to destroy all action, as well as speculation. Nature will always main tain her rights, and prevail in the end over any abstract reasoning whatsoever. Though we should conclude, for instance, as in the foregoing section, that, in all reasonings from experience, there is a step taken by the mind which is not supported by any argument or process of the understanding; there is no danger that these reasonings, 
on hich-almostall knowledge-depends, will ever be affected by such a discovery. If the mind be not engaged by argument to make this step, it must be induced by some other principle of equal weight and authority; and that principle will preserve its influence as long as human nature remains the same. What that principle is may well be worth the pains of enquiry.

Suppose a person, though endowed with the strong. est faculties of reason and reflection, to be brought on a sudden into this world; he would, indeed, immediately observe a continual succession of objects, and one event following another; but he would not be able to discover anything farther. He would not, at first, by any reasoning, be able to reach the idea of cause and effect; since the particular powers, by which all natural operations are performed, never appear to th? senses; nor is it reasonable to conclude, merely because one event, in one instance, precedes another, that therefore the one is the cause, the other the effect. Their conjunction may be arbitrary and casual. There may be no reason to infer the existence of one from the appearance of the other. And in a word, such a person, without more experience, could never employ his conjecture or reasoning concerning any matter of fact, or be assured of anything beyond what was immediately present to his memory and senses.

Suppose, again, that he has acquired more experience, and has lived so long in the world as to have observed familiar objects or events to be constantly conjoined together; what is the consequence of this experience? He immediately infers the existence of one object from the appearance of the other. Yet he has not, by all his experience, acquired any idea or knowledge of the secret power by which the one object pro. 
¿duces the other; nor is it, by any process of reasoning, he is engaged to draw this inference. But still he finds himself determined to draw it: And though he should be convinced that his understanding has no part in the operation, he would nevertheless continue in the same course of thinking. There is some other principle which determines him to form such a conclusion.

This principle is Custom or Habit. For wherever the repetition of any particular act or operation produces a propensity to renew the same act or operation, without being impelled by any reasoning or process of the understanding, we always say, that this propensity is the effect of Custom. By employing that word, wepretend not to have given the ultimate reason of such a propensity. We only point out a principle of human nature, which is universally acknowledged, and which is well known by its effects. Perhaps we can push our enquiries no farther, or pretend to give the cause of this cause; but must rest contented with it as the ultimate principle, which we can assign, of all our conclusions from experience. It is sufficient satisfaction, that we can go so far, without repining at the narrowness of our faculties because they will carry us no far. ther. And it is certain we here advance a very intelligible proposition at least, if not a true one, when we assert that, after the constant conjunction of two objects-heat and flame, for instance, weight and solidity. - we are determined by custom alone to expect the one from the appearance of the other. This hypothesis seems even the only one which explains the difficulty, why we draw, from a thousand instances, an inference which we are not able to draw from one instance, thia is, in no respect, different from them. Reason is incap- br of any such variation. The conclusions which it 


\section{draws from considering one circle are the same which} it would form upon surveying all the circles in the universe. But no man, having seen only one body move after being impelled by another, could infer that every other body will move after a like impulse. All inferences from experience, therefore, are effects of custom, not of reasoning.

1 Nothing is more useful than for writers, even, on moral, folitical, or physical subjects, to distinguish between reason and experience, and to suppose, that these species of argumentation are entirely different from each other. The former are taken for the mere result of our intellectual faculties, which, by considering $d$ priori the nature of things, and examining the effects, that must follow from their operation, establish particular principles of science and philosophy. The latter are supposed to be derived entirely from sense and observation, by which we learn what has actually resulted from the operation of particular objects, and are thence able to infer, what will, fivr the future, result from them. Thus, for instance, the limitations and restraints of civil government, and a legal constitution, may be defended, either from reason, which reflecting on the great frailty and corruption of human nature, teaches, that no man can safely be trusted with unlimited authority; or from experience and history, which inform us of the enormous abuses, that amtition, in every age and country, has been found to make of so imprudent a confidence.

The same distinction between reason and experience is maintained in all our deliberations concerning the conduct of life; while the experienced statesman, general, physician, or merchant is trusted and followed; and the unpractised novice, with whatever natural talents endowed, neglected and despised. Though it be allowed, that reason may form very plausible conjectures with regard to the consequences of such a particular conduct in such particular circumstances; it is still supposed imperfect, without the assistance of experience, which is alone able to give stability and certainty to the maxims, derived from study and reflection.

But notwithstanding that this distinction be thus universally received, both in the active speculative scenes of life, I shall not scruple to pronounce, that it is, at bottom, erroneous, at least, superficial

If we examine thóse arguments, which, in any of the sciences above mentioned, are supposed to be the mere effects of reasoning and reflection, they will b 3 found to terminate, at last, in some general principle or conclusion, for which we can assign no reason but observation and experience. The only difference between them and those maxims, which are vulgarly esteemed the result of pure experience, is, that the former cannot be established without some process of thought, and some refection on what we have observed, in order to distinguish its circumstances, and trace its consequences: Whereas in the latter, the experienced event is exactly and fully familiar to that which we infer as the result of any particular situation. The history of a Tiberins or 2 Nero makes us dread a like tyranny, were our monarchs freed from the restraints of laws and senates But the observation of any fraud or cruelty 
Custom, then, is the great guide of human life. It is that principle alone which renders our experience useful to us, and makes us expect, for the future, a similar train of events with those which have appeared in the past. Without the influence of custom, we should be entirely ignorant of every matter of fact beyend what is immediately present to the memory and senses. We should never know how to adjust means to ends, or to employ our natural powers in the production of any effect. There would be an end at once of allaction, as well as of the chief part of speculation.

But here it may be proper to remark, that though our conclusions from experience carry us beyond our memory and senses, and assure us of matters of fact which happened in the most distant places and most remote ages, yet some fact must always be present to the senses or memory, from which we may first proceed in drawing these conclusions. A man, who should find in a desert country the remains of pompous build. ings, would conclude that the country had, in ancient

in private life is sufficient, with the aid of a little thought, to give us the same apprehension; while it serves as an instance of the general corruption of human nature, and shows us the danger which we must incur by reposing an (ntire confidence in mankind. In both cases, it is experience which is ultimately the foundation of our inference and conclusion.

There is no man so young and unexperienced, as not to have formed, from observation, many general and just maxims concerning human affairs and the conduct of life; but it must be confessed, that, when a man comes to put these in practice, he will be extremely liable to error, till time and farther experience both enlarge these maxims, and teach him their proper use and application. In every situation or incident, there are many particular and seemingly minute circumstances, which the man of greatest talent is, at first, apt to overlook, though on them the justness of his conclusions, and consequently the prudence of his conduct, entirely depend. Not to mention, that, to a young beginner, the general observations and maxims occur not always on the proper occasions, nor can be immediately applied with due calmness and distinction. The truth is, an unexperienced reasoner could be no rea: soner at all, were he absolutely unexperienced; and when we assign tha character to any one, we mean it only in a comparative sense, and suppose him possessed of experience, in a smal'er and mors 'mperfect degree. 
times, been cultivated by civilized inhabitants; but did nothing of this nature occur to him, he could never form such an inference. We learn the events of former ages from history; but then we must peruse the volumes in which this instruction is contained, and thence carry up our inferences from one testimony to another, till we arrive at the eyewitnesses and spectators of these distant events. In a word, if we proceed not upon some fact, present to the memory or senses, our reasonings would be merely hypothetical; and however the particular links might be connected with each other, the whole chain of inferences would have nothing to support it, nor could we ever, by its means, arrive at the knowledge of any real existence. If I ask why you believe any particular matter of fact, which you relate, you must tell me some reason; and this reason will be some other fact, connected with it. But as you cannot proceed after this manner, in infinitum, you must at last terminate in some fact, which is present to your memory or senses; or must allow that your belief is entirely without foundation.

What, then, is the conclusion of the whole matter ? A simple one; though, it must be confessed, pretty remote from the common theories of philosophy. All belief of matter of fact or real existence is derived merely from some object, present to the memory or senses, and a customary conjunction between that and some other object. Or in other words; having found in many instances, that any two kinds of objectsflame and heat, snow and cold-have always been conjoined together; if flame or snow be presented anew to the senses, the mind is carried by custom to expect heat or cold, and to believe that such a quality does exist, and will discover itself upon a nearer approach. 
This belief is the necessary result of placing the mind in such circumstances. It is an operation of the soul, when we are so situated, as unavoidable as to feel the passion of love, when we receive benefits; or hatred, when we meet with injuries. All these operations are a species of natural instincts, which no-reasoning or process of the thought and understanding is able either to produce or to prevent.

At this point, it would be very allowable for us to stop our philosophical researches. In most questions we can never make a single step farther; and in all questions we must terminate here at last, afterour most restless and curious enquiries. But still oưr curiosity will be pardonable, perhaps commendable, if it carry us on to still farther researches, and make us examine more accurately the nature of this belief, and of the customary conjunction, whence it is derived. By this means we may meet with some explications and analogies that will give satisfaction; at least to such as love the abstract sciences, and can be entertained with speculations, which, however accurate, may still retain a degree of doubt and uncertainty. As to readers of a different taste; the remaining part of this section is not calculated for them, and the following enquiries may well be understood, though it be neglected.

\section{PART II.}

Nothing is more free than the imagination of man; - and though it cannot exceed that original stock of ideas furnished by the internal and external senses, it has unlimited power of mixing, compounding, separating, and dividing these ideas, in all the varieties of fiction and vision. It can feign a train of events, with ail the appearance of reality, ascribe to them a partic- 
ular time and place, conceive them as existent, and paint them out to itself with every circumstance, that belongs to any historical fact, which it believes with the greatest certainty. Wherein, therefore, consists the difference between such a fiction and belief ? It lies not merely in any peculiar idea, which is annexed to such a conception as commands our assent, and which is wanting to every known fiction. For as the mind has authority over all its ideas, it could voluntarily annex this particular idea to any fiction, and con, sequently be able to believe whatever it pleases; contrary to what we find by daily experience. We can, in our conception, join the head of a man to the body of a horse ; but it is not in our power to believe that such an animal has ever really existed.

It follows, therefore, that the difference between - fiction and belief lies in some sentiment or feeling, which is annexed to the latter, not to the former, and which depends not on the will, nor can be commanded at pleasure. It must be excited by nature, like all other sentiments; and must arise from the particular situation, in which the mind is placed at any particular juncture. Whenever any object is presented to the memory or senses, it immediately, by the force of custom, carries the imagination to conceive that object, which is usually conjoined to it; and this conception is attended with a feeling or sentiment, different from the loose reveries of the fancy. In this consists the whole nature of belief. For as there is no matter of fact which we believe so firmly that we cannot conceive the contrary, there would be no difference between the conception assented to and that which is rejected, were it not for some sentiment which distinguishes the one from the other. If I see a billiard- 
ball moving towards another, on a smooth table, I can easily conceive it to stop upon contact. This conception implies no contradiction; but still it feels very differently from that conception by which I represent to myself the impulse and the communication of motion from one ball to another.

Were we to attempt a definition of this sentiment, we should, perhaps, find it a very difficult, if not an impossible task; in the same manner as if we should endeavour to define the feeling of cold or passion of anger, to a creature who never had any experience of these sentiments. Belief is the true and proper name of this feeling; and no one is ever at a loss to know the meaning of that term; because every man is every moment conscious of the sentiment represented by it. It may not, however, be improper to attempt a description of this sentiment ; in hopes we may, by that means, arrive at some analogies, which may afford a more perfect explication of it. I say, then, that belief is nothing but a more vivid, lively, forcible, firm, steady conception of an object, than what the imagination alone is ever able to attain. This variety of terms, which may seem so unphilosophical, is intended only to express that act of the mind, which renders realities, or what is taken for such, more present to us than fictions, causes them to weigh more in the thought, and gives them a superior influence on the passions and imagination. Provided we agree about the thing, it is needless to dispute about the terms. The imagination has the command over all its ideas, and can join and mix and vary them, in all the ways possible. It may conceive fictitious objects with all the circumstances of place and time. It may set them, in a manner, before our eyes, in their true colours, just as they might 
have existed. But as it is impossible that this faculty of imagination can ever, of itself, reach belief, it is evident that belief consists not in the peculiar nature or order of ideas, but in the manner of their conception, and in their feeling to the mind. I confess, that it is impossible perfectly to explain this feeling or manner of conception. We may make use of words which express something near it. But its true and proper name, as we observed before, is belief; which is a term that every one sufficiently understands in common life. And in philosophy, we can go no farther than assert, that belief is something felt by the mind, which distinguishes the ideas of the judgement from the fictions of the imagination. It gives them more weight and influence; makes them appear of greater importance; enforces them in the mind; and renders them the governing principle of our actions. I hear at present, for instance, a person's voice, with whom I am acquainted; and the sound comes as from the next room. This impression of my senses i.mmediately conveys my thought to the person, together with all the surrounding objects. I paint them out to myself as existing at present, with the same qualities and relations, of which I formerly knew them possessed. These ideas take faster hold of my mind than i leas of an enchanted castle. They are very different to the feeling, and have a much greater influence of every kind, either to give pleasure or pain, joy or sorrow.

Let us, then, take in the whole compass of this doctrine, and allow, that the sentiment of belief is nothing but a conception more intense and steady than what attends the mere fictions of the imagination, and that this manner of conception arises from a customary conjunction of the object with something present to 
the memory or senses: I believe that it will not be difficult, upon these suppositions, to find other operations of the mind analogous to it, and to trace up these phenomena to principles still more general.

We have already observed that nature has established connexions among particular ideas, and that no sooner one idea occurs to our thoughts than it intro. duces its correlative, and carries our attention towards it, by a gentle and insensible movement. These principles of connexion or association we have reduced to three, namely, Resemblance, Contiguity and Causation; which are the only bonds that unite our thoughts together, and beget that regular train of reflection or discourse, which, in a greater or less degree, takes place among mankind. Now here arises a question, on which the solution of the present difficulty will depend. Does it happen, in all these relations, that, when one of the objects is presented to the senses or memory, the mind is not only carried to the conception of the correlative, but reaches a steadier and stronger conception of it than what otherwise it would have been able to attain? This seems to be the case with that belief which arises from the relation of cause. and effect. And if the case be the same with the other relations or principles of associations, this may be established as a general law, which takes place in all the operations of the mind.

We may, therefore, observe, as the first experiment to our present purpose, that, upon the appearance of the picture of an absent friend, our idea of him is evidently enlivened by the resemblance, and that every passion, which that idea occasions, whether of joy or sorrow, acquires new force and vigour. In producing this effect, there concur both a relation and a present 
impression. Where the picture bears him no resemblance, at least was not intended for him, it never so much as conveys our thought to him: And where it is absent, as well as the person, though the mind may pass from the thought of the one to that of the other, it feels its idea to be rather weakened than enlivened by that transition. We take a pleasure in viewing the picture of a friend, when it is set before us; but when it is removed, rather choose to consider him directly than by reflection in an image, which is equally distant and obscure.

The ceremonies of the Roman Catholic religion may be considered as instances of the same nature. The devotees of that superstition usually plead in excuse for the mummeries, with which they were upbraided, that they feel the good effect of those external motions, and postures, and actions, in enlivening their devotion and quickening their fervour, which otherwise would decay, if directed entirely to distant and immaterial objects. We shadow out the objects of our faith, say they, in sensible types and images, and render them more present to us by the immediate presence of these types, than it is possible for us to do merely by an intellectual view and contemplation. Sensible objects have always a greater influence on the fancy than any other; and this influence they readily convey to those ideas to which they are related, and which they resemble. I shall only infer from these practices, and this reasoning, that the effect of resemblance in enlivening the ideas is very common; and as in every case a resemblance and a present impression must concur, we are abundantly supplied with experiments to prove the reality of the foregoing principle. 
We may add force to these experiments by others of a different kind, in considering the effects of contuguity as well as of resemblance. It is certain that distance diminishes the force of every idea, and that. upon our approach to any object; though it does not discover itself to our senses; it operates upon the mind with an influence, which imitates an immediate impression. The thinking on any object readily transports the mind to what is contiguous; but it is onlv the actual presence of an object, that transports it with

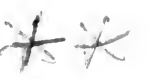
a superior vivacity. When $I$ am a few miles from home, whatever relates to it touches me more nearly than when I am two hundred leagues distant; though even at that distance the reflecting on any thing in the neighbourhood of my friends or family naturally produces an idea of them. But as in this latter case, both the objects of the mind are ideas; notwithstanding there is an easy transition between them; that transitinn alone is not able to give a superior vivacity to any of the ideas, for want of some immediate impression. ${ }^{1}$

No one can doubt but causation has the same influence as the other two relations of resemblance and contiguity. Superstitious people are fond of the reliques of saints and holy men, for the same reason, that they seek after types or images, in order to enliven

1 ' Naturane nobis, inquit, datum dicam, an errore quodam, ut, coun ea loca videamus, in quibus memoria dignos viros acceperimus multum esse versatos, magis noveamur, quam siquando eorum ipsorum aut facta audiamus aut scriptum aliquod legamus? Velut ego nunc moveor. Venit enim mihi Plato in mentem, quem accepimus primum hic disputare solitum: cuins etiam illi hortuli propinqui non memoriam solum mihi afferunt, sed ipsum videntur in conspectu meo hic ponere. Hic Speusippus, hic Xenocrates, hic eins auditor Polemo; cuius ipsa illa sessio fuit, quam videmus. Equidem etiam curiam nostram, Hostiliam dico, non hanc novam, quae mihi minor esse videtur postquam est maior, solebam intuens, Scipionem, Catonem, Laelium: nostrum vero in primis avum cogitare. Tanta vis admonitionis est in locis; ut non sine causa ex his memoriae deducta sit disciplina.'

Cicero de Finibus. Lib. v. 
their devotion, and give them a more intimate and strong conception of those exemplary lives, which they desire to imitate. Now it is evident, that one of the best reliques, which a devotee could procure, would be the handywork of a saint; and if his cloaths and furniture are ever to be considered in this light, it is because they were once at his disposal, and were moved and affected by him; in which respect they are to be considered as imperfect effects, and as connected with him by a shorter chain of consequences than any of those, by which we learn the reality of his existence.

Suppose, that the son of a friend, who had been long dead or absent, were presented to us; it is evi. dent, that this object would instantly revive its correlative idea, and recall to our thoughts all past intimacies and familiarities, in more lively colours than they would otherwise have appeared to us. This is another phaenomenon, which seems to prove the principle above mentioned.

We may observe, that, in these phaenomena, the belief of the correlative object is always presupposed: without which the relation could have no effect. The influence of the picture supposes, that we believe our friend to have once existed. Contiguity to home can never excite our ideas of home, unless we believe that it really exists. Now I assert, that this belief, where it reaches beyond the memory or senses, is of a similar nature, and arises from similar causes, with the transition of thought and vivacity of conception here explained. When I throw a piece of dry wood into a fire, my mind is immediately carried to conceive, that it augments, not extinguishes the flame. This transition of thought from the cause to the effect proceeds not from reason. It derives its origin altogether from 
custom and experience. And as it first begins from an object, present to the senses, it renders the idea or conception of flame more strong and lively than any loose, floating reverie of the imaginaticn. That idea arises immediately. The thought moves instantly towards it, and conveys to it all that force of conception, which/ is derived from the impression present to the senses. When a sword is levelled at my breast, does not the idea of wound and pain strike me more strongly, than when a glass of wine is presented to me, even though by accident this idea should occur after the appearance of the latter object? But what is there in this whole matter to cause such a strong conception, except only a present object and a customary transition to the idea of another object, which we have been accustomed to conjoin with the former? This is the whole operation of the mind, in all our conclusions concerning matter of fact and existence; and it is a satisfaction to find some analogies, by which it may be explained. The transition from a present object does in all cases give strength and solidity to the related idea.

Here, then, is a kind of pre-established harmony between the course of nature and the succession of jur ideas; and though the powers and forces, by which the former is governed, be wholly unknown to us; yet our thoughts and conceptions have still, we find, gone on in the same train with the other works of nature. Custom is that principle, by which this correspondence has been effected; so necessary to the subsistence of our species, and the regulation of our conduct, in every circumstarce and occurrence of human life. Had not the presence of an object, instantly excited the idea of those objects, commonly conjoined with it, all our knowledge must have been limited to the narrow sphere 
of our memory and senses; and we should never have been able to adjust means to ends, or employ our natural powers, either to the producing of good, or avoiding of evil. Those, who delight in the discovery and contemplation of final causes, have here ample subject to employ their wonder and admiration.

I shall add, for a further confirmation of the foregoing theory, that, as this operation of the mind, by which we infer like effects from like causes, and vice yersa, is so essential to the subsistence of all human creatures, it is not probable, that it could be trusted to the fallacious deductions of our reason, which is slow in its operations; appears not, in any degree, during the first years of infancy; and at best is, in every age and period of human life, extremely liable to error and mistake. It is more conformable to the ordinary wisdom of nature to secure so necessary an act of the mind, by some instinct or mechanical tendency, which may be infallible in its operations, may discover itself at the first appearance of life and thought, and may be independent of all the laboured deductions of the understanding. As nature has taught us the use of our limbs, without giving us the knowledge of the muscles and nerves, by which they are actuated; so has she implanted in us an instinct, which carries forward the thought in a correspondent course to that which she has established among external objects; though we are ignorant of those powers and forces, on which this regular course and succession of objects totally depends. 


\title{
SECTION VI.
}

\author{
OF PROBABILITY. ${ }^{1}$
}

THOUGH there be no such thing as Chance in the I world; our ignorance of the real cause of anv event has the same influence on the understanding. and begets a like species of belief or opinion.

There is certainly a probability, which arises from a superiority of chances on any side; and according as this superiority encreases, and surpasses the opposite chances, the probability receives a proportionable encrease, and begets still a higher degree of belief or assent to that side, in which we discover the superiority. If a dye were marked with one figure or number of spots on four sides, and with another figure or number of spots on the two remaining sides, it would be more probable, that the former would turn up than the latter; though, if it had a thousand sides marked in the same manner, and only one side different, the probability would be much higher, and our belief or expectation of the event more steady and secure. This process of the thought or reasoning may seem triviai and obvious; but to those who consider it more nar-

I Mr. Locke divides all arguments into demonstrative and probable. In this view, we must say, that it is only probable all men must die, or that hite sun will rise to-morrow. But to conform our language more to common use, we ought to divide arguments into demonstrations, proofs, and probabilitirs. By proofs meaning such arguments from experience as leave no room for doubt or opposition. 
rowly, it may, perhaps, afford matter for curious speculation.

It seems evident, that, when the mind looks for ward to discover the event, which may result from the throw of such a dye, it considers the turning up of each particular side as alike probable; and this is the very nature of chance, to render all the particular events, comprehended in it, entirely equal. But finding a greater number of sides concur in the one event than in the other, the mind is carried more frequentiy to that event, and meets it oftener, in revolving the various possibilities or chances, on which the ultimate result depends. This concurrence of several views in one particular event begets immediately, by an inexplicable contrivance of nature, the sentiment of belief. and gives that event the advantage over its antagonist. which is supported by a smaller number of views, and recurs less frequently to the mind. If we allow, that - belief is nothing but a firmer and stronger conception of an object than what attends the mere fictions of the imagination, this operation may, perhaps, in some measure, be accounted for. The concurrence of these several views or glimpses imprints the idea more s'rongly on the imagination; gives it superior force and vigour; renders its influence on the passions and affections more sensible; and in a word, begets that reliance or security, which constitutes the nature of belief and opinion.

The case is the same with the probability of causes, as with that of chance. There are some causes, which are entirely uniform and constant in producing a particular effect; and no instance has ever yet been found of any failure or irregularity in their operation. Fire has always burned, and water suffocated every human 
creature: The production of motion by impulse and gravity is an universal law, which has hitherto admitted of no exception. But there are other causes which have been found more irregular and uncertain; nor has rhubarb always proved a purge, or opium a soporific to every one, who has taken these medicines. It is true, when any cause fails of producing its usual effect, philosophers ascribe not this to any irregularity 'n nature; but suppose, that some secret causes, in the particular structure of parts, have prevented the operation. Our reasonings, however, and conclusions concerning the event are the same as if this principle had no place. Being determined by custom to transfer the past to the future, in all our inferences; where the past has been entirely regular and uniform, we expect the event with the greatest assurance, and leave no room for any contrary supposition. But where different effects have been found to follow from causes, which are to appearance exactly similar, all these various effects must occur to the mind in transferring the past to the future, and enter into our consideration, when we determine the probability of the event. Though we give the preference to that which has been found most usual, and believe that this effect will exist, we must not overlook the other effects, but must assign to each of them a particular weight and authority, in proportion as we have found it to be more or less frequent. It is more probable, in almost every country of Europe, that there will be frost sometime in January, than that the weather will continue open throughout the whole month; though this probability varies according to the different climates, and approaches to a certainty in the more northern kingdoms. Here then it seems evident, that, when we transfer the 
past to the future, in order to determine the effect, which will result from any cause, we transfer all the different events, in the same proportion as they have appeared in the past, and conceive one to have existed a hundred times, for instance, another ten times, and another once. As a great number of views do here concur in one event, they fortify and confirm it to the imagination, beget that sentiment which we call belicf, and give its object the preference above the contrary event, which is not supported by an equal number of experiments, and recurs not so frequently to the thought in transferring the past to the future. Let any one try to account for this operation of the mind upon any of the received systems of philosophy, and he will be sensible of the difficulty. For my part, I shall think it sufficient, if the present hints excite the curiosity of philosophers, and make them sensible how defective all common theories are in treating of such curious and such sublime subjects. 


\section{SECTION VII.}

OF THE IDEA OF NECESSARY CONNEXION.

$$
\text { PART I. }
$$

THE great advantage of the mathematical sciences 1 above the moral consists in this, that the ideas of the former, being sensible, are always clear and determinate, the smallest distinction between them is immediately perceptible, and the same terms are still expressive of the same ideas, without ambiguity or variation. An oval is never mistaken for a circle, nor an hyperbola for an ellipsis. The isosceles and scalenum are distinguished by boundaries more exact than vice and virtue, right and wrong. If any term be defined in geometry, the mind readily, of itself, substitutes, on all occasions, the definition for the term defined: Or even when no definition is employed, the object itself may be presented to the senses, and by. that means be steadily and clearly apprehended. But the finer sentiments of the mind, the operations of the understandiug, the various agitations of the passions, though really in themselves distinct, easily escape us, when surveyed by reflection; nor is it in our power to recall the original object, as often as we have occasion to contemplate it. Ambiguity, by this means, is gradually introduced into our reasonings : Similar objects are readily taken to be the same: And the conclusion becomes at last very wide of the premises. 
Ore may safely, however, affirm, that, if we consider these sciences in a proper light, their advantages and disadvantages nearly compensate each other, and reduce both of them to a state of equality. If the mind, with greater facility, retains the ideas of geometry clear and determinate, it must carry on a much longer and more intricate chain of reasoning, and compare ideas much wider of each other, in order to reach the abstruser truths of that science. And if moral ideas are apt, without extreme care, to fall into obscurity and confusion, the inferences are always much shorter in these disquisitions, and the intermediate steps, which lead to the conclusion, much fewer than in the sciences which treat of quantity and number. In reality, there is scarcely a proposition in Euclid so simple, as not to consist of more parts, than are to be found in any moral reasoning which runs not into chimera and conceit. Where we trace the principles of the human mind through a few steps, we may be very well satisfied with our progress; considering how soon nature throws a bar to all our enquiries concerning causes, and reduces us to an acknowledgment of our ignorance. The chief obstacle, therefore, to our improvement in the moral or metaphysical sciences is the obscurity of the ideas, and ambiguity of the terms. The principal difficulty in the mathematics is the length of inferences and compass of tinought, requisite to the forming of any conclusion. And, perhaps, our progress in natural philosophy. is chiefly retarded by the want of proper experiments and phaenomena, which are often discovered by chance, and cannot always be found, when requisite, even by the most diligent and prudent enquiry. As moral philosophy seems hitherto to have received less improve- 
ment than either geometry or physics, we may conclude, that, if there be any difference in this respect among these sciences, the difficulties, which obstruce the progress of the former, require superior care an capacity to be surmounted.

There are no ideas, which occur in metaphysics' more obscure and uncertain, than those of power, force. energy or necessary connexion, of which it is every mom. ent necessary for us to treat in all our disquisitions. We shall, therefore, endeavour, in this section, to fix, if possible, the precise meaning of these terms, and thereby remove some part of that obscurity, which is so much complained of in this species of philosophy.

It seems a proposition, which will not admit of much dispute, that all our ideas are nothing but copies of our impressions, or, in other words, that it is impossible for us to think of any thing, which we have not antecedently felt, either by our external or internal senses. I have endeavoured ${ }^{1}$ to explain and prove this proposition, and have expressed my hopes, that, by a proper application of it, men may reach a greater clearness and precision in philosophical reasonings, than what they have hitherto been able to attain. Complexideas may, perhaps, be well known by definition, which is nothing but an enumeration of those parts or simple ideas, that compose them. But when we have pushed up definitions to the most simple ideas, and find still some ambiguity and obscurity; what resource are we then possessed of ? By what invention can we throw light upon these ideas, and render them altogether precise and determinate to our intellectual view! Produce the impressions or original sentiments, from which the ideas are copied. These impressions are al

1 Section II. 
strong and sensible. They admit not of ambiguity. They are not only placed in a full light themselves, but may throw light on their correspondent ideas, which lie in obscurity. And by this means, we may, perhaps, attain a new microscope or species of optics, by which, in the moral sciences, the most minute, and most simple ideas may be so enlarged as to fall readily under our apprehension, and be equally known with the grossest and most sensible ideas, that can be the object of our enquiry.

To be fully acquainted, therefore, with the idea of power or necessary connexion, let us examine its impression; and in order to find the impression with greater certainty, let us search for it in all the sources, from which it may possibly be derived.

When we look about us towards external objects, and consider the operation of causes, we are never able, in a single instance, to discover any power or necessary connexion; any quality, which binds the effect to the cause, and renders the one an infallible consequence of the other. We only find, that the one does actually, in fact, follow the other. The impulse of one billlard-ball is attended with motion in the second. This is the whole that appears to the outward senses. The mind feels no sentiment or inward impression from this succession of objects : Consequently there is not, in any single, particular instance of cause and effect, any thing which can suggest the idea of power or necessary connexion.

From the first appearance of an object, we never can conjecture what effect will result from it. But were the power or energy of any cause discoverable by the mind, we could foresee the effect, even without experience; and might, at first, pronounce with cer- 
tainty concerning it, by mere dint of thought and reasoning.

In reality, there is no part of matter, that does ever, by its sensible qualities, discover any power or energy, or give us ground to imagine, that it could produce any thing, or be followed by any other object, which we could denominate its effect. Solidity, extension, motion; these qualities are all complete in themselves, and never point out any other event which may result from them. The scenes of the universe are continually shifting, and one object follows another in an uninterrupred succession; but the power of force, which actuates the whole machine, is entirely concealed from us, and never discovers itself in any of the sensible qualities of body. We know, that, in fact, heat is a constant attendant of flame; but what is the connexion between them, we have no room so much as to conjecture or imagine. It is impossible, therefore, that the idea of power can be derived from the contemplation of bodies, in single instances of their operation; because no bodies ever discover any power, which can be the original of this idea. ${ }^{1}$

Since, therefore, external objects as they appear to the senses, give us no idea of power or necessary connexion, by their operation in particular instances, let us see, whether this idea be derived from refiexion on the operations of our own minds, and be copied from any internal impression. It may be said, that we are every moment conscious of internal power; while we

$1 \mathrm{Mr}$. Locke, in his chapter of power, says, that, finding from experience, that there are several new productions in matter, and concluding that there must somewhere be a power capable of producing them, we arrive at last by this reasoning at the idea of power. But no reasoning can ever give us a new original, simple idea; as this philosopher himself confesses. This, therefore can never be the origin of that idea. 
¿eel, that, by the simple command of our will, we can move the organs of our body, or direct the faculties of our mind. An act of volition produces motion in our limbs, or raises a new idea in our imagination. This influence of the will we know by consciousness. Hence we acquire the idea of power or energy; and are certain, that we ourselves and all other intelligent beings are possessed of power. This idea, then, is an idea of reflection, since it arises from reflecting on the operations of our own mind, and on the command which is exercised by will, both over the organs of the body and faculties of the soul.

We shall proceed to examine this pretension; and first with regard to the influence of volition over the organs of the body. This influence, we may observe, is a fact, which, like all other natural events, can be known only by experience, and can never be foreseen from any apparent energy or power in the cause, which connects it with the effect, and renders the one an infallible consequence of the other. The motion of our body follows upon the command of our will. Of this we are every moment conscious. But the means, by which this is effected; the energy, by which the will performs so extraordinary an operation; of this we are so far from being immediately conscious, that it must for ever escape our most diligent enquiry.

For firsi; is there any principle in all nature more mysterious than the union of soul with body; by which a supposed spiritual substance acquires such an influence over a material one, that the most refined thought is able to actuate the grossest matter? Were we empowered, by a secret wish, to remove mountains, or control the planets in their orbit; this extensive authority would not be more extraordinary, nor more 
beyond our comprehension. But if by consciousness we perceived any power or energy in the will, we must know this power; we must know its connexion with the effect; we must know the secret union of soul and body, and the nature of both these subsiances; by which the one is able to operate, in so many instances, upon the other.

Secondly, We are not able to move all the organs of the body with a like authority; though we cannot assign any reason besides experience, for so remarkable a difference between one and the other. Why has the will an influence over the tongue and fingers, not over the heart and liver? This question would never embarrass us, were we conscious of a power in the former case, not in the latter. We should then perceive, independent of experience, why the authority of will over the organs of the body is circumscribed within such particular limits. Being in that case fully acquainted with the power or force, by which it operates, we should also know, why its influence reaches precisely to such boundaries, and no farther.

A man, suddenly struck with palsy in the leg or arm, or who had newly lost those members, frequently endeavours, at first to move them, and employ them in their usual offices. Here he is as much conscious of power to command such limbs, as a man in perfect health is conscious of power to actuate any member which remains in its natural state and condition. But consciousness never deceives. Consequently, neither in the one case nor in the other, are we ever conscious of any power. We learn the influence of our will from experience alone. And experience only teaches us, how one event constantly follows another; without 
instructing us in the secret connexion, which binds them together, and renders them inseparable.

Thirdly, We learn from anatomy, that the immediate oiject of power in voluntary moticn, is not the member itself which is moved, but certain muscles, and nerves, and animal spirits, and, perhaps, something still more minute and more unknown, through which the motion is successfully propagated, ere it reach the member itself whose motion is the immediate object of volition. Can there be a more certain proof that the power, by which this whole operation is performed, so far from being directly and fully known by an inward sentiment or consciousness, is, to the last degree, mysterious and unintelligible? Here the mind wills a certain event: Immediately another event, unknown to ourselves, and totally different from the one intended, is produced: This event produces another, equally unknown: Till at last, through a long succession, the desired event is produced. But if the original power wers felt, it must be known: Were it known, its effect also must be known; since all power is relative to its effect. And vice versa, if the effect be not known, the power cannot be known nor felt. How indeed can we be conscious of a power to move our limbs, when we have no such power; but only that to move certain animal spirits, which, though they produce at ast the motion of our limbs, yet operate in such a manner as is wholly beyond our comprehension?

We may, therefore, conclude from the whole, I hope, without any temerity, though with assurance; that our idea of power is not copied from any sentiment or consciousness of power within ourselves, when we give rise to animal motion, or apply our limbs, 5 their proper use and office. That their motion follows 
the command of the will is a matter of common experience, like other natural events: But the power or energy by which this is effected, like that in other natural events, is unknown and inconceivable. ${ }^{1}$

Shall we then assert, that we are conscious of a power or energy in our own minds, when, by an act or command of our will, we raise up a new idea, fix the mind to the contemplation of it, turn it on all sides, and at last dismiss it for some other idea, when we think that we have surveyed it with sufficient accuracy? I believe the same arguments will prove, that even this command of the will gives us no real idea of force or energy.

First, It must be allowed, that, when we know a power, we know that very circumstance in the cause, by which it is enabled to produce the effect : For these are supposed to be synonimous. We must, therefore, know both the cause and effect, and the relation between them. But do we pretend to be acquainted with the nature of the human soul and the nature of an idea, or the aptitude of the one to produce the other? This is a real creation; a production of something out of nothing: Which implies a power so great, that it may

1 It may be pretended, that the resistance which we meet with in bodies, obliging us frequently to exert our force, and call up all our power, this gives us the idea of force and power. It is this nisus, or strong endeavour, of which we are conscious, that is the original impression from which this idea is copied. But, first, we attribute power to a vast number of objects, where we never can suppose this resistance or exertion of force to take place; to the Supreme Being, who never meets with any resistance; to the mind in its command over its ideas and limbs, in common thinking and motion, where the effect follows immediately upon the will, without any exertion or summoning up of force; to inanimate matter, which is not capable of this sentiment. Secondly, This sentiment of an endeavour to overcome resistance has no known connexion with any event: What follows it, we know by experience; but could not know it d priori. It must, however, be confessed. that the animal nisus, which we experience, though it can afford no accurate precise idea of power, enters very much into that vulgar, inaccurate idea. which is formed of it. 
seem, at first sight, beyond the reach of any being, less than infinite. At least it must be owned, that such a power is not felt, nor known, nor even conceivable by the mind. We only feel the event, namely, the existence of an idea, consequent to a command of the will: But the manner, in which this operation is performed, the power by which it is produced, is entirely beyond our comprehension.

Secondly, The command of the mind over itself is limited, as well as its command over the body; and these limits are not known by reason, or any acquaintance with the nature of cause and effect, but only by experience and observation, as in all other natural events and in the operation of external objects. Our authority over our sentiments and passions is much weaker than that over our ideas; and even the latter authority is circumscribed within very narrow boundaries. Will any one pretend to assign the ultimate reason of these boundaries, or show why the power is deficient in one case, not in another.

Thirdly, This self-command is very different at difierent times. A man in health possesses more of it than one languishing with sickness. We are more master of our thoughts in the morning than in the evening: Fasting, than after a full meal. Can we give any reason for these variations, except experience? Where then is the power, of which we pretend to be conscious? Is there not here, either in a spiritual or material substance, or both, some secret mechanism or structure of parts, upon which the effect depends, and which, being entirely unknown to us, renders the power or energy of the will equally unknown and incomprehensible?

Volition is surely an act of the mind, with which 
we are sufficiently acquainted. Reflect upon it. Consider it on all sides. Do you find anything in it like this creative power, by which it raises from nothing a new idea, and with a kind of Fiat, imitates the omnipotence of its Maker, if I may be allowed so to speak, who called forth into existence all the various scenes of nature? So far from being conscious of this energy in the will, it requires as certain experience as that of which we are possessed, to convince us that such extraordinary effects do ever result from a simple act of volition.

The generality of mankind never find any difficulty in accounting for the more common and familiar operations of nature-such as the descent of heavy bodies, the growth of plants, the generation of animals, or the nourishment of bodies by food: But suppose that, in all these cases, they perceive the very force or energy of the cause, by which it is connected with its effect, and is for ever infallible in its operation. They acquire, by long habit, such a turn of mind, that, upon the appearace of the cause, they immediately expect with assurance its usual attendant, and hardly conceive it possible that any other event could result from it. It is only on the discovery of extraordinary phaenomena, such as earthquakes, pestilence, and prodigies of any kind, that they find themselves at a loss to assign a proper cause, and to explain the manner in which the effect is produced by it. It is usual for men, in şuch difficulties, to have recourse to some invisible intelligent principle ${ }^{1}$ as the immediate cause of that event which surprises them, and which, they think, cannot be accounted for from the common powers of nature. But philosophers, who carry their scrutiny a

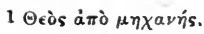


sittle farther, immediately perceive that, even in the most familiar events, the energy of the cause is as unintelligible as in the most unusual, and that we only learn by experience the frequent Conjunction of objects, without being ever able to comprehend anything like Connexion between them. Here, then, many philosophers think themselves obliged by reason to have recourse, on all occasions, to the same principle, which the vulgar never appeal to but in cases that appear miraculous and supernatural. They acknowledge mind and intelligence to be, not only the ultimate and original cause of all things, but the immediate and sole cause of every event which appears in nature. They pretend that those objects which are commonly denominated causes, are in reailty nothing but occasions; and that the true and direct principle of every effect is not any power or force in nature, but a volition of the Supreme Being, who wills that such particular objects should for ever be conjoined with each other. Instead of saying that one billard-ball moves another by a force which it has derived from the author of nature, it is the Deity himself, they say, who, by a particular volition, moves the second ball, being determined to this operation by the impulse of the first ball, in consequence of those general laws which he has laid down to himself in the government of the universe. But philosophers advancing still in their inquiries, discover that, as we are totally ignorant of the power on which depends the mutual operation of bodies, we are no less ignorant of that power on which depends the operation of mind on body, or of body on mind; nor are we able, either from our senses or consciousness, to assign the ultimate principle in one case more than in the other. The same ignorance, therefore, reduces them 
to the same conclusion. They assert that the Deity is the immediate cause of the union between soul and body; and that they are not the organs of sense, which, being agitated by external objects, produce sensations in the mind; but that it is a particular volition of our omnipotent Maker, which excites such a sensation, in consequence of such a motion in the organ. In like manuer, it is not any energy in the will that produces local motion in our members: It is God himself, who is pleased to second our will, in itself impotent, and to command that motion which we erroneously attribute to our own power and efficacy. Nor do philosophers stop at this conclusion. They sometimes extend the same inference to the mind itself, in its internal operations. Our mental vision or conception of ideas is nothing but a revelation made to ứs by our Maker. When we voluntarily turn our thoughts to any object, and raise up its image in the fancy, it is not the will which creates that idea: It is the universal Creator, who discovers it to the mind, and renders it present to us.

Thus, according to these philosophers, every thing is full of God. Not content with the principle, that nothing exists but by his will, that nothing possesses any power but by his concession: They rob nature, and all created beings, of every power, in order to render their dependence on the Deity still more sensible and immediate. They consider not that, by this theory, they diminish, instead of magnifying, the grandeur of those attributes, which they affect so much to celebrate. It argues surely more power in the Deity to delegate a certain degree of power to inferior creatures, than to produce every thing by his own immediate volition. It argues more wisdom to contrive at 
first the fabric of the world with such perfect foresight that, of itself, and by its proper operation, it may serve all the purposes of providence, than if the great Creator were obliged every moment to adjust its parts, and animate by his breath all the wheels of that stupendous machine.

But if we would have a more philosophical confutation of this theory, perhaps the two following reflections may suffice.

First, it seems to me that this theory of the universal energy and operation of the Supreme Being is too bold ever to carry conviction with it to a man, sufficiently apprized of the weakness of human reason, and the narrow limits to which it is confined in all its operations. Though the chain of arguments which conduct to it were ever so logical, there must arise a strong suspicion, if not an absolute assurance, that it has carried us quite beyond the reach of our faculties, when it leads to conclusions so extraordinary, and so remote from common life and experience. We are got into fairy land, long ere we have reached the last steps of our theory; and there we have no reason to trust our common methods of argument, or to think that our usual analogies and probabilities have any authority. Our line is too short to fathom such immense abysses. And however we may flatter ourselves that we are guided, in every step which we take, by a kind of verisimilitude and experience, we may be assured that this fancied experience has no authority when we thus apply it to subjects that lie entirely out of the sphere of experience. But on this we shall have occasion to touch afterwards. ${ }^{1}$

Secondly, I cannot perceive any force in the argu1 Section XII. 
ments on which this theory is founded. We are ig. norant, it is true, of the manner in which bodies oper. ate on each other: Their force or energy is entirely incomprehensible: But are we not equally ignorant. of the manner or force by which a mind, even the su. preme mind, operates either on itself or on body? Whence, I beseech you, do we acquire any idea of it ? We have no sentiment or consciousness of this power in ourselves. We have no idea of the Supreme Being but what we learn from reflection on our own faculties. Were our ignorance, therefore, a good reason for rejecting any thing, we should be led into that principle of denying all energy in the Supreme Being as much as in the grossest matter. We surely comprehend as little the operations of one as of the other. Is it more difficult to conceive that motion may arise from impulse than that it may arise from volition? All we know is our profound ignorance in both cases. ${ }^{1}$

\section{PART II.}

But to hasten to a conclusion of this argument, which is already drawn out to too great a length: We have sought in vain for an idea of power or necessary connexion in all the sources from which we could sup-

1 I need not examine at length the vis inertiae which is so much talked of in the new philosophy, and which is ascribed to matter. We find by experi. ence, that a body at rest or in motion continues for ever in its present state, till put from it by some new cause; and that a body impelled takes as much motion from the impelling body as it acquires itself. These are facts. When we call this a vis inertiae, we only mark these facts, without pretending to have any idea of the inert power; in the same manner as, when we talk of gravity, we mean certain effects, without comprehending that active power. It was never the meaning of SiR IsAAc NEwToN to rob second causes of all force or energy; though some of his followers have endeavoured to establish that theory upon his authority. On the contrary, that great philosopher had recourse to an etherial active fluid to explain his universal attraction; though he was so cautious and modest as to allow, that it was a mere hypothesis, not 
pose it to be derived. It appears that, in single instances of the operation of bodies, we never can, by our utmost scrutiny, discover any thing but one event following another, without being able to comprehend any force or power by which the cause operates, or any connexion between it and its supposed effect. The same difficulty occurs in contemplating the operations of mind on body-where we observe the motion of the latter to follow upon the volition of the former, but are not able to observe or conceive the tie which binds together the motion and volition, or the energy by which the mind produces this effect. The authority of the will over its own faculties and ideas is not a whit more comprehensible: So that, upon the whole, there appears not, throughout all nature, any one instance of connexion which is conceivable by us. All events seem entirely loose and separate. One event follows another; but we never can observe any tie between them. They seem conjoined, but never connected. And as we can have no idea of any thing which never appeared to our outward sense or inward sentiment, the necessary conclusion seems to be that we have no idea of connexion or power at all, and that these words are absolutely without any meaning, when employed either in philosophical reasonings or common life.

But there still remains one method of avoiding this conclusion, and one source which we have not yet examined. When any natural object or event is pre-

to be insisted on, without more experiments. I must confess, that there is something in the fate of opinions a little extraordinary. DES CARTES insinu. ated that doctrine of the universal and sole efficacy of the Deity, without insisting on it. MALEBRANCHE and other CARTESians made it the foundation of all their philosophy. It had, however, no authority in England. Locke, Clarke, and Cudowth, never so much as take notice of it, but suppose all along, that matter has a real, though subordinate and derived power. By what means las it become so prevalent among our modern metaphysicians ? 
sented, it is impossible for us, by any sagacity or pen. etration, to discover, or even conjecture, without experience, what event will result from it, or to carrv our foresight beyond that object which is immediatelv present to the memory and senses. Even after one instance or experiment where we have observed a particular event to follow upon another, we are not entitled to form a general rule, or foretell what will happen in like cases; it being justly esteemed an unpardonable temerity to judge of the whole course of nature from one single experiment, however accurate or certain. But when one particular species of event has always, in all instances, been conjoined with another, we make no longer any scruple of foretelling one upon the appearance of the other, and of employing that reasoning which can alone assure us of any matter of fact or existence. We then call the one object, Cause; the other, Effect. We suppose that there is some connexion between them; some power in the one, by which it infallibly produces the other, and operates with the greatest certainty and strongest necessity.

It appears, then, that this idea of a necessary con. nexion among events arises from a number of similar instances which occur of the constant conjunction of these events; nor can that idea ever be suggested by any one of these instances, surveyed in all possible lights and positions. But there is nothing in a num. ber of instances, different from every single instance, which is supposed to be exactly similar; except only. that after a repetition of similar instances, the mind is carried by habit, upon the appearançe of one event, to expect its usual attendant, and to believe that it will exist. This connexion, therefore, which we feel in the mind, this customary transition of the imagination 
from one object to its usual attendant, is the sentiment or impression from which we form the idea of power or necessary connexion. Nothing farther is in the case. Contemplate the subject on all sides; you will never find any other origin of that idea. This is the sole difference between one instance, from which we can never receive the idea of connexion, and a number of similar instances, by which it is suggested. The first time a man saw the communication of motion by im. pulse, as by the shock of two billiard balls, he could not pronounce that the one event was connected: but only that it was conjoined with the other. After he has observed several instances of this nature, he then pronounces them to be connected. What alteration has happened to give rise to this new idea of connexion? Nothing but that he now feels these events to be connected in his imagination, and can readily foretell the existence of one from the appearance of the other. When we say, therefore, that one object is connected with another, we mean only that they have acquired a connexion in our thought, and give rise to this inference, by which they become proofs of each other's existence: A conclusion which is somewhat extraordinary, but which seems founded on sufficient evidence. Nor will its evidence be weakened by any general diffidence of the understanding, or sceptical suspicion concerning every conclusion which is new and extraordinary. No conclusions can be more agreeable to scepticism than such as make discoveries concerning the weakness and narrow limits of human reason and capacity.

And what stronger instance can be produced of the surprising ignorance and weakness of the understanding than the present? For surely, if there be any re. 
lation among objects which it imports to us to know perfectly, it is that of cause and effect. On this are founded all our reasonings concerning matter of fact or existence. By means of it alone we attain any assurance concerning objects which are removed from the present testimony of our memory and senses. The only immediate utility of all sciences, is to teach us, how to control and regulate future events by their causes. Our thoughts and enquiries are, therefore, every moment, employed about this relation: Yet so imperfect are the ideas which we form concerning it, that it is impossible to give any just definition of cause, except what is drawn from something extraneous and foreign to it. Similar objects are always conjoined with similar. Of this we have experience. Suitably to this experience, therefore, we may define a cause to be an object, followed by another, and where all the objects similar to the first are followed by objects similar to the second. Or in other words where, if the first object had not been, the second never had existed. The appearance of a cause always conveys the mind, by a customary transition, to the idea of the effect. Of this also we have experience. We may, therefore, suitably to this experience, form another definition of cause, and call it, an object followed by another undwhose appearance always conveys the thought to $t$ it of her 4 But though both these definitions be draw $~$ fre a circumstances foreign to the cause, we cannor remedy this inconvenience, or attain any more perfect definition, which may point out that circumstance in the cause, which gives it a connexion with its effect. We have no idea of this connexion, nor even any distinct notion what it is we desire to know, when we endeavour at a conception of it. We say, for instance, that the vibration of this string is 
the cause of this particular sound. But what do we mean by that affirmation? We either mean that this vibration is followed by this sound, and that all similar vibrations have been followed by similar sounds: Or, that this vibration is followed by this sound, and that upon the appearance of one the mind anticipates the senses, and forms immediately an idea of the other. We may consider the relation of cause and effect in either of these two lights; but beyond these, we have no idea of it. ${ }^{1}$

To recapitulate, therefore, the reasonings of this section: Every idea is copied from some preceding impression or sentiment; and where we cannot find any impression, we may be certain that there is no. idea. In all single instances of the operation of bodies or minds, there is nothing that produces any impres-

1 According to these explications and definitions, the idea of power is relative as much as that of cause; and both have a reference to an effect, or some other event constantly conjoined with the former. When we consider the unknown circumstance of an object, by which the degree or quantity of its effect is fixed and determined, we call that its power: And accordingly, it is allowed by all philosophers, that the effect is the measure of the power. But if they had any idea of power, as it is in itself, why could not they meas. ure it in itself ? The dispute whether the force of a body in motion be as its velocity, or the square of its velocity; this dispute, I say, needed not be de. cided by comparing its effects in equal or unequal times; but by a direct mensuration and comparison.

As to the frequent use of the words, Force, Power, Energy, \&c., which ev. ery where occur in common conversation, as well as in philosophy; that is no proof, that we are acquainted, in any instance, with the connecting principle between cause and effect, or can account ultimately for the production of one thing to another. These words, as commonly used, have very loose meanings annexed to them; and their ideas are very uncertain and confused. No animal can put external bodies in motion without the sentiment of a nisus or endeavoui; and every animal has a sentiment or feeling from the stroke or blow of an external object, that is in motion. These sensations, which are merely animal, and from which we can a priori draw no inference. we are apt to transfer to inanimate objects, and to suppose, that they have some such feelings, whenever they transfer or receive motion. With regard to energies, which are exerted, without our annexing to them any idea of communicated motion, we consider only the constant experienced conjunction of the events; and as we feel a customary connexion between the ideas, we transfer that feeling to the objects; as nothing is more usual than to apply to external bodies every internal sensation which they occasion. 
sion, nor consequently can suggest any idea of power or necessary connexion. But when many uniform instances appear, and the same object is always followed by the same event; we then begin to entertain the notion of cause and connexion. We then feel a new sentiment or impressson, to wit, a customary connexion in the thought or imagination between one object and its usual attendant; and this sentiment is the original of that idea which we seek for. For as this idea arises from a number of similar instances, and not from any single instance, it must arise from that circumstance, in which the number of instances differ from every individual instance. But this customary connexion or transition of the imagination is the only circumstance in which they differ. In every other particular they are alike. The first instance which we saw of motion communicated by the shock of two billiard balls (to return to this obvious illustration) is exactly similar to any instance that may, at present, occur to us; except only, that we could not, at first, infer one event from the other; which we are enabled to do at present, after so long a course of uniform experience. I know not whether the reader will readily apprehend this reasoning. I am afraid that, should I multiply words about it, or throw it into a greater variety of lights, it would only become more obscure and intricate. In all abstract reasonings there is one point of view which, if we can happily hit, we shall go farther towards illustrating the subject than by all the eloquence in the world. This point of view we should endeavour to reach, and reserve the flowers of rhetoric for subjects which are more adapted to them. 


\section{SECTION VIII.}

\section{OF LIBERTY AND NECESSITY.}

\section{PART I.}

I' $\Gamma$ might reasonably be expected in questions which have been canvassed and disputed with great eagerness, since the first origin of science and philosophy, that the meaning of all the terms, at least, should have been agreed upon among the disputants; and our enquiries, in the course of two thousand years, been able to pass from words to the true and real subject of the controversy. For how easy may it seem to give exact definitions of the terms employed in reasoning, and make these definitions, not the mere sound of words, the object of future scrutiny and examination? But if we consider the matter more narrowly, we shall be apt to draw a quite opposite conclusion. From this circumstance alone, that a controversy has been long kept on foot, and remains still undecided, we may presume that there is some ambiguity in the expression, and that the disputants affix different ideas to the terms employed in the controversy. For as the faculties of the mind are supposed to be naturally alike in every individual; otherwise nothing could be more fruitless than to reason or dispute together; it were impossible, if men affix the same ideas to their terms, that they could so long form different opinions of the same subject; especially when they communicate their 
views, and each party turn themselves on all sides, in search of arguments which may give them the victory over their antagonists. It is true, if men attempt the discussion of questions which lie entirely beyond the reach of human capacity, such as those concerning the origin of worlds, or the economy of the intellectual system or region of spirits, they may long beat the air in their fruitless contests, and never arrive at any determinate conclusion. But if the question regard any subject of common life and experience, nothing; one would think, could preserve the dispute so long undecided but some ambiguous expressions, which keep the antagonists still at a distance, and hinder them from grappling with each other.

This has been the case in the long disputed question concerning liberty and necessity; and to so remarkable a degree that, if I be not much mistaken, we shall find, that all mankind, both learned and ignorant, have always been of the same opinion with regard to this subject, and that a few intelligible definitions would immediately have put an end to the whole controversy. I own that this dispute has been so much canvassed on all hands, and has led philosophers into such a labyrinth of obscure sophistry, that it is no wonder, if a sensible reader indulge his ease so far as to turn a deaf ear to the proposal of such a question, from which he can expect neither instruction nor entertainment. But the state of the argument here proposed may, perhaps, serve to renew his attention; as it has more novelty, promises at least some decision of the controversy, and will not much disturb his ease by any intricate or obscure reasoning.

I hope, therefore, to make it appear that all men have ever agreed in the doctrine both of necessity and 
of liberty, according to any reasonable sense, which can bè put on these terms; and that the whole controversy has hitherto turned merely upon words. We shall begin with examining the doctrine of necessity.

It is universally allowed that matter, in all its operations, is actuated by a necessary force, and that every natural effect is so precisely determined by the energy of its cause that no other effect, in such particular circumstances, could possibly have resulted from it. The degree and direction of every motion is, by the laws of nature, prescribed with such exactness that a living creature may as soon arise from the shock of two bodies as motion in any other degree or direction than what is actually produced by it. Would we, therefore, form a just and precise idea of necessity, we must consider whence that idea arises when we apply it to the operation of bodies.

It seems evident that, if all the scenes of nature were continually shifted in such a manner, that no two events bore any resemblance to each other, but every object was entirely new, without any similitude to whatever had been seen before, we should never, in that case, have attained the least idea of necessity, or of a connexion among these objects. We might say, upon such a supposition, that one object or event has followed another; not that one was produced by the other. The relation of cause and effect must be utterly unknown to mankind. Inference and reasoning concerning the operations of nature would, from that moment, be at an end; and the memory and senses remain the only canals, by which the knowledge of any real existence could possibly have access to the mind. Our idea, therefore, of necessity and causation arises entirely from the uniformity observable in the opera- 
tions of nature, where similar objects are constantly conjoined together, and the mind is determined by custom to infer the one from the appearance of the other. These two circumstances form the whole of that necessity, which we ascribe to matter. Beyond the constant conjunction of similar objects, and the consequent inference from one to the other, we have no notion of any necessity or connexion.

If it appear, therefore, that all mankind have ever allowed, without any doubt or hesitation, that these two circumstances take place in the voluntary actions of men, and in the operations of mind; it must follow, that all mankind have ever agreed in the doctrine of necessity, and that they have hitherto disputed, merely for not understanding each other.

As to the first circumstance, the constant and regular conjunction of similar events, we may possibly satisfy ourselves by the following considerations. It is universally acknowledged that there is a great uniformity among the actions of men, in all nations and ages, and that human nature remains still the same, in its principles and operations. The same motives always produce the same actions: The same events follow from the same causes. Ambition, avarice, selflove, vanity, friendship, generosity, public spirit: these passions, mixed in various degrees, and distributed through society, have been, from the beginning of the world, and still are, the source of all the actions and enterprises, which have ever been observed among mankind. Would you know the sentiments, inclinations, and course of life of the Greeks and Romans? Study well the temper and actions of the French and English: You cannot be much mistaken in transferring to the former most of the observations which you 
have made with regard to the latter. Mankind are so much the same, in all times and places, that history informs us of nothing new or strange in this particular. Its chief use is only to discover the constant and universal principles of human nature, by showing men in all varieties of circumstances and situations, and furnishing us with materials from which we may form our observations and become acquainted with the regular springs of human action and behaviour. These records of wars, intrigues, factions, and revolutions, are so many collections of experiments, by which the politician or moral philosopher fixes the principles of his science, in the same manner as the physician or natural philosopher becomes acquainted with the nature of plants, minerals, and other external objects, by the experiments which he forms concerning them. Nor are the earth, water, and other elements, examined by Aristotle, and Hippocrates, more like to those which at present lie under our observation than the men described by Polybius and Tacitus are to those who now govern the world.

Should a traveller, returning from a far country, bring us an account of men, wholly different from any with whom we were ever acquainted; men, who were entirely divested of avarice, ambition, or revenge; who knew no pleasure but friendship, generosity, and public spirit; we should immediately, from these circumstances, detect the falsehood, and prove him a liar, with the same certainty as if he had stuffed his narration with stories of centaurs and dragons, miracles and prodigies. And if we would explode any forgery in history, we cannot make use of a more convincing argument, than to prove, that the actions ascribed to any person are directly contrary to the course of 
rature, and that no human motives, in such circumstances, could ever induce him to such a conduct. The veracity of Quintus Curtius is as much to be suspected, when he describes the supernatural courage of Alexander, by which he was hurried on singly to attack multitudes, as when he describes his supernatural force and activity, by which he was able to resist them." So readily and universally do we ackncwledge a uniformity in human motives and actions as well as in the operations of body.

Hence likewise the benefit of that experience, acquired by long life and a variety of business and company, in order to instruct us in the principles of human nature, and regulate our future conduct, as well as speculation. By means of this guide, we mount up to the knowledge of men's inclinations and motives, from their actions, expressions, and even gestures; and again descend to the interpretation of their actions from our knowledge of their motives and inclinations. The general observations treasured up by a course of experience, give us the clue of human nature, and teach us to unravel all its intricacies. Pretexts and appearances no longer deceive us. Public declarations pass for the specious colouring of a cause. And though virtue and honour be allowed their proper weight and authority, that perfect disinterestedness, so often pretended to, is never expected in multitudes and parties; seldom in their leaders; and scarcely even in individuals of any rank or station. But were there no uniformity in human actions, and were every experiment which we could form of this kind irregular and anomalous, it were impossible to collect any general observations concerning mankind; and no experience, however accurately digested by reflection, would ever 
serve to any purpose. Why is the aged husbandman more skilful in his calling than the young beginner but because there is a certain uniformity in the operation of the sun, rain, and earth towards the production of vegetables; and experience teaches the old practitioner the rules by which this operation is governed and directed.

We must not, however, expect that this uniformity of human actions should be carried to such a length as that all men, in the same circumstances, will always act precisely in the same manner, without making any allowance for the diversity of characters, prejudices, and opinions. Such a uniformity in every particular, is found in no part of nature. On the contrary, from observing the variety of conduct in different men, we are enabled to form a greater variety of maxims, which still suppose a degree of uniformity and regularity.

Are the manners of men different in different ages and countries? We learn thence the great force of custom and education, which mould the human mind from its infancy and form it into a fixed and established character. Is the behaviour and conduct of the one sex very unlike that of the other? Is it thence we become acquainted with the different characters which nature has impressed upon the sexes, and which she preserves with constancy and regularity? Are the actions of the same person much diversified in the different periods of his life, from infancy to old age? This affords room for many general observations concerning the gradual change of our sentiments and inclinations, and the different maxims which prevail in the different ages of human creatures. Even the characters, which are peculiar to each individual, have a uniformity in their influence; otherwise our acquain- 
tance witl the persons and our observation of their concuct could never teach us their dispositions, cr. serve to direct our behaviour with regard to then.

I grant it possible to find some actions, which seem to have no regular connexion with any known motives, and are exceptions to all the measures of conduct which have ever been established for the government of men. But if we would willingly know what judgement should be formed of such irregular and extraordinary actions, we may consider the sentiments commonly entertained with regard to those irregular events which appear in the course of nature, and the operations of external objects. All causes are not conjoined to their usual effects with like uniformity. An artificer, who handles only dead matter, may be disappointed of his aim, as well as the politician, who directs the conduct of sensible and intelligent agents.

The vulgar, who take things according to their first appearance, attribute the uncertainty of events to such an uncertainty in the causes as makes the latter often fail of their usual influence; though they meet with no impediment in their operation. But philosophers, observing that, almost in every part of nature, there is contained a vast variety of springs and principles, which are hid, by reason of their minuteness or remoteness, find, that it is at least possible the contrariety of events may not proceed from any contingency in the cause, but from the secret operation of contrary causes. This possibility is converted into certainty by farther observation, when they remark that, upon an exact scrutiny, a contrariety of effects always betrays a contrariety of causes, and proceeds from their mutual opposition. A peasant can give no better reason for the stopping of any clock or watch than to 
say that it does not commonly go right: But an artist easily perceives that the same force in the spring or pendulum has always the same influence on the wheels; but fails of its usual effect, perhaps by reason of a grain of dust, which puts a stop to the whole movement. From the observation of several parallel instances, philosophers form a maxim that the connexion between all causes and effects is equally necessary, and that its seeming uncertainty in some instances proceeds from the secret opposition of contrary causes.

Thus, for instance, in the human body, when the usual symptoms of health or sickness disappoint our expectation; when medicines operate not with their wonted powers; when irregular events follow from any particular cause; the philosopher and physician are not surprised at the matter, nor are ever tempted to deny, in general, the necessity and uniformity of those principles by which the animal economy is conducted. They know that a human body is a mighty complicated machine: That many secret powers lurk in it, which are altogether beyond our comprehension: That to us it must often appear very uncertain in its operations: And that therefore the irregular events, which outwardly discover themselves, can be no proof that the laws of nature are not observed with the greatest regularity in its internal operations and government.

The philosopher, if he be consistent, must apply the same reasoning to the actions and volitions of intelligent agents. The most irregular and unexpected resolutions of men may frequently be accounted for by those who know every particular circumstance of their character and situation. A person of an obliging disposition gives a peevish answer: But he has the toothache, or has not dined. A stupid fellow discovers an 
uncommon alacrity in his carriage: But he has met with a sudden piece of good fortune. Or even when an action, as sometimes happens, cannot be particularly accounted for, either by the person himself or by others; we know, in general, that the characters of men are, to a certain degree, inconstant and irregular. This is, in a manner, the constant character of human nature; though it be applicable, in a more particular manner, to some persons who have no fixed rule for their conduct, but proceed in a continued course of caprice and inconstancy. The internal principles and motives may operate in a uniform manner, notwithstanding these seeming irregularities; in the same manner as the winds, rain, clouds, and other variations of the weather are supposed to be governed by steady principles; though not easily discoverable by human sagacity and enquiry.

Thus it appears, not only that the conjunction between motives and voluntary actions is as regular and uniform as that between the cause and effect in any part of nature; but also that this regular conjunction has been universally acknowledged among mankind, and has never been the subject of dispute, either in philosophy or common life. Now, as it is from past experience that we draw all inferences concerning the - future, and as we conclude that oljects will always be conjoined together which we find to have always been conjoined; it may seem superfluous to prove that this experienced uniformity in human actions is a source whence we draw inferences concerning them. But in order to throw the argument into a greater variety of lights we shall also insist, though briefly, on this latter topic.

The mutual dependence of men is so great in all 
societies that scarce any human action is entirely complete in itself, or is performed without some reference to the actions of others, which are requisite to make it answer fully the intention of the agent. The poorest artificer, who labours alone, expects at least the protection of the magistrate, to ensure him the enjoyment of the fruits of his labour. Healso expects that, when he carries his goods to market, and offers them at a reasonable price, he shall find purchasers, and shall be able, by the money he acquires, to engage others to supply him with those commodities which are requisite for his subsistence. In proportion as men extend their dealings, and render their intercourse with others more complicated, they always comprehend, in their schemes of life, a greater variety of voluntary actions, which they expect, from the proper motives, to co-operate with their own. In all these conclusions they take their measures from past experience, in the same manner as in their reasonings concerning external objects; and firmly believe that men, as well as all the elements, are to continue, in their operations, the same that they have ever found them. A manufacturer reckons upon the labour of his servants for the execution of any work as much as upon the tools which he employs, and would be equally surprised were his expectations disappointed. In short, this experimental inference and reasoning concerning the actions of others enters so much into human life, that no man, while awake, is ever a moment without employing it. Have we not reason, therefore, to affirm that all mankind have always agreed in the doctrine of necessity according to the foregoing definition and explication of it?

Nor have philosuphers ever entertained a different 
opinion from the people in this particular. For, not to mention that almost every action of their life supposes that opinion, there are even few of the speculative parts of learning to which it is not essential. What would become of history, had we not a dependence on the veracity of the historian according to the experience which we have had of mankind? How could politics be a science, if laws and forms of government had not a uniform influence upon society? Where would be the foundation of morals, if particular characters had no certain or determinate power to produce particular sentiments, and if these sentiments had no constant operation on actions? And with what pretence could we employ our criticism upon any poet or polite author, if we could not pronounce the conduct and sentiments of his actors either natural or unnatural to such characters, and in such circumstances? It seems almost impossible, therefore, to engage either in science or action of any kind without acknowledging the doctrine of necessity, and this inference from motive to voluntary actions, from characters to conduct.

And indeed, when we consider how aptly natura and moral evidence link together, and form only. one chain of argument, we shall make no scruple to allow that they are of the same nature, and derived from the same principles. A prisoner who has neither money nor interest, discovers the imoncei'iliito of his escape, as well when he considers the obssscrutiof the goaler, as the walls and bars with which he is surrounded; and, in all attempts for his freedom, chooses rather to work upon the stone and iron of the one, than upon the inflexible nature of the other. The same prisoner, when conducted to the scaffold, foresees his death as 
certainly from the constancy and fidelity of his guards, as from the operation of the axe or wheel. His mind runs along a certain train of ideas: The refusal of the soldiers to consent to his escape; the action of the executioner; the separation of the head and body; bleeding, convulsive motions, and death. Here is a connerted chain of natural causes and voluntary actions; but the mind feels no difference between them in passing from one link to another: Nor is less certain of the future event than if it were connected with the objects present to the memory or senses, by a train of causes, cemented together by what we are pleased to call a physical necessity. The same experienced union has the same effect on the mind, whether the united objects be motives, volition, and actions; or figure and motion. We may change the name of tnings; but their nature and their operation on the understanding never change.

Were a man, whom I know to be honest and opulent, and with whom I live in intimate friendship, to come into my house, where I am surrounded with my servants, I rest assured that he is not to stab me before he leaves it in order to rob me of my silver standish; and I no more suspect this event than the falling of the house itself, which is new, and solidly built and founded.-But he may have been seized with a sudden and unknown frenzy. - So may a sudden earthquake arise, and sha'1ens 'ot o'ble my house about my ears. I shall ther. $t$ no. nge the suppositions. I shall say that I know with certainty that he is not to put his hand into the fire and hold it there till it be consumed : And this event, I think I can foretell with the same assurance, as that, if he throw himself out at the window, and meet with no obstruction. he will not remain 
a moment suspended in the air. No suspicion of an unknown frenzy can give the least possibility to the former event, which is so contrary to all the known principles of human nature. A man who at noon leaves his purse full of gold on the pavement at Charing-Cross, may as well expect that it will fly away like a feather, as that he will find it untouched an hour after. Above one half of human reasonings contain inferences of a similar nature, attended with more or less degrees of certainty proportioned to our experience of the usual conduct of mankind in such particular situations.

I have frequently considered, what could possibly be the reason why all mankind, though they have ever, without hesitation, acknowledged the doctrine of necessity in their whole practice and reasoning, have yet not discovered such a reluctance to acknowl. edge it in words, and have rather shown a propensity, in all ages, to profess the contrary opinion. The matter, I think, may be accounted for after the following manner. If we examine the operations of body, and the production of effects from their causes, we shall find that all our faculties can never carry us farther in our knowledge of this relation than barely to observe that particular objects are constantly conjoined together, and that the mind is carried, by a customary transition, from the appearance of one to the belief of the other. But though this conclusion concerning human ignorance be the result of the strictest scrutiny of this subject, men still entertain a strong propensity to believe that they penetrate farther into the powers of nature, and perceive something like a necessary connexion between the cause and the effect. When again they turn their reflections towards the operations of their 
own minds, and feel no such connexion of the motive and the action; they are thence apt to suppose, that there is a difference between the effects which result from material force, and those which arise from thought and intelligence. But being once convinced that we know nothing farther of causation of any kind than merely the constant conjunction of objects, and the consequent inference of the mind from one to another, and finding that these two circumstances are universally allowed to have place in voluntary actions; we may be more easily led to own the same necessity common to all causes. And though this reasoning may contradict the systems of many philosophers, in ascribing necessity to the determinations of the will, we shall find, upon reflection, that they dissent from it in words only, not in their real sentiment. Necessity, according to the sense in which it is here taken, has never yet been rejected, nor can ever, I think, be rejected by any philosopher. It may only, perhaps, be pretended that the mind can perceive, in the operations of matter, some farther connexion between the cause and effect; and connexion that has not place in voluntary actions of intelligent beings. Now whether it be so or not, can only appear upon examination; and it is incumbent on these philosophers to make good their assertion, by defining or describing that necessity, and pointing it out to us in the operations of material causes.

It would seem, indeed, that men begin at the wrong end of this question concerning liberty and necessity, when they enter upon it by examining the faculties of the soul, the influence of the understanding, and the operations of the will. Let them first discuss a more simple question, namely, the operations of body and 
of brute unintelligent matter; and try whether they can there form any idea of causation and necessity, except that of a constant conjunction of objects, and subsequent inference of the mind from one to another. If these circumstances form, in reality, the whole of that necessity, which we conceive in matter, and if these circumstances be also universally acknowledged to take place in the operations of the mind, the dispute is at an end; at least, must be owned to be thenceforth merely verbal. But as long as we will rashly suppose, that we have some farther idea of necessity and causation in the operations of external objects; at the same time, that we can find nothing farther in the voluntary actions of the mind; there is no possibility of bringing the question to any determinate issue, while we proceed upon so erroneous a supposition. The only method of undeceiving us is to mount up higher; to examine the narrow extent of science when applied to material causes; and to convince ourselves that all we know of them is the constant conjunction and inference above mentioned. We may, perhaps, find that it is with difficulty we are induced to fix such narrow limits to human understanding: But we can afterwards find no difficulty when we come to apply this doctrine to the actions of the will. For as it is evident that these have a regular conjunction with motives and circumstances and characters, and as we always draw inferences from one to the other, we must be obliged to acknowledge in words that necessity, which we have already avowed, in every deliberation of our lives, and in every step of our conduct and behaviour. ${ }^{1}$

1 The frevalence of the doctrine of liberty may be accounted for, from another cause, viz. a false sensation or seciniog experience which we have, 
But to proceed in this reconciling project with re. gard to the question of liberty and necessity; the most contentious question of metaphysics, the most contentious science; it will not require many words to prove, that all mankind have ever agreed in the doctrine of liberty as well as in that of necessity, and that the whole dispute, in this respect also, has been hitherto merely verbal. For what is meant by liberty, when applied to voluntary actions? We cannot surely mean that actions have so little connexion with motives, inclinations, and circumstances, that one does not follow with a certain degree of uniformity from the other, and that one affords no inference by which we can conclude the existence of the other. For these are

or may have, of liberty or indifference, in many of our actions. The necessity of any action, whether of matter or of mind, is not, properly speaking, a quality in the agent, but in any thinking or intelligent being, who may consider the action; and it consists chiefly in the determination of his thoughts to infer the existence of that action from some preceding objects; as liberty, when opposed to necessity, is nothing but the want of that determination, and a certain looseness or indifference, which we feel, in passing, or not passing, from the idea of one object to that of any succeeding one. Now we may observe, that, though, in reflecting on human actions, we seldom feel such a looseness, or indifference, but are commonly able to infer them with considerable certainty from their motives, and from the dispositions of the agent; yet it frequently happens, that, in performing the actions themselves, we are sensible of something like it: And as all resembling objects are readily taken for each other, this has been employed as a demonstrative and even intuitive proof of human liberty. We feel, that our actions are subject to our will, on most occasions; and imagine we feel, that the will itself is subject to nothing, because, when by a denial of it we are provoked to try, we feel, that it moves easily every way, and produces an image of itself (or a Velleity. as it is called in the schools) even on that side, on which it did not settle, This image, or faint motion, we persuade ourselves, could, at that time, have been compleated into the thing itself; because, should that be denied, we find, upon a second trial, that, at present, it can. We consider not, that the fantastical desire of shewing liberty, is here the motive of our actions. And it seems certain, that, however we may imagine we feel a liberty within ourselves, a spectator can commonly infer our actions from our motives and character; and even where he cannot, he concludes in general, that he might, were he perfectly acquainted with every circumstance of our situation and temper, and the most secret springs of our complexion and disposition. Now this is the very essence of necessity, according to the foregoing doctrine. 
plain and acknowledged matters of fact. By liberty, then, we can only mean $a$ power of acting or not acting, according to the determinations of the will; that is, if we choose to remain at rest, we may; if we choose to move, we also may. Now this hypothetical liberty is universally allowed to belong to every one who is not a prisoner and in chains. Here, then, is no subject of dispute.

Whatever definition we may give of liberty, we should be careful to observe two requisite circumstances; first, that it be consistent with plain matter of fact; secondly, that it be consistent with itself. If we observe these circumstances, and render our definition intelligible, I am persuaded that all mankind will be found of one opinion with regard to it.

It is universally allowed that nothing exists without a cause of its existence, and that chance, when strictly examined, is a mere negative word, and means not any real power which has anywhere a being in nature. But it is pretended that some causes are necessary, some not necessary. Here then is the advantage of definitions. Let any one define a cause, without comprehending, as a part of the definition, a necessary connexion with its effect; and let him show distinctly the origin of the idea, expressed by the definition; and I shall readily give up the whole controversy. But if the foregoing explication of the matter be received, this must be absolutely impracticable. Had not objects a regular conjunction with each other, we should never have entertained any notion of cause and effect; and this regular conjunction produces that inference of the understanding, which is the only connexion, that we can have any comprehension of. Whoever attempts a definition of cause, exclusive of 
these circumstances, will be obliged either to employ unintelligible terms or such as are synonymous to the term which he endeavours to define. ${ }^{1}$ And if the definition above mentioned be admitted; liberty, when opposed to necessity, not to constraint, is the same thing with chance; which is universally allowed to have no existence.

\section{PART II.}

THERE is no method of reasoning more common, and yet none more blameable, than, in philosophical disputes, to endeavour the refutation of any hypothesis, by a pretence of its dangerous consequences to religion and morality. When any opinion leads to absurdities, it is certainly false; but it is not certain that an opinion is false, because it is of dangerous consequence. Such topics, therefore, ought entirely to be forborne; as serving nothing to the discovery of truth, but only to make the person of an antagonist odious. This I observe in general, without pretending to draw any advantage from it. I frankly submit to an examination of this kind, and shall venture to affirm that the doctrines, both of necessity and of liberty, as above explained, are not only consistent with morality, but are absolutely essential to its support.

Necessity may be defined two ways, conformably

1 Thus, if a cause be defined, that which produces any thing; it is easy to observe, that producing is synonimous to causing. In like manner, if a cause be defined, that by which any thing exists; this is liable to the same objection. For what is meant by these words, by which? Had it been said, that a cause is that after which any thing constantly exists; we should have understood the terms. For this is, indeed, all we know of the matter. And this constancy forms the very essence of necessity, nor have we any other idea of it. 
to the two definitions of cause, of which it makes an essential part. It consists either in the constant conjunction of like objects, or in the inference of the understanding from one object to another. Now necessity, in both these senses, (which, indeed, are at bottom the same) has universally, though tacitly, in the schools, in the pulpit, and in common life, been allowed to belong to the will of man; and no one has ever pretended to deny that we can draw inferences concerning human actions, and that those inferences are founded on the experienced union of like actions, with like motives, inclinations, and circumstances. The only particular in which any one can differ, is, that either, perhaps, he will refuse to give the name of necessity to this property of human actions: But as long as the meaning is understood, I hope the word can do no harm: Or that he will maintain it possible to discover something farther in the operations of matter. But this, it must be acknowledged, can be of no consequence to morality or religion, whatever it may be to natural philosophy or metaphysics. We may here be mistaken in asserting that there is no idea of any other necessity or connexion in the actions of body: But surely we ascribe nothing to the actions of the mind, but what everyone does, and must readily allow of. We change no circumstance in the received orthodox system with regard to the will, but only in that with regard to material objects and causes. Nothing, therefore, can be more innocent, at least, than this doctrine.

All laws being founded on rewards and punishments, it is supposed as a fundamental principie, that these motives have a regular and uniform influence on the mind, and both produce the good and prevent the 
evil actions. We may give to this influence what name we please; but, as it is usually conjoined with the action, it must be esteemed a cause, and be looked upon as an instance of that necessity, which we would here establish.

The only proper object of hatred or vengeance is a person or creature, endowed with thought and consciousness; and when any criminal or injurious actions excite that passion, it is only by their relation to the person, or connexion with him. Actions are, by their very nature, temporary and perishing; and where they proceed not from some cause, in the charact $\epsilon r$ and disposition of the person who performed them, they can neither redound to his honour, if good; nor infamy, if evil. The actions themselves may be blameable; they may be contrary to all the rules of morality and religion: But the person is not answerable for them; and as they proceeded from nothing in him that is durable and constant, and leave nothing of that nature behind them, it is impossible he can, upon their account, become the object of punishment or vengeance. According to the principle, therefore, which denies necessity, and consequently causes, a man is as pure and untainted, after having committed the most horrid crime, as at the first moment of his birth, nor is his character anywise concerned in his actions, since they are not derived from it, and the wickedness of the one can never be used as a proof of the depravity of the other.

Men are not blamed for such actions as they perform ignorantly and casually, whatever may be the consequences. Why? but because the principles of these actions are only momentary, and terminate in them alone. Men are less blamed for such actions as 
they perform hastily and unpremeditately than for such as proceed from deliberation. For what reason? but because a hasty temper, though a constant cause or principle in the mind, operates only by intervals, and infects not the whole character. Again, repentance wipes off every crime, if attended with a reformation of life and manners. How is this to be accounted for? but by asserting that actions render a person criminal merely as they are proofs of criminal principles in the mind; and when, by an alteration of these principles, they cease to be just proofs, they likewise cease to be zriminal. But, except upon the doctrine of necessity, they never were just proofs, and consequently never were criminal.

It will be equally easy to prove, and from the same arguments, that liberty, according to that definition above mentioned, in which all men agree, is also essential to morality, and that no human actions, where it is wanting, are susceptible of any moral qualities, or can be the objects either of approbation or dislike. For as actions are objects of our moral sentiment, so far only as they are indications of the internal character, passions, and affections; it is impossible that they can give rise either to praise or blame, where they proceed not from these principles, but are derived altogether frem external violence.

I pretend not to have obviated or removed all obiections to this theory, with regard to necessity and liberty. I can foresee other objections, derived from topics which have not here been treated of. It may be said, for instance, that, if voluntary actions be sub!ected to the same laws of necessity with the operations $-f$ matter, there is a continued chain of necessary causes, pre-ordained and pre-determined, reaching 
from the original cause of all to every single volition of every human creature. No contingency anywhere in the universe; no indifference; no liberty. While we act, we are, at the same time, acted upon. The ultimate Author of all our volitions is the Creator of the world, who first bestowed motion on this immense machine, and placed all beings in that particular position, whence every subsequent event, by an inevitable necessity, must result. Human actions, therefore, either can have no moral turpitude at all, as proceeding from so good a cause; or if they have any turpitude, they must involve our Creator in the same guilt, while he is acknowledged to be their ultimate cause and author. For as a man, who fired a mine, is answerable for all the consequences whether the train he employed be long or short; so wherever a continued chain of necessary causes is fixed, that Being, either finite or infinite, who produces the first, is likewise the author of all the rest, and must both bear the blame and acquire the praise which belong to them. Our clear and unalterable ideas of morality establish this rule, upon unquestionable reasons, when we examine the consequences of any human action; and these reasons must still have greater force when applied to the volitions and intentions of a Being infinitely wise and powerful. Ignorance or impotence may be pleaded for so limited a creature as man; but those imperfections have no place in our Creator. He foresaw, he ordained, he intended all those actions of men, which we so rashly pronounce criminal. And we must therefore conclude, either that they are not criminal, or that the Deity, not man, is accountable for them. But as either of these positions is absurd and impious, it follows, that the doctrine from which they 
are deduced cannot possibly be true, as being liable to all the same objections. An absurd consequence, if necessary, proves the original doctrine to be absurd, in the same manner as criminal actions render crim inal the original cause, if the connexion between them be necessary and evitable.

This objection consists of two parts, which we shall examine separately; First, that, if human actions can be traced up, by a necessary chain, to the Deity, they can never be criminal; on account of the infinite perfection of that Being from whom they are derived, and who can intend nothing but what is altogether good and laudable. Or, Secondly, if they be criminal, we must retract the attribute of perfection, which we ascribe to the Deity, and must acknowledge him to be the ultimate author of guilt and moral turpitude in all his creatures.

The answer to the first objection seems obvious and convincing. There are many philosophers who, after an exact scrutiny of all the phenomena of nature, conclude, that the WHOLE, considered as one system, is, in every period of its existence, ordered with perfect benevolence; and that the utmost possible happiness will, in the end, result to all created beings, without any mixture of positive or absolute ill or misery. Every physical ill, say they, makes an essential part of this benevolent system, and could not possibly be removed, even by the Deity himself, considered as a wise agent, without giving entrance to greater ill, or excluding greater good, which will result from it. From this theory, some philosophers, and the ancient Stoics among the rest, derived a topic of consolation under all afflictions, while they taught their pupils that those ills under which they laboured were, in real- 
ity, goods to the universe; and that to an enlarged view, which could comprehend the whole system of nature, every event became an object of joy and exultation. But though this topic be specious and sublime, it was soon found in practice weak and ineffectual. You would surely more irritate than appease a man lying under the racking pains of the gout by preaching up to him the rectitude of those general laws, which produced the malignant humours in his body, and led them through the proper canals, to the sinews and nerves, where they now excite such acute torments. These enlarged views may, for a moment, please the imagination of a speculative man, who is placed in ease and security; but neither can they dwell with constancy on his mind, even though undisturbed by the emotions of pain or passion; much less can they maintain their ground when attacked by such powerful antagonists. The affections take a narrower and more natural survey of their object; and by an economy, more suitable to the infirmity of human minds, regard alone the beings around us, and are actuated by such events as appear good or ill to the private system.

The case is the same with moral as with physical ill. It cannot reasonably be supposed, that those remote considerations, which are found of so little efficacy with regard to one, will have a more powerful influence with regard to the other. The mind of man is so formed by nature that, upon the appearance of certain characters, dispositions, and actions, it immediately feels the sentiment of approbation or blame; nor are there any emotions more essential to its frame and constitution. The characters which engage our approbation are chiefly such as contribute to the peace 
and security of human society; as the characters which excite blame are chiefly such as tend to public detriment and disturbance: Whence it may reasonably be presumed, that the moral sentiments arise, either mediately or immediately, from a reflection of these opposite interests. What though philosophical meditations establish a different opinion or conjecture; that everything is right with regard to the wHOLE, and that the qualities, which disturb society, are, in the main, as beneficial, and are as suitable to the primary intention of nature as those which more directly promote its happiness and welfare? Are such remote and uncertain speculations able to counterbalance the sentiments which arise from the natural and immediate view of the objects? A man who is robbed of a considerable sum; does he find his vexation for the loss anywise diminished by these sublime reflections? Why then should his moral resentment against the crime be supposed incompatible with them? Or why should not the acknowledgment of a real distinction between vice and virtue be reconcileable to all speculative systems of philosophy, as well as that of a real distinction between personal beauty and deformity? Both these distinctions are founded in the natural sentiments of the human mind: And these sentiments are not to be controuled or altered by any philosophical theory or speculation whatsoever.

The second objection admits not of so easy and satisfactory an answer; nor is it possible to explain distinctly, how the Deity can be the mediate cause of all the actions of men, without being the author of sin and moral turpitude. These are mysteries, which mere natural and unassisted reason is very unfit to handle; and whatever system she embraces, she must find her- 
self involved in inextricable difficulties, and even contradictions, at every step which she takes with regard to such subjects. To reconcile the indifference and contingency of human actions with prescience; or to defend absolute decrees, and yet free the Deity from being the author of sin, has been found hitherto to exceed all the power of philosophy. Happy, if she be thence sensible of her temerity, when she pries into these sublime mysteries; and leaving a scene so full of obscurities and perplexities, return, with suitable modesty, to her true and proper province, the examination of common life; where she will find difficulties enough to employ her enquiries, without launching into so boundless an ocean of doubt, uncertainty, and contradiction! 


\section{SECTION IX.}

\section{OF THE REASON OF ANIMALS}

$\Lambda$ LL our reasonings concerning matter of fact are H founded on a species of Analogy, which leads us to expect from any cause the same events, which we have observed to result from similar causes. Where. the causes are entirely similar, the analogy is perfect, and the inference, drawn from it, is regarded as certain and conclusive: nor does any man ever entertain a doubt, when he sees a piece of iron, that it will have weight and cohesion of parts; as in all other instances, which have ever fallen under his observation. But where the objects have not so exact a similarity, the analogy is less perfect, and the inference is less conclusive; though still it has some force, in proportion to the degree of similarity and resemblance. The anatomical observations, formed upon one animal, are, by this species of reasoning, extended to all animals; and it is certain, that when the circulation of the blood, for instance, is clearly proved to have place in one creature, as a frog, or fish, it forms a strong presumption, that the same principle has place in all. These analogical observations may be carried farther, even to this science, of which we are now treating; and any theory, by which we explain the operations of the understanding, or the origin and connexion of the passions in man, will acquire additional authority, if we find, that the same theory is requisite to explain 
the same phenomena in all other animals. We shall make trial of this, with regard to the hypothesis, by which we have, in the foregoing discourse, endeavoured to account for all experimental reasonings; and it is hoped, that this new point of view will serve to confirm all our former observations.

First, It seems evident, that animals as well as men learn many things from experience, and infer, that the same events will always follow from the same causes. By this principle they become acquainted with the more obvious properties of external objects, and gradually, from their birth, treasure up a knowledge of the nature of fire, water, earth, stones, heights, depths, $\& c$., and of the effects which result from their operation. The ignorance and inexperience of the young are here plainly distinguishable from the cunning and sagacity of the old, who have learned, by long observation, to avoid what hurt them, and to pursue what gave ease or pleasure. A horse, that has been accustomed to the field, becomes acquainted with the proper height which he can leap, and will never attempt what exceeds his force and ability. An old greyhound will trust the more fatiguing part of the chace to the younger, and will place himself so as to meet the hare in her doubles; nor are the conjectures, which he forms on this occasion, founded in any thing but his observation and experience.

This is still more evident from the effects of discipline and education on animals, who, by the proper application of rewards and punishments, may be taught any course of action, and most contrary to their natural instincts and propensities. Is it not experience, which renders a dog apprehensive of pain, when you menace him, or lift up the whip to beat him? Is it 
not even experience, which makes him answer to his name, and infer, from such an arbitrary sound, that you mean him rather than any of his fellows, and intend to call him, when you pronounce it in a certain manner, and with a certain tone and accent?

In all these cases, we may observe, that the animal infers some fact beyond what immediately strikes his senses; and that this inference is altogether founded on past experience, while the creature expects from the present object the same consequences, which it has always found in its observation to result from similar objects.

Secondly, It is impossible, that this inference of the animal can be founded on any process of argument or reasoning, by which he concludes, that like events must follow like objects, and that the course of nature will always be regular in its operations. For if there be in reality any arguments of this nature, they surely lie too abstruse for the observation of such imperfect understandings; since it may well employ the utmost care and attention of a philosophic genius to discover and observe them. Animals, therefore, are not guided in these inferences by reasoning: Neither are children: Neither are the generality of mankind, in their ordinary actions and conclusions: Neither are philosophers themselves, who, in all the active parts of life, are, in the main, the same with the vulgar, and are governed by the same maxims. Nature must have provided some other principle, of more ready, and more general use and application; nor can an operation of such immense consequence in life, as that of inferring effects from causes, be trusted to the uncertain process of reasoning and argumentation. Were this doubtful with regard to men, it seems to admit of 
no question with regard to the brute creation; and the conclusion being once firmly established in the one, we have a strong presumption, from all the rules of analogy, that it ought to be universally admitted, without any exception or reserve. It is custom alone, which engages animals, from every object, that strikes their senses, to infer its usual attendant, and carries their imagination, from the appearance of the one, to conceive the other, in that particular manner, which we denominate belief. No other explication can be given of this operation, in all the higher, as well as lower classes of sensitive beings, which fall under our notice and observation. ${ }^{1}$

1 Since all reasonings concerning facts or causes is derived merely from custom, it may be asked how it happens, that men so much surpass animals in reasoning, and one man so much surpasses another? Has not the same custom the same influence on all?

We shall here endeavour briefly to explain the great difference in human understandings: After which the reason of the difference between men and animals will easily be comprehended.

I. When we have lived any time, and have been accustomed to the uniformity of nature, we acquire a general habit, by which we always transfer the known to the unknown, and conceive the latter to resemble the former. By means of this general habitual principle, we regard even one experiment as the foundation of reasoning, and expect a similar event with some degree of certainty, where the experiment has been made accurately, and free from all foreign circumstances. It is therefore considered as a matter of great importance to observe the consequences of things; and as one man may very much surpass another in attention and memory and observation, this will make a very great difference in their reasoning.

2. Where there is a complication of causes to produce any effect, one mind may be much larger than another, and better able to comprehend the whole system of objects, and to infer justly their consequences.

3. One man is able to carry on a chain of consequences to a greater length trian another.

4. Few men can think long without running into a confusion of jdeas, anc mistaking one for another; and there are various degrees of this infirmity.

5. The circumstance, on which the effect depends, is frequently involved in other circumstances, which are foreign and extrinsic. The separation of it often requires great attention, accuracy, and subtilty.

6. The forming of general maxims from particular observation is a very nice operation; and nothing is more usual, from haste or narrowness of mind which sees not on all sides, than to commit mistakes in this particular. 
But though animals learn many parts of their knowledge from observation, there are also many parts of it, which they derive from the original hand of nature; which much exceed the share of capacity they possess on ordinary occasions; and in which they improve, little or nothing, by the longest practice and experience. These we denominate Instincts, and are so apt to admire as something very extraordinary, and inexplicable by all the disquisitions of human understanding. But our wonder will, perhaps, cease or diminish, when we consider, that the experimental reasoning itself, which we possess in common with beasts, and on which the whole conduct of life depends, is nothing but a species of instinct or mechanical power, that acts in us unknown to ourselves; and in its chief operations, is not directed by any such relations or comparisons of ideas, as are the proper objects of our intellectual faculties. Though the instinct be different, yet still it is an instinct, which teaches a man to avoid the fire; as much as that, which teaches a bird, with such exactness, the art of incubation, and the whole economy and order of its nursery.

7. When we reason from analogies, the man, who has the greater experience or the greater promptitude of suggesting analogies, will be the better reasoner.

8. Byasses from prejudice, education, passion, party, \&c., hang more upon one mind than another.

9. After we have acquired a confidence in human testimcny, books and conversation enlarge much more the sphere of one man's expeitence and thought than those of another.

It would be easy to discover many other circumstances that make a difference in the understandings of men. 


\title{
SECTION $\mathrm{X}$
}

\author{
OF MIRACLES.
}

\section{PART I.}

THERE is, in Dr. Tillotson's writings, an argument 1 against the real presence, which is as concise, and elegant, and strong as any argument can possibly be supposed against a doctrine, so little worthy of a serious refutation. It is acknowledged on all hands, says that learned prelate, that the authority, either of the scripture or of tradition, is founded merely in the tes. timony of the apostles, who were eye-witnesses to those miracles of our Saviour, by which he proved his divine mission. Our evidence, then, for the truth of the Christian religion is less than the evidence for the truth of our senses; because, even in the first authors of our religion, it was no greater; and it is evident it must diminish in passing from them to their disciples; nor can any one rest such confidence in their testimony, as in the immediate object of his senses. But a weaker evidence can never destroy a stronger; and therefore, were the doctrine of the real presence ever so clearly revealed in scripture, it were directly contrary to the rules of just reasoning to give our assent to it. It contradicts sense, though both the scripture and tradition, on which it is supposed to be built, carry not such evidence with them as sense; when they are considered merelv as external evidences, and are 
not brought home to every one's breast, by the immeaiate operation of the Holy Spirit.

Nothing is so convenient as a decisive argument of this kind, which must at least silence the most arrogant bigotry and superstition, and free us from their impertinent solicitations. I flatter myself, that I have discovered an argument of a like nature, which, if just, will, with the wise and learned, be an everlasting check to all kinds of superstitious delusion, and consequently, will be useful as long as the world endures. For so long, I presume, will the accounts of miracles and prodigies be found in all history, sacred and profane.

Though experience be our only guide in reasoning concerning matters of fact; it must be acknowledged, that this guide is not altogether infallible, but in some cases is apt to lead us into errors. One, who in our climate, should expect better weather in any week of June than in one of December, would reason justly, and conformably to experience; but it is certain, that he may happen, in the event, to find himself mistaken. However, we may observe, that, in such a case, he would have no cause to complain of experience; because it commonly informs us beforehand of the uncertainty, by that contrariety of events, which we may learn from a diligent observation. All effects follow not with like certainty from their supposed causes. Some events are found, in all countries and all ages, to have been constantly conjoined together: Others are found to have been more variable, and sometimes to disappoint our expectations; so that, in our reasonings concerning matter of fact, there are all imaginable degrees of assurance, from the highest certainty to the icwest species of moral evidence. 
A wise man, therefore, proportions his belief to the evidence. In such conclusions as are founded on an infallible experience, he expects the event with the last degree of assurance, and regards his past experience as a full proof of the future existence ct that event. In other cases, he proceeds with more caution: $\mathrm{He}$ weighs the opposite experiments: $\mathrm{He}$ considers which side is supported by the greater number of experiments: to that side he inclines, with doubt and hesitation; and when at last he fixes his judgement, the evidence exceeds not what we properly call probability. All probability, then, supposes an opposition of experiments and observations, where the one side is found to overbalance the other, and to produce a degree of evidence, proportioned to the superiority. A hundred instances or experiments on one side, and fifty on another, afford a doubtful expectation of any event; though a hundred uniform experiments, with only one that is contradictory, reasonabiy begets a pretty strong degree of assurance. In all cases, we must balance the opposite experiments, where they are opposite, and deduct the smaller number from the greater, in order to know the exact force of the superior evidence.

To apply these principles to a particular instance; we may observe, that there is no species of reasoning more common, more useful, and even necessary to hruman life, than that which is derived from the testimony of men, and the reports of eye-witnesses and spectators. This species of reasoning, perhaps, =ne m.ay deny to be founded on the relation of cause and effect. I shall not dispute about a word. It will be sufficient to observe that our assurance in any argument of this kind is derived from no other principls 
than our observation of the veracity of human testimony, and of the usual conformity of facts to the reports of witnesses. "It being a general maxim, that no objects have any discoverable connexion together, and that all the inferences, which we can draw from one to another, are founded merely on our experience of their constant and regular conjunction; it is evident, that we ought not to make an exception to this maxim in favour of human testimony, whose connexion with any event seems, in itself, as little necessary as any other. Were not the memory tenacious to a certain degree; had not men commonly an inclination to truth and a principle of probity, were they not sensible to shame, when detected in a falsehood: Were not these, I say, discovered by experience to be qualities, inherent in human nature, we should never repose the least confidence in human testimony. A man delirious, or noted for falsehood and villany, has no manner of authority with us.

And as the evidence, derived from witnesses and human testimony, is founded on past experience, so it varies with the experience, and is regarded either as proof or a probability, according as the conjunction between any particular kind of report and any kind of object has been found to be constant or variable. There are a number of circumstances to be taken into consideration in all judgements of this kind; and the ultimate standard, by which we determine all disputes, that may arise concerning them, is always derived from experience and observation. Where this experience is not entirely uniform on any side, it is attended with an unavoidable contrariety in our judgements, and with the same opposition and mutual destruction of argument as in every other kind of evidence. We fre- 
quently hesitate concerning the reports of others. We balance the opposite circumstances, which cause any doubt or uncertainty; and when we discover a superiority on one side, we incline to it; but still with a dininution of assurance, in proportion to the force of its antagonist.

This contrariety of evidence, in the present case, may be derived from several different causes; from the opposition of contrary testimony; from the character or number of the witnesses; from the manner of their delivering their testimony; or from the union of all these circumstances. We entertain a suspicion concerning any matter of fact, when the witnesses contradict each other; when they are but few, or of a doubtful character; when they have an interest in what they affirm; when they deliver their testimony with hesitation, or on the contrary, with too violent asseverations. There are many other particulars of the same kind, which may diminish or destroy the force of any argument, derived from human testimony.

Suppose, for instance, that the fact, which the testimony endeavours to establish, partakes of the extraordinary and the marvellous; in that case, the evidence, resulting from the testimony, admits of a diminution, greater or less, in proportion as the fact is more or less unusual. The reason why we place any credit in witnesses and historians, is not derived from any connexion, which we perceive $a$ priori, between testimony and reality, but because we are accustomed to find a conformity between them. But when the fact attested is such a one as has seldom fallen under our observation, here is a contest of two opposite experiences; of which the one destroys the other, as far as its force goes, and the superior can only operate on the mind by the 
force, which remains The very same principle of experience, which gives us a certain degree of assurance in the testimony of witnesses, gives us also, in this case, another degree of assurance against the fact, which they endeavour to establish; from whicr contradiction there necessarily arises a counterpoize, and mutual destruction of belief and authority.

$I$ should not believe such a story were it told me by Cato, was a proverbial saying in Rome, even during the lifetime of that philosophical patriot. ${ }^{1}$ The incredibility of a fact, it was allowed, might invalidate so great an authority.

The Indian prince, who refused to believe the first relations concerning the effects of frost, reasoned justly; and it naturally required very strong testimony to engage his assent to facts, that arose from a state of nature, with which he was unacquainted, and which bore so little analogy to those events, of which he had had constant and uniform experience. Though they were not contrary to his experience, they were not conformable to it. ${ }^{2}$

1 Plutarch, in vita Catonis.

2 No Indian, it is evident, could have experience that water did not freeze in cold climates. This is placing nature in a situation quite unknown to him; and it is impossible for him to tell a priori what will result from it. It is making a new experiment, the consequence of which is always uncertain. One may sometimes conjecture from analogy what will follow; but still this is but conjecture. And it must be confessed, that, in the present case of freezing, the event follows contrary to the rules of analogy, and is such as a rational Indian would not look for. The operations of cold upon water are not gradual, according to the degrees of cold; but whenever it comes to the freezing point, the water passes in a moment, from the utmost liqui ${ }^{1} 1 \mathrm{y}$ to perfect hardness. Such an event, therefore, may be denominated extrusodi. nary, anc requires a pretty strong testimony, to render it credible to people in a warn slimate: But still it is not miraculous, nor contrary to nniform experience of the course of nature in cases where all the circumstances are the same. The inhabitants of Sumatra have always seen water fluid in their own elimate, and the freezing of their rivers ought to be deemed a prodigy: $\mathrm{Bu}$ they never saw water in Muscovy during the winter; and therefore they car not reasonablv be positive what would there be the consequence. 
But in order to encrease the probability against the testimony of witnesses, let us suppose, that the fact, which they affirm, instead of being only marvellous, is really miraculous; and suppose also, that the testimony considered apart and in itself, amounts to an entire proof; in that case, there is proof against proof, of which the strongest must prevail, but still with a diminution of its force, in proportion to that of its åntagonist.

A miracle is a violation of the laws of nature ; and as a firm and unalterable experience has established these laws, the proof against a miracle, from the very nature of the fact, is as entire as any argument from experience can possibly be imagined. Why is it more than probable, that all men must die; that lead cannot, of itself, remain suspended in the air; that fire consumes wood, and is extinguished by water; unless it be, that these events are found agreeable to the laws of nature, and there is required a violation of these laws, or in other words, a miracle to prevent them? Nothing is esteemed a miracle, if it ever happen in the common course of nature. It is no miracle that a man, seemingly in good health, should die on a sudden: because such a kind of death, though more unusual than any other, has yet been frequently observed to happen. But it is a miracle, that a dead man should come to life; because that has never been observed in any age or country. There must, therefore, be a uniform experience against every miraculous event, otherwise the event would not merit that appellation. And as a uniform experience amounts to a proof, there is here a direct and full proof, from the nature of the fact, against the existence of any miracle; nor can such a 
proof be destroyed, or the miracle rendered credible, but by an opposite proof, which is superior. ${ }^{1}$

The plain consequence is (and it is a general maxim worthy of our attention), "That no testimony is sufficient to establish a miracle, unless the testimony be of such a kind, that its falsehood would be more miraculous, than the fact, which it endeavours to establish; and even in that case there is a mutual destruction of arguments, and the superior only gives us an assurance suitable to that degree of force, which remains, after deducting the inferior.' When anyone tells me, that he saw a dead man restored to life, I immediately consider with myself, whether it be more probable, that this person should either deceive or be deceived, or that the fact, which he relates, should really have happened. I weigh the one miracle against the other; and according to the superiority, which I discover, I pronounce my decision, and always reject the greater miracle. If the falsehood of his testimony would be more miraculous, than the event which he

1 Sometimes an event may not, in itself, seem to be contrary to the laws of nature, and yet, if it were real, it might, by reason of some circumstances, be denominated a miracle; because, in fact, it is contrary to these laws. Thus if a person, claiming a divine authority, should command a sick person to be well, a healthful man to fall down dead, the clouds to pour rain, the winds to blow, in short, should order maniy natural events, which immediately follow upon his command; these might justly be esteemed miracles, because they are really, in this case, contrary to the laws of nature. For if any suspicion remain, that the event and command concurred by accident, there is no miracle and no transgression of the laws of nature. If this suspicion be removed, there is evidently a miracle, and a transgression of these laws; because nothing can be more contrary to nature than that the voice or command of a man should have such an influence. A miracle may be accurately defined, a transgression of a laze of nature by a particular volition of the Deity, or by the interposition of some invisibie agent. A miracle may either be discoverable by men or not. This alters not its nature and essence. The raising of a house or ship into the air is a visible miracle. The raising of a feather, when the wind wants ever so little of a force requisite for that purpose, is as real a 3iracle. though not so sensible with regard to us. 
relates; then, and not till then, can he pretend to command my belief or opinion.

\section{Part II.}

In the foregoing reasoning we have supposed, that the testimony, upon which a miracle is founded, may possibly amount to an entire proof, and that the falsehood of that testimony would be a real prodigy: But it is easy to shew, that we have been a great deal too liberal in our concession, and that there never was a miraculous event established on so full an evidence.

For first, there is not to be found, in all history, any miracle attested by a sufficient number of men, of such unquestioned good-sense, education, and learning, as to secure us against all delusion in themselves; of such undoubted integrity, as to place them beyond all suspicion of any design to deceive others; of such credit and reputation in the eyes of mankind, as to have a great deal to lose in case of their being detected in any falsehood; and at the same time, attesting facts performed in such a public manner and in so celebrated a part of the world, as to render the detection unavoidable: All which circumstances are requisite to give us a full assurance in the testimony of men.

Secondly. We may observe in human nature a principle which, if strictly examined, will be found to diminish extremely the assurance, which we might, from human testimony, have, in any kind of prodigy. The maxim, by which we commonly conduct ourselves in our reasonings, is, that the objects, of which we have no experience, resemble those, of which we have; that what we have found to be most usual is aiways most probabie: and that where there is an opposition 
of arguments, we ought to give the preference to such as are founded on the greatest number of past observations. But though, in proceeding by this rule, we readily reject any fact which is unusual and incredible in an ordinary degree; yet in advancing farther, the mind observes not always the same rule; but when anything is affirmed utterly absurd and miraculous, it rather the more readily admits of such a fact, upon account of that very circumstance, which ought to destroy all its authority. The passion of surprise and wonder, arising from miracles, being an agreeable emotion, gives a sensible tendency towards the belief of those events, from which it is derived. And this goes so far, that even those who cannot enjoy this pleasure immediately, nor can believe those miraculous events, of which they are informed, yet love to partake of the satisfaction at second-hand or by rebound, and place a pride and delight in exciting the admiration of others.

With what greediness are the miraculous accounts of travellers received, their descriptions of sea and land monsters, their relations of wonderful adventures, strange men, and uncouth manners? But if the spirit of religion join itself to the love of wonder, there is an end of common sense; and human testimony, in these circumstances, loses all pretensions to authority. A religionist may be an enthusiast, and imagine he sees what has no reality: he may know his narrative to be false, and yet persevere in it, with the best intentions in the world, for the sake of promoting so holy a cause: or even where this delusion has not place, vanity, excited by so strong a temptation, operates on him more powerfully than on the rest of mankind in any other circumstances; and self-interest with equal force. His auditors may not have, and commonly have not, suf- 
ticient judgement to canvass his evidence: what judgement they have, they renounce by principle, in these sublime and mysterious subjects: or if they were ever so willing to employ it, passion and a heated imagination disturb the regularity of its operations. Their credulity increases his impudence : and his impudence overpowers their credulity.

Eloquence, when at its highest pitch, leaves little room for reason or reflection; but addressing itself entirely to the fancy or the affections, captivates the willing hearers, and subdues their understanding. Happily, this pitch it seldom attains. But what a Tully or a Demosthenes could scarcely effect over a Roman or Athenian audience, every Capuchin, every itinerant or stationary teacher can perform over the generality of mankind, and in a higher degree, by touching such gross and vulgar passions.

The many instances of forged miracles, and prophecies, and supernatural events, which, in all ages, have either been detected by contrary evidence, or which detect themselves by their absurdity, prove sufficiently the strong propensity of mankind to the extraordinary and the marvellous, and ought reasonably to beget a suspicion against all relations of this kind. This is our natural way of thinking, even with regard to the most common and most credible events. For instance: There is no kind of report which rises so easily, and spreads so quickly, especially in country places and provincial towns, as those concerning marriages; insomuch that two young persons of equal condition never see each other twice, but the whole neighbourhood immediately join them together. The pleasure of telling a piece of news so interesting, of propagating it, and of being the first reporters of it, 
spreads the intelligence. And this is so well known, that no man of sense gives attention to these reports, cill he find them confirmed by some greater evidence. Do not the same passions, and others still stronger, incline the generality of mankind to believe and report, with the greatest vehemence and assurance, all religious miracles?

Thirdly. It forms a strong presumption against all supernatural and miraculous relations, that they are observed chiefly to abound among ignorant and barbarous nations; or if a civilized people has ever given admission to any of them, that people will be found to have received them from ignorant and barbarous ancestors, who transmitted them with that inviolable sanction and authority, which always attend received opinions. When we peruse the first histories of all nations, we are apt to imagine ourselves transported into some new world; where the whole frame of nature is disjointed, and every element performs its operations in a different manner, from what it does at present. Battles, revolutions, pestilence, famine and death, are never the effect of those natural causes, which we experience. Prodigies, omens, oracles, judgements, quite obscure the few natural events, that are intermingled with them. But as the former grow thinner every page, in proportion as we advance nearer the $\Rightarrow$ nlightened ages, we soon learn, that there is nothing mysterious or supernatural in the case, but that all proceeds from the usual propensity of mankinc towards the marvellous, and that, though this inclination may at intervals receive a check from sense and learning, it can never be thoroughly extirpated from human nature.

It is strange, a judicious reader is apt to say, upon 
the perusal of these wonderful historians, that such prodigious events never happen in our days. But it is nothing strange, I hope, that men should lie in all ages. You must surely have seen instances enough of that frailty. You have yourself heard many such marvellous relations started, which, being treated with scorn by all the wise and judicious, have at last been abandoned even by the vulgar. Be assured, that those renowned lies, which have spread and flourished to such a monstrous height, arose from like beginnings; but being sown in a more proper soil, shot up at last into prodigies almost equal to those which they relate.

It was a wise policy in that false prophet, Alexander, who though now forgotten, was once so famous, to lay the first scene of his impostures in Paphlagonia, where, as Lucian tells us, the people were extremely ignorant and stupid, and ready to swallow even the grossest delusion. People at a distance, who are weak enough to think the matter at all worth enquiry, have no opportunity of receiving better information. The stories come magnified to them by a hundred circumstances. Fools are industrious in propagating the imposture; while the wise and learned are contented, in general, to deride its absurdity, without informing themselves of the particular facts, by which it may be distinctly refuted. And thus the impostor above mentioned was enabled to proceed, from his ignorant Paphlagonians, to the enlisting of votaries, even among the Grecian philosophers, and men of the most eminent rank and distinction in Rome: nay, could engage the attention of that sage emperor Marcus Aurelius; so far as to make him trust the success of a military expedition to his deluisve prophecies.

The advantages are so great, of starting an impos. 
ture among an ignorant people, that, even though the delusion should be too gross to impose on the generality of them (which, though seldom, is sometimes the case) it has a much better chance for succeeding in remote countries, than if the first scene had been laid in a city renowned for arts and knowledge. The most ignorant and barbarous of these barbarians carry the report abroad. None of their countrymen have a large correspondence, or sufficient credit and authority to contradict and beat down the delusion. Men's inclination to the marvellous has full opportunity to display itself. And thus a story, which is universally exploded in the place where it was first started, shall pass for certain at a thousand miles distance. But had Alexander fixed his residence at Athens, the philosophers of that renowned mart of learning had immediately spread, throughout the whole Roman empire, their sense of the matter; which, being supported by so great authority, and displayed by all the force of reason and eloquence, had entirely opened the eyes of mankind. It is true; Lucian, passing by chance through Paphlagonia, had an opportunity of performing this good office. But, though much to be wished, it does not always happen, that every Alexander meets with a Lucian, ready to expose and detect his impostures.

I may add as a fourth reason, which diminishes the authority of prodigies, that there is no testimony for any, even those which have not been expressly detected, that is not opposed by an infinite number of witnesses; so that not only the miracle destroys the credit of testimony, but the testimony destroys itself. To make this the better understood, let us consider, that, in matters of religion, whatever is different is contrary; and that it is impossible the religions of 
ancient Rome, of Turkey, of Siam, and of China should, all of them, be established on any solid foundation. Every miracle, therefore, pretended to have been wrought in any of these religions (and all of them abound in miracles), as its direct scope is to establish the particular system to which it is attributed; so has it the same force, though more indirectly, to overthrow every other system. In destroying a rival system, it likewise destroys the credit of those miracles, on which that system was established; so that all the prodigies of different religions are to be regarded as contrary facts, and the evidences of these prodigies, whether weak or strong, as opposite to each other. According to this method of reasoning, when we believe any miracle of Mahomet or his successors, we have for our warrant the testimony of a few barbarous Arabians: And on the other hand, we are to regard the authority of Titus Livius, Plutarch, Tacitus, and, in short, of all the authors and witnesses, Grecian, Chinese, and Roman Catholic, who have related any miracle in their particular religion; I say, we are to regard their testimony in the same light as if they had mentioned that Mahometan miracle, and had in express terms contradicted it, with the same certainty as they have for the miracle they relate. This argument may appear over subtile and refined; but is not in reality different from the reasoning of a judge, who supposes, that the credit of two witnesses, maintaining a crime against any one, is desiroyed by the testimony of two others, who affirm him to have been two hundred leagues distant, at the same instant when the crime is said to have been committed.

One of the best attested miracles in all profane history: is that which Tacitus reports of Vespasian, who 
cured a blind man in Alexandria, by means of his spittle, and a lame man by the mere touch of his foot; in obedience to a vision of the god Serapis, who had enjoined them to have recourse to the Emperor, for these miraculous cures. The story may be seen in that fine historian; ${ }^{1}$ where every circumstance seems to add weight to the testimony, and might be displayed at large with all the force of argument and eloquence, if any one were now concerned to enforce the evidence of that exploded and idolatrous superstition. The gravity, solidity, age, and probity of so great an emperor, who, through the whole course of his life, conversed in a familiar manner with his friends and courtiers, and never affected those extraordinary airs of divinity assumed by Alexander and Demetrius. The historian, a cotemporary writer, noted for candour and veracity, and withal, the greatest and most penetrating genius, perhaps, of all antiquity; and so free fron: any tendency to credulity, that he even lies under the contrary imputation, of atheism and profaneness: The persons, from whose authority he related the miracle, of established character for judgement and veracity, as we may well presume; eye-witnesses of the fact, and confirming their testimony, after the Flavian family was despoiled of the empire, and could no longer give any reward, as the price of a lie. Utrumque, qui interfuere, nunc quoque memorant, postquam nullum mendiacio pretium. To which if we add the public nature of the facts, as related, it will appear, that no evidence can well be supposed stronger for so gross and so palpable a falsehood.

- There is also a memorable story related by Cardi1 Hist. lib. v. cap. 8 . Suetonius gives nfarly the same account in orta
Vesp. 
nal de Retz, which may well deserve nur consideration When that intriguing politician fled into Spain, to avoid the persecution of his enemies, he passed through Saragossa, the capital of Arragon, where he was shewn, in the cathedral, a man, who had served seven years as a doorkeeper, and was well known to every body in town, that had ever paid his devotions at that church. $\mathrm{He}$ had been seen, for so long a time, wanting a leg; but recovered that limb by the rubbing of holy oil upon the stump; and the cardinal assures us that he saw him with two legs. This miracle was vouched by all the canons of the church; and the whole company in town were appealed to for a confirmation of the fact: whom the cardinal found, by their zealous devotion, to be thorough believers of the miracle. Here the relater was also cotemporary to the supposed prodigy, of an incredulous and libertine character, as well as of great genius; the miracle of so singular a nature as could scarcely admit of a counterfeit, and the witnesses very numerous, and all of them, in a manner, spectators of the fact, to which they gave their testimony. And what adds mightily to the force of the evidence, and may double our surprise on this occasion, is, that the cardinal himself, who relates the story, seems not to give any credit to it, and consequently cannot be suspected of any concurrence in the holy fraud. He considered justly, that it was not requisite, in order to reject a fact of this nature, to be able accurately to disprove the testimony, and to trace its falsehood, through all the circumstances of knavery and credulity which produced it. He knew, that, as this was commonly altogether impossible at any small distance of time and place; so was it extremely difficult, even where one was immediately present, by reason of the 
bigotry, igusranse, cunning, and roguery cf a great part of mantind. He therefore concluded, like a just reasonex, that such an evidence carried falsehood upon the very face of it, and that a miracle, supported by any human testimony, was more properly a subject of derision than of argument.

There surely never was a greater number of miracles ascribed to one person, than those, which were lately said to have been wrought in France upon the tomb of Abbe Paris, the famous Jansenist, with whose sanctity the people were so long deluded. The curing of the sick, giving hearing to the deaf, and sight to the blind, were every where talked of as the usual effects of that holy sepulchre. But what is more extraordinary; many of the miracles were immediately proved upon the spot, before judges of unquestioned integrity, attested by witnesses of credit and distinc. tion, in a learned age, and on the most eminent theatre that is now in the world. Nor is this all : a rela. tion of them was published and dispersed everywhere; nor were the Jesuits, though a learned body, supported by the civil magistrate, and determined enemies to those opinions, in whose favour the miracles were said to have been wrought, ever able distinctly to refute or detect them. Where shall we find such a number of circumstances, agreeing to the corroboration of one fact? And what have we to oppose to such a cloud of witnesses, but the absolute impossibility or miraculous nature of the events, which they relate? And this surely, in the eyes of all reasonable people, will alone be regarded as a sufficient refutation.

Is the consequence just, because some human testimony has the utmost force and authority in some cases, when it relates the battle of Philippi or Pharsa. 
lia for instance; that therefore all kinds of testimony must, in all cases, have equal force and authority? Suppose that the Cæsarean and Pompeian factions had, each of them, claimed the victory in these batties. and that the historians of each party had uniformly ascribed the advantage to their own side; how could markind, at this distance, have been able to determine between them? The contrariety is equally strong between the miracles related by Herodotus or Plutarch, and those delivered by Mariana, Bede, or any monkish historian.

The wise lend a very academic faith to every report which favours the passion of the reporter; whether it magnifies his country, his family, or himself, or in any other way strikes in with his natural inclinations and propensities. But what greater temptation than to appear a missionary, a prophet, an ambassador from heaven? Who would not encouriter many dangers and difficulties, in order to attain so sublime a character? Or if, by the help of vanity and a heated imagination, a man has first made a convert of himself, and entered seriously in to the delusion; who ever scruples to make use of pious frauds, in support of so holy and merito. rious a cause?

The smallest spark may here kindle into the greatest flame; because the materials are always prepared for it. The avidum genus auricularum, ${ }^{1}$ the gazing populace, receive greedily, without examination, whatever soothes superstition, and promotes wonder.

How many stories of this nature have, in all ages, been detected and exploded in their infancy? How many more have been celebrated for a tine, and have afterwards sunk into neglect and oblivion? Where

\section{X.ucret}


such reports, therefore, fly about, the solution of the phenomenon is obvious; and we judge in conformity to regular experience and observation, when w€ account for it by the known and natural principles of credulity and delusion. And shall we, rather than have a recourse to so natural a solution, allow of a miraculous violation of the most established laws of nature?

I need not mention the difficulty of detecting a falsehood in any private or even public history, at the place, where it is said to happen; much more when the scene is removed to ever so small a distance. Even a court of judicature, with all the authority, ac. curacy, and judgement, which they can employ, find themselves often at a loss to distinguish between truth and falsehood in the most recent actions. But the matter never comes to any issue, if trusted to the common method of altercations and debate and flying rumours; especially when men's passions have taken part on either side.

In the infancy of new religions, the wise and learned commonly esteem the matter too inconsiderable to deserve their attention or regard. And when afterwards they would willingly detect the cheat, in order to undeceive the deluded multitude, the season is now past, and the records and witnesses, which might clear up the matter, have perished beyond reccvery.

No means of detection remain, but those which must be drawn from the very testimony itself of the reporters: and these, though always sufficient with the judicious and knowing, are commonly soo fine to fall under the comprehension of the vulgar.

Upon the whole, then, it appears, that no testi. mony for any kind of miracle has ever amounted to a 
probability, much less to a proof; and that, even supposing it amounted to a proof, it would be opposed by arother proof; derived from the very nature of the fact, which it would endeavour to establish. It is experience only, which gives authority to human testimony'; and it is the same experience, which assures us of the laws of nature. When, therefore, these two kinds of experience are contrary, we have nothing to do but substract the one from the other, and embrace an opinion, either on one side or the other, with that assurance which arises from the remainder. But according to the principle here explained, this substraction, with regard to all popular religions, amounts to an entire annihilation; and therefore we may establish it as a maxim, that no human testimony can have such force as to prove a miracle, and make it a just foundation for any such system of religion.

I beg the limitations here made may be remarked. when I say, that a miracle can never be proved, so as to be the foundation of a system of religion. For 1 own, that otherwise, there may possibly be miracles, or violations of the usual course of nature, of such a kind as to admit of proof from human testimony, though, perhaps, it will be impossible to find any such in all the records of history. Thus, suppose, ali authors, in all languages, agree, that, from the first of January 1600 , there was a total darkness over the whole earth fo: eight days: suppose that the tradition of this extzaordinary event is still strong and lively among the people: that all travellers, who return from foreign countries, bring us accounts of the same tradition. without the least variation or contradiction : it is evident, that our present philosophers, instead of doubting the fact, ought to receive it as certain, and ought 
to search for the causes whence it might be derived. The decay, corruption, and dissolution of nature, is an event rendered probable by so many analogies, that any phenomenon, which seems to have a tendency towards that catastrophe, comes within the reach of human testimony, if that testimony be very extensive and uniform.

But suppose, that all the historians who treat of England, should agree, that, on the first of January I60o, Queen Elizabeth died; that both before and after her death she was seen by her physicians and the whole court, as is usual with persons of her rank; that her successor was acknowledged and proclaimed by the parliament; and that, after being in. terred a month, she again appeared, resumed the throne, and governed England for three years: I must confess that I should be surprised at the concurrence of so many odd circumstances, but should not have the least inclination to believe so miraculous an event. I should not doubt of her pretended death, and of those other public circumstances that followed it: I should only assert it to have been pretended, and that it neither was, nor possibly could be real. You would in vain object to me the difficulty, and almost impossibility of deceiving the world in an affair of such consequence; the wisdom and solid judgement of that renowned queen; with the little or no advantage which she could reap from so poor an artifice: All this might astonish me; but I would still reply, that the knavery and folly of men are such common phenomena, that I should rather believe the most extraordinary events to arise from their concurrence, than admit of so signal a violation of the laws of nature.

But should this miracle be ascribed to anv new 
system of religion; men, in all ages, have been so much imposed on by ridiculous stories of that kind, that this very circumstance would be a full proof of a cheat, and sufficient, with all men of sense, not only to make them reject the fact, but even reject it without farther examination. Though the Being to whom the miracle is ascribed, be, in this case, Almighty, it does not, upon that account, become a whit more probable; since it is impossible for us to know the attributes or actions of such a Being, otherwise than from the experience which we have of his productions, in the usual course of nature. This still reduces us to past observation, and obliges us to compare the instances of the violation of truth in the testimony of men, with those of the violation of the laws of nature by miracles, in order to judge which of them is most likely and probable. As the violations of truth are more common in the testimony concerning religious miracles, than in that concerning any other matter of fact; this must diminish very much the authority of the former testimony, and make us form a general resolution, never to lend any attention to it, with whatever specious pretence it may be covered.

Lord Bacon seems to have embraced the same principles of reasoning. 'We ought,' says he, 'to make a collection or particular history of all monsters and prodigious births or productions, and in a word of every thing new, rare, and extraordinary in nature. But this must be done with the most severe scrutiny, lest we depart from truth. Above all, every relation must be considered as suspicious, which depends in any degree upon religion, as the prodigies of Livy: And no less so, every thing that is to be found in the writers of natural magic or alchimy, or such authora 
who seem, all of them, to have an unconquerable appetite for falsehood and fable.' 1

I am the better pleased with the method of reason. ing here delivered, as I think it may serve to confound those dangerous friends or disguised enemies to the Christian Religion, who have undertaken to defend it by the principles of human reason. Our most holy religion is founded on Faith, not on reason; and it is a sure nethod of exposing it to put it to such a trial as it is, by no means, fitted to endure. To make this more evident, let us examine those miracles, related in scripture; and not to lose ourselves in too wide a field, let us confine ourselves to such as we find in the Pentateuch, which we shail examine, according to the principles of these pretended Christians, not as the word or testimony of God himself, but as the production of a mere human writcr and historian. Here then we are first to consider a book, presented to us by a barbarous and ignorant people, written in an age when they were still more barbarous, and in all probability long after the facts which it relates, corroborated by no concurring testimony, and resembling those fabulous accounts, which every nation gives of its origin. Upon reading this book, we find it full of prodigies and miracles. It gives an account of a state of the world and of human nature entirely different from the present: Of our fall from that state: Of the age of man, extended to near a thousand years: Of the destruction of the world by a deluge: Of the arbitrary choice of one people, as the favourites of heaven; anc that people the countrymen of the author: Of their deliverance from bondage by prodigies the most aston. ishing imaginable: I desire any ore to lay his hand

A Ncv, Org. lib. ii. aph. 29. 
upon his heart, and after a serious consideration declare, whether he thinks that the falsehood of such a book, supported by such a testimony, would be more extraordinary and miraculous than all the miracles it relates; which is, however, necessary to make it be received, according to the measures of probability above established.

What we have said of miracles may be applied, without any variation, to prophecies; and indeed, all prophecies are real miracles, and as such only, can be admitted as proofs of any revelation. If it did not exceed the capacity of human nature to foretell future events, it would be absurd to employ any prophecy as an argument for a divine mission or authority from heaven. So that, upon the whole, we may conclude, that the Christian Religion not only was at first attended with miracles, but even at this day cannot be believed by any reasonable person without one. Mere reason is insufficient to convince us of its veracity : And whoever is moved by Faith, to assent to it, is conscious of a continued miracle in his own person, which subverts all the principles of his understanding, and gives him a determination to believe what is most contrary to custom and experience. 


\section{SECTION XI.}

OF A PARTICULAR PROVIDENCE AND OF A FUTURE STATE.

T WAS ately engaged in conversation with a friend 1 who loves sceptical paradoxes; where, though he advanced many principles, of which I can by no means approve, yet as they seem to be curious, and to bear some ralation to the chain of reasoning carried on throughout this enquiry, I shall here copy them from my memory as accurately as I can, in order to submit them to the judgement of the reader.

Our conversation began with my admiring the singular good fortune of philosophy, which, as it requires entire liberty above all other privileges, and chiefly flourishes from the free opposition of sentiments and argumentation, received its first birth in an age and country of freedom and toleration, and was never cramped, even in its most extravagant principles, by any creeds, concessions, or penal statutes. For, except the banishment of Protagoras, and the death of Socrates, which last event proceeded partly from other motives, there are scarcely any instances to be met with, in ancient history, of this bigotted jealousy, with which the present age is so much infested. Epicurus lived at Athens to an advanced age, in peace anc rranquillity: Epicureans ${ }^{1}$ were even admitted to receive the sacerciotal character, and to officiate at the altar,

1 Luciani $\sigma \nu \mu \pi$. मे $\Lambda a \pi i \theta a$. 
in the most sacred rites of the established religion: And the public encouragement ${ }^{1}$ of pensions and sala. ries was afforded equally, by the wisest of all the Roman emperors, " to the professors of every sect of philosophy. How requisite such kind of treatment was to philosophy, in her early youth, vill easily be conceived, if we reflect, that, even at present, when she may be supposed more hardy and robust, she bears with much difficulty the inclemency of the seasons, and those harsh winds of calumny and persecution, which blow upon her.

You admire, says my friend, as the singular good fortune of philosophy, what seems to result from the natural course of things, and to be unavoidable in every age and nation. This pertinacious bigotry, of which you complain, as so fatal to philosophy, is really her offspring, who, after allying with superstition, separates himself entirely from the interest of his parent, and becomes her most inveterate enemy and persecutor. Speculative dogmas of religion, the present occasions of such furious dispute, could not possibly be conceived or admitted in the early ages of the world; when mankind, being wholly illiterate, formed an idea of religion more suitable to their weak apprehension, and composed their sacred tenets of such tales chiefly as were the objects of traditional belief, more than of argument or disputation. After the first alarm, therefore, was over, which arose from the new paradoxes and principles of the philosophers; these teachers seem ever after, during the ages of antiquity, to have lived in great harmony with the established superstition, and to have made a fair parti- 
tion of mankind between them; the former claiming all the learned and wise, the latter possessing all the vulgar and illiterate.

It seems then, say $I$, that you leave politics entirely out of the question, and never suppose, that a wise magistrate zan justly be jealous of certain tenets of philosophy, such as those of Epicurus, which, denying a divine existence, and consequently a providence and a future state, seem to loosen, in a great measure, the ties of morality, and may be supposed, for that reason, pernicious to the peace of civil society.

I know, replied he, that in fact these persecutions never, in any age, proceeded from calm reason, or from experience of the pernicious consequences of philosophy; but arose entirely from passion and prejudice. But what if I should advance farther, and assert, that if Epicurus had been accused before the people, by any of the sycophants or informers of those days, he could easily have defended his cause, and proved his principles of philosophy to be as salutary as those of his adversaries, who endeavoured, with such zeal, to expose him to the public hatred and jealousy?

I wish, said I, you would try your eloquence upon so extraordinary a topic, and make a speech for Epicurus, which might satisfy, not the mob of Athens, if you will allow that ancient and polite city to have contained any mob, but the more philosophical part of his audience, such as might be supposed capable of comprehending his arguments.

The matter would not be difficult, upon such conditions, replied he: And if you please, I shall suppose myself Epicurus for a moment, and make you stand for the Athenian people, and shall deliver you such an harangue as will fill all the urn with white beans, and 
leave not a black cne to gratify the malice of $\mathrm{my}$ adversaries.

Very well : Pray proceed upon these suppositions.

I come hither, $\mathrm{O}$ ye Athenians, to justify in your ssembly what I maintained in my school, and I find rnyself impeached by furious antagonists, instead of reasoning with calm and dispassionate enquirers. Your deliberations, which of right should be directed to questions of public good, and the interest of the commonwealth, are diverted to the disquisitions of speculative philosophy; and these magnificent, but perhaps fruitless enquiries, take place of your more familiar but more useful occupations. But so far as in me lies, I will prevent this abuse. We shall not here dis. pute concerning the origin and government of worlds. We shall only enquire how far such questions concern the public interest. And if I can persuade you, that they are entirely indifferent to the peace of society and security of government, I hope that you will presently send us back to our schools, there to examine, at leisure, the question the most sublime, but at the same time, the most speculative of all philosophy.

The religious philosophers, not satisfied with the tradition of your forefathers, and doctrine of your priests (in which I willingly acquiesce), indulge a rash curiosity, in trying how far they can establish religion upon the principles of reason; and they thereby excite, instead of satisfying, the doubts, which naturally arise from a diligent and scrutinous enquiry. They paint, in the most magnificent colours, the order, beauty, and wise arrangement of the universe; and then ask, if such a glorious display of intelligence could proceed from the fortuitous concourse of atoms, or if chance could produce what the greatest genius can never suf- 
ficiently admire. I shall not examine the justness of this argument. I shall allow it to be as solid as my antagonists and accusers can desire. It is sufficient, if $I$ can prove, from this very reasoning, that the question is entirely speculative, and that, when, in my philosophical disquisitions, I deny a providence and a future state, I undermine not the foundations of society, but advance principles, which they themselves, upcn their own topics, if they argue consistently, must allow to be solid and satisfactory.

You then, who are my accusers, have acknowledged, that the chief or sole argument for a divine existence (which I rever questioned) is derived from the order of nature; where there appear such marks of intelligence and design, that you think it extravagant to assign for its cause, either chance, or the blind and unguided force of matter. You allow, that this is an argument drawn from effects to causes. From the order of the work, you infer, that there must have been project and forethought in the workman. If you cannot make out this point, you allow, that your conclusion fails; and you pretend not to establish the conclusion in a greater latitude than the phenomena of nature will justify. These are your concessione. I desire you to mark the consequences.

When we infer any particular cause from an effecr, we must proportion the one to the other, and can never be allowed to ascribe to the cause any qualities, but what are exactly sufficient to produce the effect. A body of ten ounces raised in any scale may serve as a proof, that the counterbalancing weight exceeds ten ounces; but can never afford a reason that it exceeds a hundred. If the cause, assigned for any effect, be not sufficient to produce it, we must either reject that 
cause, or add to it such qualities as will give it a just proportion to the effect. But if we ascribe to it further qualities, or affirm it capable of producing other effects, we can only indulge the licence of conjecture, and arbitrarily suppose the existence of qualities and energies, without reason or authority.

The same rule holds, whether the cause assigned be brute unconscious matter, or a rational intelligent being. If the cause be known only by the effect, we never ought to ascribe to it any qualities, beyond what are precisely requisite to produce the effect: Nor can we, by any rules of just reasoning, return back from the cause, and infer other effects from it, beyond those by which alone it is known to us. No one, merely from the sight of one of Zeuxis's pictures, could know, that he was also a statuary or architect, and was an artist no less skilful in stone and marble than in colours. The talents and taste, displayed in the particular work before us; these we may safely conclude the workman to be possessed of. The cause must be proportioned to the efiect; and if we exactly and precisely proportion it, we shall never find in it any qualities, that point farther, or afford an inference concerning any other design or performance. Such qualities must be somewhat beyond what is merely requisite for producing the effect, which we examine.

Allowing, therefore, the gods to be the authors of the existence or order of the universe ; it follows, that they possess that precise degree of power, intelligence, and benevolence, which appears in their workmanship; but nothing farther can ever be proved, except we call in the assistance of exaggeration and flattery to supply the defects of argument and reasoning. So far as the traces of any attributes, at present, appear, so far may 
we conclude these attributes to exist. The supposition of farther attributes is mere hypothesis; much more the supposition, that, in distant regions of sface or periods of time, there has been, or will be, a more magnificent display of these attributes, and a scheme of administration more suitable to such imaginary virtues. We can never be allowed to mount up from the universe, the effect, to Jupiter, the cause; and then descend downwards, to infer any new effect from that cause; as if the present effects alone were not entirely worthy of the glorious attributes, which we ascribe to that deity. The knowledge of the cause being derived solely from the effect, they must be exactly adjusted to each other; and the one can never refer to anything farther, or be the foundation of any new inference and conclusion.

You find certain phenomena in nature. You seek a cause or author. You imagine that you have found him. You afterwards become so enamoured of this offspring of your brain, that you imagine it impossible, but he must produce something greater and more perfect than the present scene of things, which is so full of ill and disorder. You forget, that this superlative intelligence and benevolence are entirely imaginary, or, at least, without any foundation in reason; and that you have no ground to ascribe to him any qualities, but what you see he has actually exerted and displayed in his productions. Let your gods, therefcre, $O$ philosophers, be suited to the present appearances of nature: and presume not to alter these appearances by arbitrary suppositions, in order to suit them to the attributes, which you so fondly ascribe to your deities.

When priests and poets, supported by your authorit $7, \mathrm{O}$ Athenians, talk of a golden or silver age, which 
preceded the present state of vice and misery, I hear them with attention and with reverence. But when philosophers, who pretend to neglect authority, and to cultivate reason, hold the same discourse, I pay them not, I own, the same obsequious submission and pious deference. I ask, who carried them into the celestiai regions, who admitted them into the councils of the gods, who opened to them the book of fate, that they thus rashly affirm, that their deities have executed, or will execute, any purpose beyond what has actually appeared? If they tell me, that they have mounted on the steps or by the gradual ascent of reason, and by drawing inferences from effects to causes. I still insist, that they have aided the ascent of reason by the wings of imagination; otherwise they could not thus change their manner of inference, and argue from causes to effects; presuming, that a more perfect production than the present world would be more suitable to such perfect beings as the gods, and forgetting that they have no reason to ascribe to these celestial beings any perfection or any attribute, but what can be found in the present world.

Hence all the fruitless industry to account for the ill appearances of nature, and save the honour of the gods; while we must acknowledge the reality of that evil and disorder, with which the world so much abounds. The obstinate and intractable qualities of matter, we are told, or the observance of general laws, or some such reason, is the sole cause, which controlled the power and benevolence of Jupiter, and obliged him to create mankind and every sensible creature so imperfect and so unhappy. These attributes then, are, it seems, beforehand, taken for granted, in their greatest latitude. And upon that supposition, I own 
that such conjectures may, perhaps, be admitted as plausible solutions of the ill phenomena. But still 1 ask, Why take these attributes for granted, or why ascribe to the cause any qualitics but what actually appear in the effect? Why torture your brain to justify the course of nature upon suppositions, which, for aught you know, may be entirely imaginary, and of which there are to be found no traces in the course of nature?

The religious hypothesis, therefore, must be considered only as a particular method of accounting for the visible phenomena of the universe: but no just reasoner will ever presume to infer from it any single fact, and alter or add to the phenomena, in any single particular. If you think, that the appearances of things prove such causes, it is allowable for you to draw an inference concerning the existence of these causes. In such complicated and sublime subjects, every one should be indulged in the liberty of conjecture and argument. But here you ought to rest. If you come backward, and arguing from your inferred causes, conclude, that any other fact has existed, or will exist, in the course of nature, which may serve as a fuller display of particular attributes; I must admonish you, that you have departed from the method of reasoning, attached to the present subject, and have certainly added something to the attributes of the cause, beyond what appears in the effect; otherwise you could never, with tolerable sense or propriety, add anything to the effect, in order to rende: it more worthy of the cause.

Where, then, is the odiousness of that doctine, which $\mathrm{I}$ teach in my school, or rather, which I exam. ine in my gardens? Or what do you find in this 
whole question, wherein the security of good morals, or the peace and order of society, is in the least con. cerned?

I deny a providence, you say, and supreme governor of the world, who guides the course of events, and punishes the vicious with infamy and disappointment, and rewards the virtuous with honour and success, in all their undertakings. But surely, I deny not the course itself of events, which lies open to every one's inquiry and examination. I acknowledge, that, in the present order of things, virtue is attended with more peace of mind than vice, and meets with a more favourable reception from the world. I am sensible, that, according to the past experience of mankind, friendship is the chief joy of human life, and moderation the only source of tranquillity and happiness. I never balance between the virtuous and the vicious course of life; but am sensible, that, to a welldisposed mind, every advantage is on the side of the former. And what can you say more, allowing all your suppositions and reasonings? You tell me, indeed, that this disposition of things proceeds from intelligence and design. But whatever it proceeds from, the disposition itself, on which depends our happiness or misery, and consequently our conduct and deportment in life is still the same. It is still open for me, as well as you, to regulate my behaviour, by my experience of past events. And if you affirm, that, while a divine providence is allowed, and a supreme distributive justice in the universe, I ought to expect some more particular reward of the good, and punishmeni of the bad, beyond the ordinary course of events; I here find the same fallacy, which I have before endeavoured to detect. You persist in imagin- 
ing, that, if we grant that divine existence, for which you so earnestly contend, you may safely infer consequences from it, and add something to the experienced order of nature, by arguing from the attributes which you ascribe to your gods. You seem not to remember, that all your reasonings on this subject can only be drawn from effects to causes; and that every argument, deducted from causes to effects, must of necessity be a gross sophism; since it is impossible for you to know anything of the cause, but what you have antecedently, not inferred, but discovered to the full, in the effect.

But what must a philosopher think of those vain reasoners, who, instead of regarding the present scene of things as the sole object of their contemplation, so far reverse the whole course of nature, as to render this life merely a passage to something farther; a porch, which leads to a greater, and vastly different building; a prologue, which serves only to introduce the piece, and give it more grace and propriety? Whence, do you think, can such philosophers derive their idea of the gods? From their own conceit and imagination surely. For if they derived it from the present phenomena, it would never point to anything farther, but must be exactly adjusted to them. That the divinity may possibly be endowed with attributes, which we have never seen exerted; may be governed by principles of action, which we cannot discover to be satisfied : all this will freely be allowed. But still this is mere possibility and hypothesis. We never can have reason to infer any attributes, or any principles of action in him, but so far as we know them to have been exerted and satisfied.

Are there any marks of a distributive justice in the 
world? If you answer in the affirmative, I conclude, that, since justice here exerts itself, it is satisfied. If you reply in the negative, I conclude, that you have then no reason to ascribe justice, in our sense of 1 , to the gods. If you hold a medium between affirmation and negation, by saying, that the justice of the gods, at present, exerts itself in part, but not in its full extent; I answer, that you have no reason to give it any particular extent, but only so far as you see it, at present, exert itself.

Thus I bring the dispute, $\mathrm{O}$ Athenians, to a short issue with my antagonists. The course of nature lies open to my contemplation as well as to theirs. The experienced train of events is the great standard, by which we all regulate our conduct. Nothing else can be appealed to in the field, or in the senate. Nothing else ought ever to be heard of in the school, or in the closet. In vain would our limited understanding break through those boundaries, which are too narrow for our fond imagination. While we argue from the course of nature, and infer a particular intelligent cause, which first bestowed, and still preserves order in the universe, we embrace a principle, which is both uncertain and useless. It is uncertain; because the subject lies entirely beyond the reach of human experience. It is useless; because our knowledge of this cause being derived entirely from the course of nature, we can never, according to the rules of just reasoning, return back from the cause with any new inference, or making additions to the common and experienced course of nature, establish any new principles of conduct and behaviour. 
I observe (said I, finding he had finished his ha rangue) that you neglect not the artifice of the demagogues of old; and as you were pleased to make me stand for the people, you insinuate yourself into my favour by embracing those principles, to which, you know, I have always expressed a particular attachment. But allowing you to make experience (as indeed I think you ought) the only standard of our judgement concerning this, and all other questions of fact; I doubt not but, from the very same experience, to which you appeal, it may be possible to refute this reasoning, which you have put into the mouth of Epicurus. If you saw, for instance, a half-finished building, surrounded with heaps of brick and stone and mortar, and all the instruments of masonry; could you not infer from the effect, that it was a work of design and contrivance? And could you not return again, from this inferred cause, to infer new additions to the effect, and conclude, that the building would soon be finished, and receive all the further improvements, which art could bestow upon it? If you saw upon the sea-shore the print of one human foot, you would conclude, that a man had passed that way, and that he had also left the traces of the other foot, though effaced by the rolling of the sands or inundation of the waters. Why then do you refuse to admit the same method of reasoning with regard to the order of nature? Consider the world and the present life only as an imperfect building, from which you can infer a superior intelligence; and arguing from that superior intelligence, which can leave nothing imperfect; why may you not infer a more finished scheme or plan, which will receive its completion in scme distant point of space or time? Are not these methods of reasoning 
exactly similar? And under what pretence can you embrace the one, while you reject the other?

The infinite difference of the subjects, replied he, is a sufficient foundation for this difference in my conclusions. In works of human art and contrivance, it is allowable to advance from the effect to the cause, and returning back from the cause, to form new inferences concerning the effect, and examine the alterations, which it has probably undergone, or may still undergo. But what is the foundation of this method of reasoning? Plainly this : that man is a being, whom we know by experience, whose motives and designs we are acquainted with, and whose projects and inclinations have a certain connexion and coherence, according to the laws which nature has established for the government of such a creature. When, therefore, we find, that any work has proceeded from the skill and industry of man; as we are otherwise acquainted with the nature of the animal, we can draw a hundred inferences concerning what may be expected from him; and these inferences will all be founded in experience and observation. But did we know man only from the single work or production which we examine, it were impossible for us to argue in this manner; because our knowledge of all the qualities, which we ascribe to him, being in that case derived from the production, it is impossible they could point to anything further, or be the foundation of any new inference. The print of a foot in the sand can only prove, when considered alone, that there was some figure adapted to it, by which it was produced: but the print of a human foot proves likewise, from our other experiense, that there was probably another foot, which also left its impression, though effaced by time or 
other accidents. Here we mount from the effect to the cause; and descending again from the cause, infer alterations in the effect; but this is not a continuation of the same simple chain of reasoning. We comprehend in this case a hundred other experiences and observations, concerning the usual figure and members of that species of animal, without which this method of argument must be considered as fallacious and sophistical.

The case is not the same with our reasonings from the works of nature. The Deity is known to us only by his productions, and is a single being in the universe, not comprehended under any species or genus, from whose experienced attributes or qualities, we can, by analogy, infer any attribute or quality in him. As the universe shews wisdom and goodness, we infer wisdom and goodness. As it shews a particular degree of these perfections, we infer a particular degree of them, precisely adapted to the effect which we examine. But further attributes or further degrees of the same attributes, we can never be authorised tc infer or suppose, by any rules of just reasoning. Now, without some such license of supposition, it is impossible for us to argue from the cause, or infer any alteration in the effect, beyond what has immediately fallen under our observation. Greater good produced by this Being must still prove a greater degree of goodness: a more impartial distribution of rewards and punishments must proceed from a greater regard to justice and equity. Every supposed addition to the works of nature makes an addition to the attributes of the Author of nature; and consequently, being entirely unsupported by any reason or argument, can 
never be admitted but as mere conjecture and hy. pothesis. ${ }^{1}$

The great source of our mistake in this subject, and of the unbounded licence of conjecture, which we indulge, is, that we tacitly consider ourselves, as in the place of the Supreme Being, and conclude, that he will, on every occasion, observe the same conduct, which we ourselves, in his situation, would have embraced as reasonable and eligible. But, besides that the ordinary course of nature may convince us, that almost everything is regulated by principles and maxims very different from ours; besides this, I say, it must evidently appear contrary to all rules of analogy to reason, from the intentions and project of men, tos those of a Being so different, and so much superior. In human nature, there is a certain experienced coherence of designs and inclinations; so that when, from any fact, we have discovered one intention of any man, it may often be reasonable, from experience, to infer another, and draw a long chain of conclusions concerning his past or future conduct. But this

1 In general, it may, I think, be established as a maxim, that where any cause is known only by its particular effects, it must be impossible to infer any new effects from that cause; since the qualities, which are requisite to produce these new effects along with the former, must either be different, or superior, or of more extensive operation, than those which simply produced the effect, whence alone the cause is supposed to be known to us. We can never, therefore, have any reason to suppose the existence of these qualities. To say, that the new effects proceed only from a continuation of the same energy. which is already known from the first effects, will not remove the difficulty. For even granting this to be the case (which can seldom be supposed), the very continuation and exertion of a like energy (for it is impossible it can be absolutely the same), I say, this exertion of a like energy, in a different period of space and time, is a very arbitrary supposition, and what there cannot possibly be any traces of in the effects, from which all our knowledge of the cause is originally derived. Let the inferred cause be exactly proportioned (as it should be) to the known effect; and it is impossible that it can possess any qualities, from which new or different effects can be inferred. 
method of reasoning can never have place with regard to a Being, so remote and incomprehensible, who bears much less analogy to any other being in the universe than the sun to a waxen taper, and who discovers himself only by some faint traces or cutlines, beyond which we have no authority to ascribe to him any attribute or perfection. What we imagine to be a superior perfection, may really be a defect. Or were it ever so much a perfection, the ascribing of it to the Supreme Being, where it appears not to have been really exerted, to the full, in his works, savours more of flattery and panegyric, than of just reasoning and sound philosophy. All the philosophy, therefore, in the world, and all the religion, which is nothing but a species of philosophy, will never be able to carry us beyond the usual course of experience, or give us measures of conduct and behaviour different from those which are furnished by reflections on common life. No new fact can ever be inferred from the religious hypothesis; no event foreseen or foretold; no 'reward or punishment expected or dreaded, beyond what is already known by practice and observation. So that my apology for Epicurus will still appear solid and satisfactory; nor have the political interests of society any connexion with the philosophical disputes concerning metaphysics and religion.

There is still one circumstance, replied $I_{3}$ which you seem to have overlooked. Though I should allow your premises, I must deny your conclusion. You conclude, that religious doctrines and reasonings can have no influence on life, because they ought to have no influence; never considering, that men reason not in the same manner you do, but draw many consequences from the belief of a divine Existence, and sup- 
pose that the Deity will inflict punishments on vice, and bestow rewards on virtue, beyond what appear in the ordinary course of nature. Whether this reasoning of theirs be just or not, is no matter. Its influence on their life and conduct must still be the same. And, those, who attempt to disabuse them of such prejudices, may, for aught I know, be good reasoners, but I cannot allow them to be good citizens and politicians; since they free men from one restraint upon their passions, and make the infringement of the laws of society, in one respect, more easy and secure.

After all, I may, perhaps, agree to your general conclusion in favour of liberty, though upon different premises from those, on which you endeavour to found it. I think, that the state ought to tolerate every principle of philosophy; nor is there an instance, that any government has suffered in its political interests by such indulgence. There is no enthusiasm among philosophers; their doctrines are not very alluring to the people; and no restraint can be put upon their reasonings, but what must be of dangerous consequence to the sciences, and even to the state, by paving the way for persecution and oppression in points, where the generality of mankind are more deeply interested and concerned.

But there occurs to me (continued I) with regard to your main topic, a difficulty, which I shall just propose to you without insisting on it; lest it lead into reasonings of too nice and delicate a nature. In a word, I much doubt whether it be possible for a cause to be known only by its effect (as you have all along supposed) or to be of so singular and particular a nature as to have no parallel and no similarity with any other cause or object, that has ever fallen under our 
observation. It is only when two species of objects are found to be constantly conjoined, that we can infer the one from the other; and were an effect presented, which was entirely singular, and could not be compre. hended under any known species, I do not see, that we could form any conjecture or inference at all concerning its cause. If experience and observation and analogy be, indeed, the only guides which we can reasonably follow in inferences of this nature; both the effect and cause must bear a similarity and resemblance to other effects and causes, which we know, and which we have found, in many instances, to be conjoined with each other. I leave it to your own reflection to pursue the consequences of this principle. I shall just observe, that, as the antagonists of Epicurus always suppose the universe, an effect quite singular and unparalleled, to be the proof of a Deity, a cause no less singular and unparalleled; your reasonings, upon that supposition, seem, at least, to merit our attention. There is, I own, some difficulty, how we can ever return from the cause to the effect, and, reasoning from our ideas of the former, infer any alteration on the latter, or any addition to it. 


\section{SECTION XII.}

OF THE ACADEMICAL OR SCEPTICAL PHILOSOPHY

\section{PART I.}

THERE is not a greater number of philosophical $\int$ reasonings, displayed upon any subject, than those. which prove the existence of a Deity, and refute the fallacies of Atheists; and yet the most religious philosophers still dispute whether any man can be so blinded as to be a speculative atheist. How shall we reconcile these contraditions? The knights-errant, who wandered about to clear the world of dragons and giants, never entertained the least doubt with regard to the existence of these monsters.

The Sceptic is another enemy of religion, who naturally provokes the indignation of all divines and graver philosophers; though it is certain, that no man ever met with any such absurd creature, or conversed with a man, who had no opinion or principle concerning any subject, either of action or speculation. This begets a very natural question; What is meant by a sceptic? And how far is it possible to push these philosophical principles of doubt and uncertainty?

There is a species of scepticism, antecedent to all study and philosophy, which is much inculcated by Des Cartes and others, as a sovereign preservative against error and precipitate judgement. It recommends an universal doubt, not only of all our former 
opinions and principles, but also of our very faculties; of whose veracity, say they, we must assure ourselves, by a chain of reasoning, deduced from some-original principle, which cannot possibly be fallacious or deceitful. But neither is there any such original principle, which has a prerogative above others, that are self-evident and convincing: or if there were, could we advance a step beyond it, but by the use of those very faculties, of which we are supposed to be already diffident. The Cartesian doubt, therefore, were it ever possible to be attaned by any human creature (as it plainly is not) would be entirely incurable; and no reasoning could ever bring us to a state of assurance and conviction upon any subject.

It must, however, be confessed, that this species of scepticism, when more moderate, may be understood in a very reasonable sense, and is a necessary preparative to the study of philosophy, by preserving a proper impartiality in our judgements, and weaning our mind from all those prejudices, which we may have imbibed from education or rash opinion. To begin with clear and self-evident principles, to advance by timorous and sure steps, to review frequently our conclusions, and examine accurately all their consequences; though by these means we shall make both a slow and a short progress in our systems; are the only methods, by which we can ever hope to reach truth, and attain a proper stability and certainty in our determinations.

There is another species of scepticism, consequent to science and enquiry, when men are supposed to have discovered either the absolute fallaciousness of their mental faculties, or their unfitness to reach any fixed determination in all those curious subjects of speculątion, about which they are commonly em- 
ployed. Even our very senses are brought into dispute, by a certain species of philosophers; and the maxims of common life are subjected to the same doubt as the most profound principles or conclusions cf metaphysics and theology. As these paradoxical tenets (if they may be called tenets) are to be met with in some philosophers, and the refutation of them in several, they naturally excite our curiosity, and make us enquire into the arguments, on which they may be founded.

I need not insist upon the more trite topics, employed by the sceptics in all ages, against the evidence of sense; such as those which are derived from the imperfection and fallaciousness of our organs, on numberless occasions; the crooked appearance of an oar in water; the various aspects of objects, according to their different distances; the double images which arise from the pressing one eye; with many other appearances of a like nature. These sceptical topics, indeed, are only sufficient to prove, that the senses alone are not implicitly to be depended on; but that we must correct their evidence by reason, and by considerations, derived from the nature of the medium, the distance of the object, and the disposition of the organ, in order to render them, within their sphere, the proper criteria of truth and falsehood. There are other more profound arguments against the senses, which admit not of so easy a solution.

It seems evident, that men are carried, by a natural instinct or prepossession, to repose faith in their senses; and that, without any reasoning, or even almost before the use of reason, we always suppose an external universe, which depends not on our perception, but would exist, though we and every sensible 
creature were absent or annihilated. Even the animal creation are governed by a like opinion, and preserve this belief of external objects, in all their thoughts, designs, and actions.

It seems also evident, that, when men follow this blind and powerful instinct of nature, they always suppose the very images, presented by the senses, to be the external objects, and never entertain any suspicion, that the one are nothing but representations of the other. This very table, which we see white, and which we feel hard, is believed to exist, independent of our perception, and to be something external to our mind, which perceives it. Our presence bestows not being on it: our absence does not annihilate it. It preserves its existence uniform and entire, independent of the situation of intelligent beings, who perceive or contemplate it.

But this universal and primary opinion of all men is soon destroyed by the slightest philosophy, which teaches us, that nothing can ever be present to the mind but an image or perception, and that the senses are only the inlets, through which these images are conveyed, without being able to produce any immediate intercourse between the mind and the object. The table, which we see, seems to diminish, as we remove farther from it: but the real table, which exists independent of us, suffers no alteration: it was, therefore, nothing but its image, which was present to the mind. These are the obvious dictates of reason; and no man, who reflects, ever doubted, that the existences, which we consider, when we say, this house and that tree, are no:hing but perceptions in the mind, and fleeting copies or representations of other existences, which remain uniform and independent, 
So far, then, are we necessitated by reasoning to contradict or depart from the primary instincts of nature, and to embrace a new system with regard to the evidence of our senses. But here philosophy finds herseif extremely embarrassed, when she would justify this new system, and obviate the cavils and objections of the sceptics. She can no longer plead the infallible and irresistible instinct of nature: for that led us to a quite different system, which is acknowledged fallibie and even erroneous. And to justify this pretended philosophical system, by a chain of clear and convincing argument, or even any appearance of argument, exceeds the power of all human capacity.

By what argument can it be proved, that the per sep. tions of the mind must be caused by external objects, :- entirely different from them, though resembling them (if that be possible) and could not arise either from the energy of the mind itself, or from the suggestion of some invisible and unknown spirit, or from some other cause still more unknown to us? It is acknowledged, that, in fact, many of these perceptions arise not from anything external, as in dreams, madness, and other diseases. And nothing can be more explicable than the manner, in which body should so operate upon mind as ever to convey an image of itself to a substance, supposed of so different, and even contrary a nature.

It is a question of fact, whether the perceptions $c_{4}^{\prime}$ the senses be produced by external objects, resembling them: how shall this question be determined? By experience surely; as all other questions of a like nature. But here experience is, and must be entirely silent. The mind has never anything present to it but the perceptions, and cannot possibly reach any expe- 
rience of their connexion with objects. The sicpposition of such a connexion is, therefore, without any foundation in reasoning.

Tc have recourse to the veracity of the supreme Being, in order to prove the veracity of our senses, is surely making a very unexpected circuit. If his vara. city were at all concerned in this matter, our senses would be entirely infallible; because it is not possible that he can evẹr deceive. Not to mention, that, if the external world be once called in question, we shall be at a loss to find arguments, by which we may prove the existence of that Being or any of his attributes.

This is a topic, therefore, in which the profounder and more philosophical sceptics will always triumph, when they endeavour to introduce an universal doubt into all subjects of human knowledge and enquiry. Do you follow the instincts and propensities of nature, may they say, in assenting to the veracity of sense? But these lead you to believe that the very perception or sensible image is the external object. Do you disclaim this principle, in order to embrace a more rational opinion, that the perceptions are only represen tations of something external? You here depart from your natural propensities and more obvious sentiments; and yet are not able to satisfy your reason, which can never find any convincing argument from experience to rove, that the perceptions are connected with any. external objects.

There is another sceptical topic of a like nature, derived from the most profound philosophy. which might merit our attention, were it requisite to dive ss deep, in order to discover arguments and reasonings, which can so little serve to any serious purpose. It is universally allowed by modern enquirers, that all 
the sensible qualities of objects, such as hard, soft, hot, coid, white, black, \&c. are merely secondary, and exist not in the objects themselves, but are perceptions of the mind, without any external archetype or model, which they represent. If this be allowed, with regard tc secondary qualities, it must also follow, with regard to the supposed primary qualities of extension and solidity; nor can the latter be any more entitled to that denomination than the former. The idea of extension is entirely acquired from the senses of sight and feeling; and if all the qualities, perceived by the senses, be in the mind, not in the object, the same conclusion must reach the idea of extension, which is wholly dependent on the sensible ideas or the ideas of secondary qualities. Nothing can save us from this conclusion, but the asserting, that the ideas of those primary qualities are attained by Abstraction, an opinion, which, if we examine it accurately, we shall find to be unintelligible, and even absurd. An extension, that is neither tangible nor visible, cannot possibly be conceived: and a tangible or visible extension, which is neither hard nor soft, black or white, is equally beyond the reach of human conception. Let any man try to conceive a triangle in general, which is neither Isosceles nor Scalenum, nor has any particular length or proportion of sides; and he will soon perceive the absurdity of all the scholastic notions with regard to abstraction and general ideas. ${ }^{2}$

1 This argument is drawn from Dr. Berkeley; and indeed most of the writings of that very ingenious author form the best lessons of scepticism, which are to be found either among the ancient or modern philosophers. Bayle not excepted. He professes, however, in his title-page (and undoubtedly with great truth) to have composed his book against the sceptics as well as against the atheists and free-thinkers. But that all his arguments, though otherwise intended, are, in reality, merely sceptical, appec rs from this, that they admit of no answer and produce no conviction. Their only effect is to 
Thus the first philosophical objection to the evicence of sense or to the opinion of external existence consists in this, that such an opinion, if rested on natural instinc-t, is contrary to reason, and if referred to reason, is contrary to natural instinct, and at the same time carries ne rational evidence with it, to convince an impartial erquirer. The second objection goes farther, and represents this opinion as contrary to reason: at least, it it be a principle of reason, that all sensible qualities are in the mind, not in the object. Bereave matter of a.l its intelligible qualities, both primary and secondary', you in a manner annihilate it, and leave only a certain unknown, inexplicable something, as the cause $n i$ our perceptions; a notion so imperfect, that no scepric will think it worth while to contend against it.

\section{PAKY II.}

Ir may seem a very e atravagant attempt of the sceptics to destroy reason by argument and ratiocination; yet is this the grand scope of all their enquiries and disputes. They endeavour to find objections, both to our abstract reasonings, and to those which regard matter of fact and existence.

The chief objection against all abstract reasonings is derived from the ideas of space and time; ideas, which, in common life and to a careless view, are very clear and intelligible, but when they pass through the scrutiny of the profound sciences (and they are the chief object of these sciences) afford principles, which seem full of absurdity and contradiction. No priestly

cause that momentary amazement and irresolution and conrusion, which is the result of scepticism. 
dogmas, invented on purpose to tame and subdue the rebellious reason of mankind, ever shocked common sense more than the doctrine of the infinite divisibility of extension, with its consequences; as they are pompously displayed by all geometricians and metaphysicians, with a kind of triumph and exultation. A real quantity, infinitely less than any finite quantity, containing quantities infinitely less than itself, and so on in infinitum; this is an edifice so bold and prodigious, that it is too weighty for any pretended demonstration to support, because it shocks the clearest and most natural principles of human reason. ${ }^{1}$ But what renders the matter more extraordinary, is, that these seemingly absurd opinions are supported by a chain of reasoning, the clearest and most natural; nor is it possible for us to allow the premises without admitting the consequences. Nothing can be more convincing and satisfactory than all the conclusions concerning the properties of circles and triangles; and yet, when these are once received, how can we deny, that the angle of contact between a circle and its tangent is infinitely less than any rectilineal angle, that as you ma $y$ increase the diameter of the circle in infinitum, this angle of contact becomes still less, even in infinitum, and that the angle of contact between other curves and their tangents may be infinitely less than those between any circle and its tangent, and so on, in inf-

1 Whatever disputes there may be about mathematical points, we must allow that there are physical points; that is, parts of extension, which cannot ve divided or lessened, either by the eye or imagination. These images. then, which are present to the fancy or senses, are absolutely indivisible, and consequently must be allowed by mathematicians to be infinitely less than any real part of extension; and yet nothing appears more certain to reason, than that an infinite number of them composes an infinite extension. How much pore an infinite number of those infinitely small parts of extension. whic i are still supposed infuitelv divisible. 
nitum? The demonstration of these principles scems as unexceptionable as that which proves the three angles of a triangle to be equal to twc right ones, though the latter opinion be natural and easy, and the former big with contradiction and absurdity. Reason here seems to be thrown into a kind of amazement and suspence, which, without the suggestions of any sceptic, gives her a diffidence of herself, and of the ground on which she treads. She sees a full light, which illuminates certain places; but that light borders upon the most profound darkness. And between these she is so dazzled and confounded, that she scarcely can pronounce with certainty and assurance concerning any one object.

The absurdity of these bold determinations of the abstract sciences seems to become, if possible, still more palpable with regard to time than extension. An infinite number of real parts of time, passing in succession, and exhausted one after another, appears so evident a contradiction, that no man, one should think, whose judgement is not corrupted, instead of being improved, by the sciences, would ever be able to admit of it.

Yet still reason must remain restless, and unquiet, even with regard to that scepticism, to which she is driven by these seeming absurdities and contradictions. How any clear, distinct idea can contain circumstances, contradictory to itself, or to any other clear, distinct idea, is absolutely incomprehensible; and is, perhaps, as absurd as any proposition, which can be formed. So that nothing can be more sceptical, or more full of doubt and hesitation, than this scepticism itself, which arises from some of the par- 
adoxical conclusions of geometry or the science of quantity. 1

The sceptical objections to moral evidence, or to the reasonings concerning matter of fact, are either popular or philosophical. The popular objections are derived from the natural weakness of human understanding; the contradictory opinions, which have been entertained in different ages and nations; the variations of our judgement in sickness and health, youth and old age, prosperity and adversity; the perpetual contradiction of each particular man's opinions and sentiments; with many other topics of that kind. It is needless to insist farther on this head. These objections are but weak. For as, in common life, we reason every moment concerning fact and existence, and cannot possibly subsist, without continually employing this species of argument, any popular objections, derived from thence, must be insufficient to destroy that evidence. The great subverter of Pyrrhonism or the excessive principles of scepticism is action, and employment, and the occupations of common life. These

1 It seems to me not impossible to avoir these absurdities and contradictions, if it be admitted, that there is no such thing as abstract or general ideas, properly speaking; but that all general ideas are, in reality, particularones, attached to a general term, which recalls, upon occasion, other particular ones, that resemble, in certain circumstances, the idea, present to the mind. Thus when the term Horse is pronounced, we immediately figure to ourselves the idea of a black or a white animal, of a particular size or figure: But as tnat term is also usually applied to animals of other colours, figures and sizes these ideas, though not actually present to the imagination, are easily recalled; and our reasoning and conclusion proceed in the same way, as if they were actually present. If this be admitted (as seems reasonable) it follows that all the ideas of quantity, upon which mathematicians reason, are nothing but particular, and such as are suggested by the senses and imagination, and consequently, cannot be infinitely divisible. It is sufficient to have dropped this hint at present, without prosecuting it any farther. It cer tijaly concerns all lovers of science not to expose themselves to the ridicule

contempt of the ignorant by their conclusions; and this seems the readiast solution of these difficulties. 
principles may flourish and trumph in the schools; where it is, indeed, difficult, if not impossible, to refute them. But as soon as they leave the shade, and by the presence of the real objects, which actuate our passions and sentiments, are put in opposition to the more powerful principles of our nature, they vanish like smoke, and leave the most determined sceptic in the same condition as other mortals.

The sceptic, therefore, had better keep within his proper sphere, and display those philosophical objections, which arise from more profound researches. Here he seems to have ample matter of triumph; while he justly insists, that all our evidence for any matter of fact, which lies beyond the testimony of sense or memory, is derived entirely from the relation of cause and effect; that we have no other idea of this relation than that of two objects, which have been frequently conjoined together; that we have no argument to convince us, that objects, which have, in our experience, been frequently conjoined, will likewise, in other instances, be conjoined in the same manner; and that nothing leads us to this inference but custom or a certain instinct of our nature; which it is indeed difficult to resist, but which, like other instincts, may be fallacious and deceitful. While the sceptic insists upon these topics, he shows his force, or rather, indeed, his own and our weakness; and seems, for the time at least, to destroy all assurance and conviction. These arguments might be displayed at greater lesg th, if any durable good or benefit to society couli ever be expected to result from them.

For here is the chief and most confounding objection tc excessive scepticism, that no durable good can ever result from it; while it remains in its full force 
and vigour. We need only ask such a sceptic, What his meaning is? And what he proposes by all these curious researches? He is immediately at a loss, and knows not what to answer. A Copernican or Ptolemaic. who supports each his different system of astronomy, may hope to produce a conviction, which will remain constant and durable, with his audience. A Stoic or Epicurean displays principles, which may not be durable, but which have an effect on conduct and behaviour. But a Pyrrhonian cannot expect, that his philosophy will have any constant influence on the mind : or if it had, that its influence would be beneficial to society. On the contrary, he must acknowledge, if he will acknowledge anything, that all human life must perish, were his principles universally and steadily to prevail. All discourse, all action would immediately cease; and men remain in a total lethargy, till the necessities of nature, unsatisfied, put an end to their miserable existence. It is true; so fatal an event is very little to be dreaded. Nature is always too strong for principle. And though a Pyrrhonian may throw himself or others into a momentary amazement and confusion by his profound reasonings; the first and most trival event in life will put to flight all his doubts and scruples, and leave him the same, in every point of action and speculation, with the philosophers of every other sect, or with those who never concerned themselves in any philosophical researches. When he awakes from his dream, he will be the first to join in the laugh against himself, and to confess, that all his objections are mere amusement, and can have no other tendency than to show the whimsical condition of mankind, who must act and reason and believe; though they are not able, by their most diligent en 
quiry, to satisfy themselves concerning the foundation of these operations, or to remove the objections, which may be raised against them.

\section{PART III.}

THERE is, indeed, a more mitigated scepticism or academical philosophy, which may be both durable and useful, and which may, in part, be the result of this Pyrrhonism, or excessive scepticism, when its undistinguished doubts are, in some measure, corrected by common sense and reflection. The greater part of mankind are, naturally apt to be affirmative and dogmatical in their opinions; and while they see objects only on one side, and have no idea of any counterpoising argument, they throw themselves precipitately into the principles, to which they are inclined; nor have they any indulgence for those who entertain opposite sentiments. To hesitate or balance perplexes their understanding, checks their passion, and suspends their action. They are, therefore, impatient till they escape from a state, which to them is so uneasy : and they think, that they could never remove themselves far enough from it, by the violence of their affirmations and obstinacy of their belief. But could such dogmatical reasoners become sensible of the strange infirmities of human understanding, even in its most perfect state, and when most accurate and cautious in its determinations; such a reflection would naturally inspire them with more modesty and reserve, and diminish their fond opinion of themselves, and their prejudice against antagonists. The illiterate may reflect on the disposition of the learned, who, amidst all the advantages of study and reflection, are 
commonly still diffident in their determinations : and if any of the learned be inclined, from their natural temper, to haughtiness and obstinacy, a small tincture of Pyrrhonism might abate their pride, by showing them, that the few advantages, which they may have attained over their fellows, are but inconsiderable, if compared with the universal perplexity and confusion, which is inherent in human nature. In general, there is a degree of doubt, and caution, and modesty, which, in all kinds of scrutiny and decision, ought for ever to accompany a just reasoner.

Another species of mitigated scepticism which may be of advantage to mankind, and which may be the natural result of the Pyrrhonian doubts and scruples, is the limitation of our enquiries to such subjects as are best adapted to the narrow capacity of human understanding. The imagination of man is naturally sublime, delighted with whatever is remote and extraordinary, and running, without control, into the most distant parts of space and time in order to avoid the objects, which custom has rendered too familiar to it. A correct judgement observes a contrary method, and avoiding all distant and high enquiries, confines itself to common life, and to such subjects as fall under daily practice and experience; leaving the more sublime topics to the embellishment of poets and orators, or tc the arts of priests and politicians. To bring us to so salutary a determination, nothing can be more serviceable, than to be once thoroughly convinced of the force of the Pyrrhonian doubt, and of the impossibility, that anything, but the strong power of natural instinct, could free us from it. Those who have a propensity to philosophy, will still continue their researches; because they reflect, that, besides the im. 
mediate pleasure, attending such an occupation, philosophical decisions are nothing but the reflections of common life, methodized and corrected. But they will never be tempted to go beyond common life, so long as they consider the imperfection of those faculties which they employ, their narrow reach, and their inaccurate operations. While we cannot give a satisfactory reason, why we believe, after a thousand experiments, that a stone will fall, or fire burn; can we ever satisfy ourselves concerning any determination, which we may form, with regard to the origin of worlds, and the situation of nature, from, and to eternity?

This narrow limitation, indeed, of our enquiries, is, in every respect, so reasonable, that it suffices to make the slightest examination into the natural powers of the human mind and to compare them with their objects, in order to recommend it to us. We shall then find what are the proper subjects of science and enquiry.

It seems to me, that the only objects of the abstract science or of demonstration are quantity and number, and that all attempts to extend this more perfect species of knowledge beyond these bounds are mere sophistry and illusion. As the component parts of quantity and number are entirely similar, their relations become intricate and involved; and nothing can be more curious, as well as useful, than to trace, by a variety of mediums their equality or inequality, through their different appearances. But as all other ideas are clearly distinct and different from each other, we can never advance farther, by our utmost scrutiny, than to observe this diversity, and, by an obvious reflection, pronounce one thing not to be another. Or if there be any difficulty in these decisions, it proceeds entirely 
from the undeterminate meaning of words, whic:n is -orrected by juster definitions. That the square of the ypothenuse is equal to the squares of the other two sides, cannot be known, let the terms be ever so exactly defined, without a train of reasoning and enquiry. But to convince us of this proposition, that where there is no property, there can be no injustice, it is only necessary to define the terms, and explain injustice to be a violation of property. This proposition is, indeed, nothing but a more imperfect definition. It is the same case with all those pretended syllogistical reasonings, which may be found in every other branch of learning, except the sciences of quantity and number; and these may safely, I think, be pronounced the only proper objects of knowledge and demonstration.

All other enquiries of men regard only matter of fact and existence; and these are evidently incapable of demonstration. Whatever is may not be. No negation of a fact can involve a contradiction. The nonexistence of any being, without exception, is as clear and distinct an idea as its existence. The proposition, which affirms it not to be, however false, is no less conceivable and intelligible, than that which affirms it to be. The case is different with the sciences, properly so called. Every proposition, which is not true, is there confused and unintelligible. That the cube root of $\sigma_{4}$ is equal to the half of 10 , is a false proposition, and can never be distinctly conceived. But that $\mathrm{Cæ}$ sar, or the angel Gabriel, or any being never existed, may be a false proposition, but still is perfectly conceivable, and implies no contradiction.

The existence, therefore, of any being can only be "proved by arguments from its cause or its effect; and these arguments are founded entirely on experience. 
If we reason a priori, anything may appear able to produce anything. The falling of a pebble may, for aught we know, extinguish the sun; or the wish of a man control the planets in their orbits. It is only experience, which teaches us the nature and bounds of cause and effect, and enables us to infer the existence of one object from that of another. ${ }^{X}$ Such is the foundation of moral reasoning, which forms the greatcr part of human knowledge, and is the source of all human action and behaviour.

Moral reasonings ? re either concerning particular or general facts. Ali deliberations in life regard the former; as also all disquisitions in history, chronology, geography, and astronomy.

The sciences, which treat of general facts, are politics, natural philosophy, physic, chemistry, \&c. where the qualities, causes and effects of a whole species of objects are enquired into.

Divinity or Theology, as it proves the existence of a Deity, and the immortality of suuls, is composed partly of reasonings concerning particular, partly concerning general facts. It has a foundation in reason, so far as it is supported by experience. But its best and most solid foundation is faith and divine reve. lation.

Morals and criticism are not so properly objects of the understanding as of taste and sentiment. Beauty, whether moral or natural, is felt, more properly than perceived. Or if we reason concerning it, and endeavour to fix its standard, we regard a new fact, to wit,

i That impious maxim of tha ancient philosophy, Ex nih.lo, nihilfit, by which the creation of matter was excluded, ceases to be a maxim according to this philosophy. Not only the wisl of the supreme Being may create matter; but, for aught we know a priori, the will of any other being might create it, or any other cause, that the most whimsical imagination can assign. 
the general tastes of mankind, or some such fact, which may be the object of reasoning and enquiry.

When we run over libraries, persuaded of these principles, what havoc must we make? If we take in our hand any volume; of divinity or school metaphysics, for instance; let us ask, Does it contain any abstract reasoning concerning quantity or number? No. Does it contain any experimental reasoning concerning matter of fact and existence? No. Commit it then to the flames: for it can contain nothing but sophistry and illusion. 
SELECTIONS FROM

A TREATISE OF HUMAN NATURE

\author{
BOOK $I$. \\ BY DAVID HUME
}



A

\section{T R E A T I S E \\ $\mathrm{O} F$}

\section{Human Nature:}

B E I N G

An ATtempt to introduce the experimental Method of Realoning

I N T O

\section{MORAL SUBJECTS.}

Rara temporum felicitas, ubi fentire, qua velis; \& qua Jen ias, dicere licet. TACIT.

\section{Book I.}

OF THE

U N D E R T A N I N G.

LONDON:

Printed for John Noon, at the White-Hart, near Mercer's-Chapel in Cheapfide.

MDCCXXXIX. 



\title{
The Contents of \\ A Treatise of Human Nature
}

\author{
BOOK I. \\ Of the Understanding.
}

PART I.

Of ideas; their origin, composition, abstraction connexion, \&c. SECT.

I. Of the origin of our ideas

II. Division of the subject .

III. Of the ideas of the memory and imagination .

$\therefore$. Of the connexion or association of ideas . .

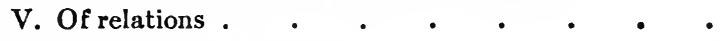

* VI. Of modes and substances $\quad . \quad$. $\quad . \quad$ - 227

VII. Of abstract ideas . . $\quad$ • • $•$.

PAGE.

PART II.

Of the ideas of space and time.

I. Of the infinite divisibility of our ideas of space and time.

II. Of the infinite divisibility of space and time .

III. Of the other qualities of our ideas of space and time

IV. Objections answer'd

V. The same subject continu'd .

* VI. Of the idea of existence and of external existence .

229

PART III.

of knowledge and probability.

*

*

$*$

I. Of knowledge

II. Of probability; and of the idea of cause and effect . 190

III. Why a cause is always necessary? .

* Only the sections thus indicated are here reproduced. 
SECT.

IV. Of the component parts of our reasonings concerning causes and effects

V. Of the impressions of the senses and memory .

VI. Of the inference from the impression to the idea .

VII. Of the nature of the idea, or belief

VIII. Of the causes of belief

IX. Of the effects of other relations, and other habits .

$\mathrm{X}$. Of the influence of belief

XI. Of the probability of chances

XII. Of the probability of causes .

XIII. Of unphilosophical probability

*XIV. Of the idca of necessary connexion

202

XV. Rules by which to judre of causes and effects

XVI. Of the reason of animals

\section{PART IV.}

Of the sceptical and other systems of philosophy

I. Of scepticism with regard to reason

* II. Of scepticisn with regard to the senses.

III. Of the antient philosophy

IV. Of the modern philosophy

V. Of the immateriality of the soul

* VI. Of personal identity

VII. Conclusion of this book

Appexdix

* Only the sectious thus indicated are here reproduced. 


\section{THE DOCTRINE OF CAUSALITY}

SELECTIONS FROM

BOOK I., PART III 



\section{$B O O K I$.}

\section{PART III.}

\section{OF KNOWLEDGE AND PROBABILITY.}

\section{Section I.}

Of knowledge.

There are ${ }^{1}$ seven different kinds of philosophical relation, viz. resemblance, identity, relations of time and place, proportion in quantity or number, degrees in any quality, contrariety, and causation. These relations may be divided into two classes; into such as depend entirely on the ideas, which we compare together, and such as may be chang'd without any change in the ideas. 'Tis from the idea of a triangle, that we discover the relation of equality, which its three angles bear to two right ones; and this relation is invariable, as long as our idea remains the same. On the contrary, the relations of contiguity and distance betwixt two objects may be chang'd merely by an alteration of their place, without any change on the objects themselves or on their ideas; and the place depends on a hundred different accidents, which cannot be foreseen by the mind. 'Tis the same case with identity and causation. Two objects. tho' perfectly resembling each other, and even appearing in the same place at different times, may be numerically different: And as the power, by which one object produces another, is never discoverable merely from their idein,

1 Part I., Sect. V. 
'tis evident cause and effect are relations, of which we receive information from experience, and not from any abstract reasoning or reflexion. There is no single phænomenon, even the most simple, which can be accounted for from the qualities of the objects, as they appear to us; or which we cou'd foresee without the help of our memory and experience.

It appears, therefore, that of these seven philosophical relations, there remain only four, which depending solely upon ideas, can be the objects of knowledge and certainty. These four are resemblance, contrariety, degrees in quality, and proportions in quantity or number. Three of these relations are discoverable at first sight, and fall more properly under the province of intuition than demonstration. When any objects resemble each other, the resemblance will at first strike the eye, or rather the mind; and seldom requires a second examination. The case is the same with contrariety, and with the degrees of any quality, No one can once doubt but existence and non-existence destroy each other, and are perfectly incompatible and contrary. And tho' it be impossible to judge exactly of the degrees of any quality, such as colour, taste, heat, cold, when the difference betwixt them is very small; yet 'tis easy to decide, that any of them is superior or inferior to another, when their difference is considerable. And this decision we always pronounce at first sight, without any enquiry or reasoning.

We might proceed, after the same manner, in fixing the proportions of quantity or number, and might at one view observe a superiority or inferiority betwixt any numbers, or figures; especially where the difference is very great and remarkable. As to equality or any exact proportion, we can only guess at it from a 
single consideration; except in very short numbers, or very limited portions of extension; which are comprehended in an instant, and where we perceive an impossibility of falling into any considerable error. In all other cases we must settle the proportions with some liberty, or proceed in a more artificial manner.

I have already observ'd, that geometry, or the art, by which we fix the proportions of figures; tho' it much excels, both in universality and exactness, the loose judgments of the senses and imagination; yet never attains a perfect precision and exactness. Its first principles are still drawn from the general appearance of the objects; and that appearance can never afford us any security, when we examine the prodigious minuteness of which nature is susceptible. Our ideas seem to give a perfect assurance, that no two right lines can have a common segment; but if we consider these ideas, we shall find, that they always suppose a sensible inclination of the two lines, and that where the angle they form is extremely small, we have no standard of a right line so precise, as to assure us of the truth of this proposition. 'Tis the same case with most of the primary decisions of the mathematics.

There remain, therefore, algebra and arithemetic as the only sciences, in which we can carry on a chain of reasoning to any degree of intricacy, and yet preserve a perfect exactness and certainty. We are possest of a precise standard, by which we can judge of the equality and proportion of numbers; and according as they correspond or not to that standard, we determine their relations, without any possibility of error. When two numbers are so combin'd, as that the one has always an unite answering to every unite of the other, we pronounce them equal; and 'tis for want of 
such a standard of equality in extension, that geometry can scarce be estcem'd a perfect and infallible science.

But here it may not be amiss to obviate a difficulty, which may arise from my asserting, that tho' geometry falls short of that perfect precision and certainty, which are peculiar to arithmetic and algebra, yet it excels the imperfect judgments of our senses and imagination. The reason why I impute any defect to geometry, is, because its original and fundamental principles are deriv'd merely from appearances; and it may perhaps be imagin'd, that this defect must always attend it, and keep it from ever reaching a greater exactness in the comparison of objects or ideas, than what our eye or imagination alone is able to attain. I own that this defect so far attends it, as to keep it from ever aspiring to a full certainty: But since these fundamental principles depend on the easiest and least deceitful appearances, they bestow on their consequences a degree of exactness, of which these consequences are singly incapable. 'Tis impossible for the eye to determine the angles of a chiliagon to be equal to 1996 right angles, or to make any conjecture, that approaches this proportion; but when it determines, that right lines cannot concur; that we cannot draw more than one right line between two given points; its mistakes can never be of any consequence. And this is the nature and use of geometry, to run us up to such appearances, as, by reason of their simplicity, cannot lead us into any considerable error.

I shail here take occasion to propose a second observation concerning our demonstrative reasonings, which is suggested by the same subject of the mathematics. 'Tis usual with mathematicians, to pretend, that those ideas, which are their objects, are of so 
refin'd and spiritual a nature, that they fall not under the conception of the fancy, but must be comprehended by a pure and intellectual view, of which the superior faculties of the soul are alone capable. The same notion runs thro' most parts of philosophy, and is principally made use of to explain our abstract ideas, and to shew how we can form an idea of a triangle, for instance, which shall neither be an isosceles nor scalenum, nor be confin'd to any particular length and proportion of sides. 'Tis easy to see, why philosophers are so fond of this notion of some spiritual and refin'd perceptions; since by that means they cover many of their absurdities, and may refuse to submit to the decisions of clear ideas, by appealing to such as are obscure and uncertain. But to destroy this artifice, we need but reflect on that principle so oft insisted on, that all our ideas are copy'd from our impressions. For from thence we may immediately conclude, that since all impressions are clear and precise, the ideas, which are copied from them, must be of the same nature, and can never, but from our fault, contain any thing so dark and intricate. An idea is by its very nature weaker and fainter than an impression; but being in every other respect the same, cannot imply any very great mystery. If its weakness render it obscure, 'tis our business to remedy that defect, as much as possible, by keeping the idea steady and precise; and till we have done so, 'tis in vain to pretend to reasoning and philosophy. 


\section{Section II.}

Of probability; and of the idea of cause and effect.

This is all I think necessary to observe concerning those four relations, which are the foundation of science; but as to the other three, which depend not upon the idea, and may be absent or present even while that remains the same, 'twill be proper to explain them more particularly. These three relations are identity, the situations in time and place, and causation.

All kinds of reasoning consist in nothing but a comparison, and a discovery of those relations, either constant or inconstant, which two or more objects bear to each other. This comparison we may make, either when both the objects are present to the senses, or when neither of them is present, or when only one. When both the objects are present to the senses along with the relation, we call this perception rather than reasoning; nor is there in this case any exercise of the thought, or any action, properly speaking, but a mere passive admission of the impressions thro' the organs of sensation. According to this way of thinking, we ought not to receive as reasoning any of the observations we may make concerning identity, and the relations of time and place; since in none of them the mind can go beyond what is immediately present to the senses, either to discover the real existence or the relations of objects. 'Tis only causation, which pro. duces such a connexion, as to give us assurance from 
the existence or action of one object, that 'twas follow'd or preceded by any other existence or action; nor can the other two relations be ever made use of in reasoning, except so far as they either affect or are affected by it. There is nothing in any objects to perswade us, that they are either always remote or always contiguous; and when from experience and observation we discover, that their relation in this particular is invariable, we always conclude there is some secret cause, which separates or unites them. The same reasoning extends to identity. We readily suppose an object may continue individually the same, tho' several times absent from and present to the senses; and ascribe to it an identity, notwithstanding the interruption of the perception, whenever we conclude, that if we had kept our eye or hand constantly upon it, it wou'd have convey'd an invariable and uninterrupted perception. But this conclusion beyond the impressions of our senses can be founded only on the connexion of cause and cffect; nor can we otherwise have any security, that the object is not chang'd upon us, however much the new object may resemble that which was formerly present to the senses. Whenever we discover such a perfect resemblance, we consider, whether it be common in that species of objects; whether possibly or probably any cause cou'd operate in producing the change and resemblance; and according as we determine concerning these causes and effects, we form our judgment concerning the identity of the object.

Here then it appears, that of those three relations, which depend not upon the mere ideas, the only one, that can be trac'd beyond our senses, and informs us of existences and objects, which we do not see or feel, 
is causation. This relation, therefore, we shall endeavour to explain fully before we leave the subject of the understanding.

To begin regularly, we must consider the idea of causation, and see from what origin it is deriv'd. 'Tis impossible to reason justly, without understanding perfectly the idea concerning which we reason; and 'tis impossible perfectly to understand any idea, without tracing it up to its origin, and examining that primary impression, from which it arises. The examination of the impression bestows a clearness on the idea; and the examination of the idea bestows a like clearness on all our reasoning.

Let us therefore cast our eye on any two objects, which we call cause and effect, and turn them on all sides, in order to find that impression, which produces an idea of such prodigious consequence. At first sight 1 perceive, that I must not search for it in any of the particular qualities of the objects; since, which-ever of these qualities I pitch on, I find some object, that is not possest of it, and yet falls under the denomination of cause or effect. And indeed there is nothing existent, either externally or internally, which is not to be consider'd either as a cause or an effect; tho' 'tis plain there is no one quality, which universally belongs to all beings, and gives them a title to that denomination.

The idea, then, of causation must be deriv'd from some relation among objects; and that relation we must now endeavour to discover. I find in the first place, that whatever objects are consider'd as causes or effects, are contiguous; and that nothing can operate in a time or place, which is ever so little remov'd from those of its existence. Tho' distant objects may sometimes scem productive of each other, they are 
commonly found upon examination to be link'd by a chain of causes, which are contiguous among themselves, and to the distant objects; and when in any particular instance we cannot discover this connexion, we still presume it to exist. We may therefore consider the relation of contiguity as essential to that of causation; at least may suppose it such, according to the general opinion, till we can find a more ${ }^{1}$ proper occasion to clear up this matter, by examining what objects are or are not susceptible of juxtaposition and conjunction:

The second relation I shall observe as essential to causes and effects, is not so universally acknowledg'd, but is liable to some controversy. 'Tis that of PRIORITY of time in the cause before the effect. Some pretend that 'tis not absolutely necessary a cause shou'd precede its effect; but that any object or action, in the very first moment of its existence, may exert its productive quality, and give rise to another object or action, perfectly co-temporary with itself. But beside that experience in most instances seems to contradict this opinion, we may establish the relation of priority by a kind of inference or reasoning. 'Tis an establish'd maxim both in natural and moral philosophy, that an object, which exists for any time in its full perfection without producing another, is not its sole cause; but is assisted by some other principle, which pushes it from its state of inactivity, and makes it exert that energy, of which it was secretly possest. Now if any cause may be perfectly co-temporary with itc effect, 'tis certain, according to this maxim, that key must all of them be so; since any one of them, which retards its operation for a single moment, exerts

\footnotetext{
I Part IV., Sect. V.
} 
not itself at that very individual time, in which it might have operated; and therefore is no proper cause. The consequence of this wou'd be no less than the destruction of that succession of causes, which we observe in the world; and indeed, the utter annihilation of time. For if one cause were co-temporary with its effect, and this effect with its effect, and so on, 'tis plain there iwou'd be no such thing as succession, and all objects must be co-existent.

If this argument appear satisfactory, 'tis well. If not, I beg the reader to allow me the same liberty, which I have us'd in the preceding case, of supposing it such. For he shall find, that the affair is of no great importance.

Having thus discover'd or suppos'd the two relations of contiguity and succession to be essential to causes and effects, I find I am stopt short, and can proceed no farther in considering any single instance. of cause and effect. Motion in one body is regarded upon impulse as the cause of motion in another. When we consider these objects with the utmost attention, we find only that the one body approaches the other; and that the motion of it precedes that of the other, but without any sensible interval. 'Tis in vain to rack ourselves with farther thought and reflexion upon this subject. We can go no farther in consider ing this particular instance.

Shou'd any one leave this instance, and pretend to define a cause, by saying it is something productive of another, 'tis evident he wou'd say nothing. For what does he mean by production? Can he give any detiniion of it, that will not be the same with that of causation? If he can; I des:-2 it may be produc'd. If 
le cannot; he here runs in a circle, and gives a synonimous term instead of a definition.

Shall we then rest contented with these two relations of contiguity and succession, as affording a compleat idea of causation? By no means. An object may be contiguous and prior to another, without being consider'd as its caise. There is a NECESSARY CONNEXion to be taken into consideration; and that relation is of much greater importance, than any of the other two above-mention'd.

Here again I turn the object on all sides, in order to discover the nature of this necessary connexion, and find the impression, or impressions, from which its idea may be deriv'd. When I cast my eye on the known qualities of objects, I immediately discover that the relation of cause and effect depends not in the least on them. When I consider their relations, I can find none but those of contiguity and succession; which I have already regarded as imperfect and unsatisfac. tory. Shall the despair of success make me assert, that I am here possest of an idea, which is not preceded by any similar impression? This wou'd be too strong a proof of levity and inconstancy; since the contrary principle has been already so firmly establish'd, as to admit of no farther doubt; at least, till we have more fully examin'd the present difficulty.

We must, therefore, proceed like those, who being in search of any thing that lies conceal'd from them, and not finding it in the place they expected, beat about all the neighbouring fields, without any certain view or design, in hopes their good fortune will at last guide them to what they search for. 'Tis necessary for us to leave the direct survey of this question concerning the nature of that neccssary connexion, which enters 
into our idea of cause and effect; and endeavour to find some other questions, the examination of which will perhaps afford a hint, that may serve to clear up the present difficulty. Of these questions there occur two, which I shall proceed to examine, viz.

First, For what reason we pronounce it necessary, that every thing whose existence has a beginning, shou'd also have a cause?

Secondly, Why we conclude, that such particular causes must necessarily have such particular effects; and what is the nature of that inference we draw from the one to the other, and of the belicf we repose in it?

I shall only observe before I proceed any farther, that tho' the ideas of cause and effect be deriv'd from the impressions of reflexion as well as from those of sensation, yet for brevity's sake, I commonly mention only the latter as the origin of these ideas; tho' I desire that whatever I say of them may also extend to the former. Passions are connected with their objects and with one another; no less than external bodies are connected together. The same relation, then, of cause and effect, which belongs to one, must be common to all of them. 


\section{Section III.}

\section{Why a cause is always necessary.}

To begin with the first question concerning the necessity of a cause: 'Tis a general maxim in philosophy, that whatever begins to exist, must have a cause of existence. This is commonly taken for granted in all reasonings, without any proof given or demanded. 'Tis suppos'd to be founded on intuition, and to be one of those maxims, which tho' they may be deny'd with the lips, 'tis impossible for men in their hearts really to doubt of. But if we examine this maxim by the idea of knowledge above-explain'd, we shall discover in it no mark of any such intuitive certainty; but on the contrary shall find, that 'tis of a nature quite foreign to that species of conviction.

All certainty arises from the comparison of ideas, and from the discovery of such relations as are unalterable, so long as the ideas continue the same. These relations are resemblance, proportions in quantity and number, degrees of any quality, and contraricty; none of which are imply'd in this proposition, Whatever has a beginning has also a cause of existence. That propcsition therefore is not intuitively certain. At least any one, who wou'd assert it to be intuitively certain, must deny these to be the only infallible relations, and must find some other relation of that kind to be imply'd in it; which it will then be time enough to examine. 
Eut here is an argument, which proves at once, that the foregoing proposition is neither intuitively ror demonstrably certain. We can never demonstrate the necessity of a cause to every new existence, or new modification of existence, without shewing at the same time the impossibility there is, that any thing can ever begin to exist without some productive principle; and where the latter proposition cannot be prov'd, we must despair of ever being able to prove the former. Now that the latter proposition is utterly incapable of a demonstrative proof, we may satisfy ourselves by considering, that as all distinct ideas are separable from each other, and as the ideas of cause and effect are evidently distinct, 'twill be easy for us to conceive any object to be non-existent this moment, and existent the next, without conjoining to it the distinct idea of a cause or productive principle. The separation, therefore, of the idea of a cause from that of a beginning of existence, is plainly possible for the imagination; and consequently the actual separation of these objects is so far possible, that it implies no contradiction nor absurdity; and is therefore incapable of being refuted by any reasoning from mere ideas; without which 'tis impossible to demonstrate the necessity of a cause.

Accordingly we shall find upon examination, that every demonstration, which has been produc'd for the necessity of a cause, is fallacious and sophistical. All the points of time and place, ${ }^{1}$ say some philosophers, in which we can suppose any object to begin to exist, are in themselves equal; and unless there be some cause, which is peculiar to one time and to one place, and which by that means determines and fixes the existence, it must remain in eternal suspence; and

$1 \mathrm{Mr}$. Hobbes. 
the object can never begin to be, for want of some thing to fix its beginning. But I ask; Is there any more difficulty in supposing the time and place to be fix'd without a cause, than to suppose the existence to be determin'd in that manner? The first question that occurs on this subject is always, whether the object shall exist or not: The next, when and where it shall begin to exist. If the removal of a cause be intuitively absurd in the one case, it must be so in the other: And if that absurdity be not clear without a proof in the one case, it will equally require one in the other. The absurdity, then, of the one supposition can never be a proof of that of the other; since they are both upon the same footing, and must stand or fall by the same reasoning.

The second argument, ${ }^{2}$ which I find us'd on this head, labours under an equal difficulty. Every thing, 'tis said, must have a cause; for if any thing wanted a cause, it would produce itself; that is, exist before it existed; which is impossible. But this reasoning is plainly unconclusive; because it supposes, that in our denial of a cause we still grant what we expressly deny, viz. that there must be a cause; which therefore is taken to be the object itself ; and that, no doubt, is an evident contradiction. But to say that any thing is produc'd, or to express myself more properly, comes into existence, without a cause, is not to affirm, that 'tis itself its own cause; but on the contrary in excluding all external causes, excludes a fortiori the thing itself which is created. An object, that exists absolutely without any cause, certainly is not its own cause; and when you assert, that the one follows from the other, you suppose the very point in question, and take 2 Dr. Clarke and others. 
it for granted, that 'tis utterly impossible any thing can ever begin to exist without a cause, but that upon the exclusion of one productive principle, we must still have recourse to another.

'Tis exactly the same case with the ${ }^{1}$ third argument, which has been employ'd to demonstrate the necessity of a cause. Whatever is produc'd without any cause, is produc'd by nothing; or in other words, has nothing for its cause. But nothing can never be a cause, no more than it can be something, or equal to two right angles. By the same intuition, that we perceive nothing not to be equal to two right angles, or not to be something, we perceive, that it can never be a cause; and consequently must perceive, that every object has a real cause of its existence.

I believe it will not be necessary to employ many words in shewing the weakness of this argument, after what I have said of the foregoing. They are all of them founded on the same fallacy, and are deriv'd from the same turn of thought. 'Tis sufficient only to observe, that when we exclude all causes we really do exclude them, and neither suppose nothing nor the object itself to be the causes of the existence; and consequently can draw no argument from the absurdity of these suppositions to prove the absurdity of that exclusion. If every thing must have a cause, it follows, that upon the exclusion of other causes we must accept of the object itself or of nothing as causes. But 'tis the very point in question, whether every thing must have a cause or not; and therefore, according to all just reasoning, it ought never to be taken for granted.

I Mr. Locks. 
They are still more frivolous, who say, that every effect must have a cause, because 'tis imply'd in the very idea of effect. Every effect necessarily pre-supposes a cause; effect being a relative term, of which cause is the correlative. But this does not prove, that every being must be preceded by a cause; no more than it follows, because every husband must have a wife, that therefore every man must be marry'd. The true state of the question is, whether every object, which begins to exist, must owe its existence to a cause; and this I assert neither to be intuitively nor demonstratively certain, and hope to have prov'd it sufficiently by the foregoing arguments.

Since it is not from knowledge or any scientific reasoning, that we derive the opinion of the necessity of a cause to every new production, that opinion must necessarily arise from observation and experience. The next question, then, shou'd naturally be, how experience gives rise to such a principle? But as I find it will be more convenient to sink this question in the following, Why we conclude, that such particular causes must necessarily have such particular effects, and why we form an inference from one to another? we shall make that the subject of our future enquiry. 'Twill, perhaps, be found in the end, that the same answer will serve for both questions.

$\begin{array}{llllll}* & * & * & * & * & * \\ * & * & * & * & * & *\end{array}$




\section{Section XIV.}

\section{Of the idea of necessary connexion.}

Having thus explain'd the manner, in which we reason beyond our immediate impressions, and conclude that such particular causes must have such particular effects; we must now return upon our footsteps to examine that question, which ${ }^{1}$ first occur'd to us, and which we dropt in our way, viz. What is our idea of necessity, when we say that two objects are necessarily connected together. Upon this head I repeat what I have often had occasion to observe, that as we have no idea, that is not deriv'd from an impression, we must find some impression, that gives rise to this idea of necessity, if we assert we have really such an idea. In order to this I consider, in what objects necessity is commonly suppos'd to lie; and finding that it is always ascrib'd to causes and effects, I turn my eye to two objects suppos'd to be plac'd in that relation; and examine them in all the situations, of which they are susceptible. I immediately perceive, that they are contiguous in time and place, and that the object we call cause precedes the other we call effect. In no one instance can I go any farther, nor is it possible for me to discover any third relation betwixt these objects. I therefore enlarge my view to comprehend several instances; where I find like objects always existing in like relations of contiguity and succession. At first sight this seems to serve but lit.?

1 Sect. 2. 
to my purpose. The reflection on several instances only repeats the same objects; and therefore can never give rise to a new idea. But upon farther enquiry I find, that the repetition is not in every particular the same, but produces a new impression, and by that means the idea, which I at present examine. For after a frequent repetition, I find, that upon the appearance of one of the objects, the mind is determin'd by custom to consider its usual attendant, and to consider it in a stronger light upon account of its relation to the first object. 'Tis this impression, then, or determination, which affords me the idea of necessity.

I doubt not but these consequences will at first sight be receiv'd without difficulty, as being evident deductions from principles, which we have already establish'd, and which we have often employ'd in our reasonings. This evidence both in the first principles, and in the deductions, may seduce us unwarily into the conclusion, and make us imagine it contains nothing extraordinary, nor worthy of our curiosity. But tho' such an inadvertence may facilitate the reception of this reasoning, 'twill make it be the more easily forgot; for which reason I think it proper to give warning, that I have just now examin'd one of the most sublime questions in philosophy, viz. that concerning the power and efficacy of causes; where all the sciences seem so much interested. Such a warning will naturally rouze up the attention of the reader, and make him desire a more full account of my doctrine, as well as of the arguments, on which it is founded. This request is so reasonable, that I cannot refuse complying with it; especially as I am hopeful that these principles, the more they are examin'd, will acquire the more force and evidence. 
There is no question, which on account of its importance, as well as difficulty, has caus'd more disputes both among antient and modern philosophers, than this concerning the efficacy of causes, or that quality which makes them be followed by their effects. But before they enter'd upon these disputes, methinks it wou'd not have been improper to have examin'd what idea we have of that efficacy, which is the subject of the controversy. This is what I find principally wanting in their reasonings, and what I shall here endeavour to supply.

I begin with observing that the terms of efficacy, agency, power, force, energy, necessity, comexion, and productive quality, are all nearly synonimous; and therefore 'tis an absurdity to employ any of them in defining the rest. By this observation we reject at once all the vulgar definitions, which philosophers have given of power and efficacy; and instead of searching for the idea in these definitions, must look for it in the impressions, from which it is originally deriv'd. If it be a compound idea, it must arise from compound impressions. If simple, from simple impressions.

I believe the most general and most popular explication of this matter, is to say, ${ }^{1}$ that finding from experience, that there are several new productions in matter, such as the motions and variations of body, and concluding that there must somewhere be a power capable of producing them, we arrive at last by this reasoning at the idea of power and efficacy. But to be convinc'd that this explication is more popular than philosophical, we need but reflect on two very obvious principles. First, That reason alone can never give rise to any original idea, and secondly, that reason, as

1 See Mr. Locke; chanter of Power. 
distinguish'd from experience, can never make us conclice, that a cause or productive quality is absolutely requisite to every beginning of existence. Both these considerations have been sufficiently explain'd; and therefore shall not at present be any farther insisted on.

I shall only infer from them, that since reason can never give rise to the idea of efficacy, that idea must be deriv'd from experience, and from some particular instances of this efficacy, which make their passage into the mind by the common channels of sensation or reflection. Ideas always represent their objects or impressions; and vice versa, there are some objects necessary to give rise to every idea. If we pretend, therefore, to have any just idea of this efficacy, we must produce some instance, wherein the efficacy is plainly discoverable to the mind, and its operations obvious to our consciousness or sensation. By the refusal of this, we acknowledge, that the idea is impossible and imaginary; since the principle of innate ideas, which alone can save us from this dilemma, has been already refuted, and is now almost universally rejected in the learned world. Our present business, then, must be to find some natural production, where the operation and efficacy of a cause can be clearly conceiv'd and comprehended by the mind, without any danger of obscurity or mistake.

In this research we meet with very little encouragement from that prodigious diversity, which is found in the opinions of those philosophers, who have pretended to explain the secret force and energy of causes. ${ }^{1}$ There are some, who maintain, that bodies operate by

1 See Father Malbranche, Book VI., Part II., chap. 3, and the illustrations upon it. 
their substantial form; others, by their accidents or qualities; several, by their matter and form; some, by their form and accidents; others, by certain virtues and faculties distinct from ail this. All these sentiments again are mix'd and vary'd in a thousand different ways; and form a strong presumption, that none of them have any solidity or evidence, and that the supposition of an efficacy in any of the known qualities of matter is entirely without foundation. This presumption must encrease upon us, when we consider, that these principles of substantial forms, and accidents, and faculties, are not in reality any of the known properties of bodies, but are perfectly unintelligible and inexplicable. For 'tis evident philosophers wou'd never have had recourse to such obscure and uncertain principles had they met with any satisfaction in such as are clear and intelligible; especially in such an affair as this, which must be an object of the simplest understanding, if not of the senses. Upon the whole, we may conclude, that 'tis impossible in any one instancer to shew the principle, in which the force and agency of a cause is plac'd ; and that the most refin'd and most vulgar understandings are equally at a loss in this particular. If any one think proper to refute this assertion, he need not put himself to the trouble of inventing any long reasonings; but may at once shew us an instance of a cause, where we discover the power or operating principle. This defiance we are oblig'd frequently to make use of, as being almost the only means of proving a negative in philosophy.

The small success, which has been met with in all the attempts to fix this power, has at last oblig'd philosophers to conclude, that the ultimate force and efficacy of nature is perfectly unknown to us, and that 
'tis in vain we search for it in all the known qualities of rnatter. In this opinion they are almost unanimous; and 'tis only in the inference they draw from it, that they discover any difference in their sentiments. For some of them, as the Cartesians in particular, having establish'd it as a principle, that we are perfectly acquainted with the essence of matter, have very naturally inferr'd, that it is endow'd with no efficacy, and that 'tis impossible for it of itself to communicate motion, or produce any of those effects, which we ascribe to it. As the essence of matter consists in extension, and as extension implies not actual motion, but only mobility; they conclude, that the energy, which produces the motion, cannot lie in the extension.

This conclusion leads them into another, which they regard as perfectly unavoidable. Matter, say they, is in itself entirely unactive, and depriv'd of any power, by which it may produce, or continue, or communicate motion: But since these effects are evident to our senses, and since the power, that produces them, must be plac'd somewhere, it must lie in the DeITy, or that divine being, who contains in his nature all excellency and perfection. 'Tis the deity, therefore, who is the prime mover of the universe, and who not only first created matter, and gave it it's original impulse, but likewise by a continu'd exertion of omnipotence, supports its existence, and successively bestows on it all those motions, and configurations, and qualities, with which it is endow'd.

This opinion is certainly very curious, and well worth our attention; but 'twill appear superfluous to examine it in this place, if we reflect a moment on our present purpose in taking notice of it. We have establish'd it as a principle, that as all ideas are deriv'd 
from impressions, or some precedent perceptions, 'tis impossible we can have any idea of power and efficacy, unless some instances can be produc'd, wherein this power is perceiv'd to exert itself. Now as these instances can never be discover'd in body, the Cartesians, proceeding upon their principle of innate ideas, have had recourse to a supreme spirit or deity, whom they consider as the only active being in the universe, and as the immediate cause of every alteration in matter. But the principle of innate ideas being allow'd to be false, it follows, that the supposition of a deity can serve us in no stead, in accounting for that idea of agency, which we sarch for in vain in all the objects which are presented to our senses, or which we are internally conscious of in our own minds. For if every idea be deriv'd from an impression, the idea of a deity proceeds from the same origin; and if no impression, either of sensation or reflection, implies any force or efficacy, 'tis equally impossible to discover or even imagine any such active principle in the deity. Since these philosophers, therefore, have concluded, that matter cannot be endow'd with any efficacious principle, because 'tis impossible to discover in it such a principle; the same course of reasoning shou'd determine them to exclude it from the supreme being. Or if they esteem that opinion absurd and impious, as it really is, I shall tell them how they may avoid it; and that is, by concluding from the very first, that they have no adequate idea of power or efficacy in any object; since neither in body nor spirit, neither in superior nor inferior natures, are they able to discover one single instance of it.

The same conclusion is unavoidable upon the hypothesis of those, who maintain the efficacy of second 
causes, and attribute a derivative, but a real power and energy to matter. For as they confess, that this energy lies not in any of the known qualities of matter, the difficulty still remains concerning the origin of its idea. If we have really an idea of power, we may attribute power to an unknown quality: But as 'tis impossible, that that idea can be deriv'd from such a quality, and as there is nothing in known qualities, which can produce it; it "follows that we deceive ourselves, when we imagine we are possest of any idea of this kind, after the manner we commonly understand it. All ideas are deriv'd from, and represent impressions. We never have any impression, that contains any power or efficacy. We never therefore have any idea of power.

It has been establish'd as a certain principle, that general or abstract ideas are nothing but individual ones taken in a certain light, and that, in reflecting on any object, 'tis as impossible to exclude from our thought all particular degrees of quantity and quality as from the real nature of things. If we be possest, therefore, of any idea of power in general, we must also be able to conceive some particular species of it; and as power cannot subsist alone, but is always regarded as an attribute of some being or existence, we must be able to place this power in some particular being, and conceive that being as endow'd with a real force and energy, by which such a particular effect necessarily results from its operation. We must distinctly and particularly conceive the connexion betwixt the cause and effect, and be able to pronounce, from a simple view of the one, that it must be follow'd or preceded by the other. This is the true manner of conceiving a particular power in a particular body: and a general idea being impossible without an indi- 
vidual; where the latter is impossible, 'tis certain the former can never exist. Now nothing is more evident, than that the human mind cannot form such an idea of two objects, as to conceive any connexion betwixt them, or comprehend distinctly that power and efficacy, by which they are united. Such a connexion wou'd amount to a demonstration, and wou'd imply the absolute impossibility for the one object not to follow, or to be conceiv'd not to follow upon the other: Which kind of connexion has already been rejected in all cases. If any one is of a contrary opinion, and thinks he has attain'd a notion of power in any particular object, I desire he may point out to me that object. But till I meet with such-a-one, which I despair of, I cannot forbear concluding, that since we can never distinctly conceive how any particular power can possibly reside in any particular object, we deceive ourselves in imagining we can form any such general idea.

Thus upon the whole we may infer, that when we talk of any being, whether of a superior or inferior nature, as endow'd with a power or force, proportion'd to any effect; when we speak of a necessary connexion betwixt objects, and suppose, that this connexion depends upon an efficacy or energy, with which any of these objects are endow'd; in all these expressions, so $a p p l y$ 'd, we have really no distinct meaning, and make use only of common words, without any clear and determinate ideas. But as 'tis more probable, that these expressions do here lose their true meaning by being zurong apply'd, than that they never have any meaning; 'twill be proper to bestow another consideration on this subject, to see if possibly we car discover the nature and origin of those ideas, we anne to them. 
Suppose two objects to be presented to us, of which the one is the cause and the other the effect; 'tis plain, that from the simple consideration of one, or both these objects we never shall perceive the tie, by which they are united, or be able certainly to pronounce, that there is a connexion betwixt them. 'Tis not, therefore, from any, one instance, that we arrive at the idea of cause and effect, of a necessary connexion of power, of force, of energy, and of efficacy. Did we never see any but particular conjunctions of objects, entirely different from each other, we shou'd never be able to form any such ideas.

But again; suppose we observe several instances, in which the same objects are always conjoin'd together, we immediately conceive a connexion betwixt them, and begin to draw an inference from one to another. This multiplicity of resembling instances, therefore, constitutes the very essence of power or connexion, and is the source, from which the idea of it arises. In order, then, to understand the idea of power, we must consider that multiplicity; nor do I ask more to give a solution of that difficulty, which has so long perplex'd us. For thus I reason. The repetition of perfectly similar instances can never alone give rise to an original idea, different from what is to be found in any particular instance, as has been observ'd, and as evidently follows from our fundamental principle, that all ideas are copy'd from impressions. Since therefore the idea of power is a new original idea, not to be found in any one instance, and which jet arises from the repetition of several instances, it follows, that the repetition alone has not that effect, bi:t must either discover or produce something new, which is the source of that idea. Did the repetition 
neither discover nor produce any thing new, our ideas might be multiply'd by it, but wou'd not be enlarg'd above what they are upon the observation of one single instance. Every enlargement, therefore, (such as the idea of power or connexion) which arises from the multiplicity of similar instances, is copy'd from some effects of the multiplicity, and will be perfectly understood by understanding these effects. Wherever we find any thing new to be discover'd or produc'd by the repetition, there we must place the power, and must never look for it in any other object.

But 'tis evident, in the first place, that the repetition of like objects in like relations of succession and contiguity discovers nothing new in any one of them; since we can draw no inference from it, nor make it a subject either of our demonstrative or probable reasonings ; ${ }^{1}$ as has been already prov'd. Nay suppose we cou'd draw an inference, 'twou'd be of no consequence in the present case; since no kind of reasoning can give rise to a new idea, such as this of power is; but wherever we reason, we must antecedently be possest of clear ideas, which may be the objects of our reasoning. The conception always precedes the understanding ; and where the one is obscure, the other is uncertain; where the one fails, the other must fail also.

Secondly, 'Tis certain that this repetition of similar objects in similar situations produces nothing new either in these objects, or in any external body. For 'twill readily be allow'd, that the several instances we have of the conjunction of resembling causes and effects are in themselves entirely independent, and that the communication of motion, which I see result at present from the shock of two billiard-balls, is totally

1 Sect. 6. 
distinct from that which I saw result from sucil an impulse a twelve-month ago. These impulses have no influence on each other. They are entirely divided by time and place; and the one might have existed and communicated motion, tho' the other never had been in being.

There is, then, nothing new either discover'd or produc'd in any objects by their constant conjunction, and by the uninterrupted resemblance of their relations of succession and contiguity. But 'tis from this resemblance, that the ideas of necessity, of power, and of efficacy, are deriv'd. These ideas, therefore, represent not any thing, that does or can belong to the objects, which are constantly conjoin'd. This is an argument, which, in every view we can examine it, will be found perfectly unanswerable. Similar in. stances are still the first source of our idea of power or necessity; at the same time that they have no influence by their similarity either on each other, or on any external object. We must therefore, turn ourselves to some other quarter to seek the origin of that idea.

Tho' the several resembling instances, which give rise to the idea of power, have no influence on each other, and can never produce any new quality in the object, which can be the model of that idea, yet the observation of this resemblance produces a new impression in the mind, which is its real model. For after we have observ'd the resemblance in a sufficient number of instances, we immediately feel a determination of the mind to pass from one object to its usual attendant, and to conceive it in a stronger light upon account of that relation. This determination is the only effect of the resemblance; and therefore must be the same with power or efficacy, whose idea is de- 
riv'd from the resemblance. The several instances of resembling conjunctions lead us into the notion of power and necessity. These instances are in themselves totally distinct from each other, and have no union but in the mind, which observes them, and collects their ideas. Necessity, then, is the effect of this observation, and is nothing but an internal impression of the mind, or a determination to carry our thoughts from one object to another. Without considering it in this view, we can never arrive at the most distant notion of it, or be able to attribute it either to external or internal objects, to spirit or body, to causes or effects.

The necessary connexion betwixt causes and effects is the foundation of our inference from one to the other. The foundation of our inference is the transition arising from the accustom'd union. These are, therefore, the same.

The idea of necessity arises from some impression. There is no impression convey'd by our senses, which can give rise to that idea. It must, therefore, be deriv'd from some internal impression, or impression of reflexion. There is no internal impression, which has any relation to the present business, but that propensity, which custom produces, to pass from an object to the idea of its usual attendant. This therefore is the essence of necessity. Upon the whole, necessity is something, that exists in the mind, not in objects; nor is it possible for us ever to form the most distant idea of it, consider'd as a quality in bodies. Either we have no idea of necessity, or necessity is nothing but that determination of the thought to pass from causes to effects and from effects to causes, according to their experienc'd union. 
Thus as the necessity, which makes two times two equal to four, or three angles of a triangle equal to two right ones, lies only in the act of the understanding, by which we consider and compare these ideas; in like manner the necessity or power, which unites causes and effects, lies in the determination of the mind to pass from the one to the other. The efficacy or energy of causes is neither plac'd in the causes themselves, nor in the deity, nor in the concurrence of these two principles; but belongs entirely to the soul, which considers the union of two or more objects in all past instances. 'Tis here that the real power of causes is plac'd, along with their connexion and necessity.

I am sensible, that of all the paradoxes, which I have had, or shall hereafter have occasion to advance in the course of this treatise, the present one is the most violent, and that 'tis merely by dint of solid proof and reasoning I can ever hope it will have admission, and overcome the inveterate prejudices of mankind. Before we are reconcil'd to this doctrine, how often must we repeat to ourselves, that the simple view of any two objects or actions, however related, can never give us any idea of power, or of a connexion betwixt them: that this idea arises from the repetition of their union: that the repetition neither discovers nor causes any thing in the objects, but has an influcnce only on the mind, by that customary transition it produces: that this customary transition is, therefore, the same with the power and necessity; which are consequently qualities of perceptions, not of objects, and are internally felt by the soul, and not perceiv'd externally in bodies? There is commonly an astonishment attendin every thing extraordinary; and this astonish- 
ment changes immediately into the highest degree of esteem or contempt, accorling as we approve or disapprove of the subject. I am much afraid, that tho' the foregoing reasoning appears to me the shortest and most decisive imaginable; yet with the generality of readers the biass of the mind will prevail, and give them a prejudice against the present doctrine.

This contrary biass is easily accounted for. 'Tis a common observation, that the mind has a great propensity. to spread itself on external objects, and to conjoin with them any internal impressions, which they occasion, and which always make their appearance at the same time that these objects discover themselves to the senses. Thus as certain sounds and smells are always found to attend certain visible objects, we naturally imagine a conjunction, even in place, betwixt the objects and qualities, tho' the qualities be of such a nature as to admit of no such conjunction, and really exist no where. But of this more fully ${ }^{1}$ hereafter. Mean while 'tis sufficient to observe, that the same propensity is the reason, why we suppose necessity and power to lie in the objects we consider, not in our mind, that considers them; notwithstanding it is not possible for us to form the most distant idea of that quality, when it is not taken for the determination of the mind, to pass from the idea of an object to that of its usual attendant.

But tho' this be the only reasonable account we can give of necessity, the contrary notion is so riveted in the mind from the principles above-mention'd, that I doubt not but my sentiments will be treated by many as extravagant and ridiculous. What! the efficacy of causes lie in the determination of the mind! As if

1 Part IV., Sect. 5. 
causes did not operate entirely indepencient of the mind, and wou'd not continue their operation, even tho' there was no mind existent to contemplate them, or reason concerning them. Thought may well depend on causes for its operation, but not causes on thought. This is to reverse the order of nature, and make that secondary, which is really primary. To every operation there is a power proportion'd; and this power must be plac'd on the body, that operates. If we remove the power from one cause, we must ascribe it to another: But to remove it from all causes, and bestow it on a being, that is no ways related to the cause or effect, but by perceiving them, is a gross absurdity, and contrary to the most certain principles of human reason.

I can only reply to all these arguments, that the case is here much the same, as if a blind man shou'd pretend to find a great many absurdities in the supposition, that the colour of scarlet is not the same with the sound of a trumpet, nor light the same with solidity. If we have really no idea of a power or efficacy in any object, or of any real connexion betwixt causes and effects, 'twill be to little purpose to prove, that an efficacy is necessary in all operations. We do not understand our own meaning in talking so, but ignorantly confound ideas, which are entirely distinct from each other. I am, indeed, ready to allow, that there may be several qualities both in material and immaterial objects, with which we are utterly unacquainted; and if we please to call these power or efficacy, 'twill be of little. consequence to the world. But when, instead of meaning these unknown qualitics, we make the terms of power and efficacy signify someining, of which we have a clear idea, and which is 
incompatible with those objects, to which we apply it, obscurity and error begin then to take place, and we are led astray by a false philosophy. This is the case, when we transfer the determination of the thought to external objects, and suppose any real intelligible connexion betwixt them; that being a quality, which can only belong to the mind that considers them.

As to what may be said, that the operations of nature are independent of our thought and reasoning, I allow it; and accordingly have observ'd, that objects bear to each other the relations of contiguity and succession; that like objects may be observ'd in several instances to have like relations; and that all this is independent of, and antecelent to the operations of the understanding. But if we go any farther, and ascribe a power or necessary connexion to these objects; this is what we can never observe in them, but must draw the idea of it from what we feel internally in contemplating them. And this I carry so far, that I am ready to convert my present reasoning into an instance of it, by a subtility, which it will not be difficult to comprehend.

When any object is presented to us, it immediately conveys to the mind a lively idea of that object, which is usually found to attend it; and this determination of the mind forms the necessary connexion of these objects. But when we change the point of view, from the objects to the perceptions; in that case the impression is to be considered as the cause, and the lively idea as the effect; and their necessary connexion is that new determination, which we feel to pass from the idea of the one to that of the other. The uniting principle among our internal perceptions is as unintelligible as that among external objects, and is not 
known to us any other way than by experience. Now the nature and effects of experience have been already sufficiently examin'd and explain'd. It never gives us any insight into the internal structure or operating principle of objects, but only accustoms the mind to pass from one to another.

'Tis now time to collect all the different parts of this reasoning, and by joining them together form an exact definition of the relation of cause and effect, which makes the subject of the present enquiry. This order wou'd not have been excusable, of first examining our inference from the relation before we had explain'd the relation itself, had it been possible to proceed in a different method. But as the nature of the relation depends so much on that of the inference, we have been oblig'd to advance in this seemingly preposterous manner, and make use of terms before we were able exactly to define them, or fix their meaning. We shall now correct this fault by giving a precise definition of cause and effect.

There may two definitions be given of this relation, which are only different, by their presenting a different view of the same object, and making us consider it either as a philosophical or as a natural relation; either as a comparison of two ideas, or as an association betwixt them. We may define a CAUSE to be "An object precedent and contiguous to another, and where all the objects resembling the former are plac'd in like relations of precedency and contiguity to those objects, that resemble the latter.' If this definition be esteem'd defective, because drawn from objects foreign to the cause, we may substitute this other definition in its place, riz. 'A CAUSE is an object precedent and contiguous to another, and so united with it, that the idea 
of the one determines the mind to form the idea of the other, and the impression of the one to form a more lively idea of the other.' Shou'd this definition tlso be rejected for the same reason, I know no other - emedy, than that the persons, who express this delicacy, should substitute a juster definition in its place. But for my part I must own my incapacity for such an undertaking. When I examine with the utmost accuracy those objects, which are commonly denominated causes and effects, I find, in considering a single instance, that the one object is precedent and contiguous to the other; and in inlarging my view to consider several instances, I find only, that like objects are constantly plac'd in like relations of succession and contiguity. Again, when I consider the influence of this constant conjunction, I perceive, that such a relation can never be an object of reasoning, and can never operate upon the mind, but by means of custom, which determines the imagination to make a transition from the idea of one object to that of its usual attendant, and from the impression of one to a more lively idea of the other. However extraordinary these sentiments may appear, I think it fruitless to trouble myself with any farther enquiry or reasoning upon the subject, but shall repose myself on them as on establish'd maxims.

'Twill only be proper, before we leave this subject, to draw some corollaries from it, by which we may remove several prejudices and popular errors, that have very much prevail'd in philosophy. First,"We may learn from the foregoing doctrine, that all causes are of the same kind, and that in particular there is no foundation for that distinction, which we sometimes make betwixt efficient causes, and causes sine qua non; or betwixt efficient causes, and formal, and material, 
and exemplary, and final causes. For as our idea of efficiency is deriv'd from the constant conjunction of two objects, wherever this is observ'd, the cause is efficient; and where it is not, there can never be a cause of any kind. For the same reason we must reject the distinction betwixt cause and occasion, when suppos'd to signify any thing essentially different from each other. If constant conjunction be imply'd in what we call occasion, 'tis a real cause. If not, 'tis no relation at all, and cannot give rise to any argument or reasoning.

Secondly, The same course of reasoning will make us conclude, that there is but one kind of necessity, as there is but one kind of cause, and that the common distinction betwixt moral and physical necessity is without any foundation in nature. This clearly appears from the precedent explication of necessity. 'Tis the constant conjunction of objects, along with the determination of the mind, which constitutes a physical necessity: And the removal of these is the same thing with chance. As objects must either be conjoin'd or not, and as the mind must either be determin'd or not to pass from one object to another, 'tis impossible to admit of any medium betwixt chance and an absolute necessity. In weakening this conjunction and determination you do not change the nature of the necessity; since even in the operation of bodies, these have different degrees of constancy and force, without producing a different species of that relation.

The distinction, which we often make betwixt power and the exercise of it, is equally without foundation.

Thirdly, We may now be able fully to overcome all that repugnance, which 'tis so natural for us to 
entertain against the foregoing reasoning, by which we endeavour'd to prove, that the necessity of a cause to every beginning of existence is not founded on any arguments either demonstrative or intuitive. Such an opinion will not appear strange after the foregoing definitions. If we define a cause to be an object precedent and contiguous. to another, and where all the objects rescmbling 'the former are plac'd in a like relation of priority and contiguity to those objects, that resemble the latter; we may easily conceive, that there is no absolute nor metaphysical necessity, that every beginning of existence shou'd be attended with such an object. If we define a cause to be, An object precedent and contiguous to another, and so united with it in the imagination, that the idea of the one determines the mind to form the idea of the other, and the impression of the one io form a more lively idea of the other; we shall make still less difficulty of assenting to this opinion. Such an influence on the mind is in itself perfectly extraordinary and incomprehensible; nor can we be certain of its reality, but from experience and observation.

I shall add as a fourth corrollary, that we can never have reason to believe that any object exists, of which we cannot form an idea. For as all our reasonings concerning existence are deriv'd from causation, and as all our reasonings concerning causation are deriv'd from the experienc'd conjunction of objects, not from any reasoning or reflexion, the same experience must give us a notion of these objects, and must remove all mystery from our conclusions. This is so evident, that 'twou'd scarce have merited our attention, were it not to obviate certain objections of this kind, which might arise against the following reasonings concern- 
ing matter and substance. I need not observe, that a full knowledge of the object is not requisite, but only of those qualities of it, which we believe to exist. 



\section{THE DOCTRINE OF SUBSTANCE}

\section{SELECTIONS FROM}

BOOK I., PARTS I., II., IV. 



\section{PART I.}

OF IDEAS, THEIR ORIGIN, COMPOSITION, CONNEXION, ABSTRACTION.

$\begin{array}{llllll}* & * & * & * & * & * \\ * & * & * & * & * & *\end{array}$

\section{Section VI.}

Of modes and substances.

I wou'd fain ask those philosophers, who found so much of their reasonings on the distinction of substance and accident, and imagine we have clear ideas of each, whether the idea of substance be deriv'd from the impressions of sensation or reflexion? If it be convey'd to us by our senses, I ask, which of them; and after what manner? If it be perceiv'd by the eyes, it must be colour; if by the ears, a sound; if by the palate, a taste; and so of the other senses. But I believe none will assert, that substance is either a colour, or sound, or a taste. The idea of substance must therefore be deriv'd from an impression of reflexion, if it really exist. But the impressions of reflexion resolve themselves into our passions and emotions; none of which can possibly represent a substance. We have therefore no idea of substance, distinct from that of a collection of particular qualities. nor have we any other meaning when we either talk or reason concerning it.

The idea of a substance as well as that of a mode, is nothing but a collection of simple ideas, that are united by the imagination, and have a particular name 
assigned them, by which we are able to recall, either to ourselves or others, that collection. But the difference betwixt these ideas consists in this, that the particular qualities, which form a substance, are commonly refer'd to an unknown something, in which they are supposed to inhere; or granting this fiction should not take place, are at least supposed to be closely and inseparably connected by the relations of contiguity and causation. The effect of this is, that whatever new simple quality we discover to have the same connexion with the rest, we immediately comprehend it among them, even tho' it did not enter into the first conception of the substance. Thus our idea of gold may at first be a yellow colour, weight, malleableness, fusibility; but upon the discovery of its dissolubility in aqua regia, we join that to the other qualities, and suppose it to belong to the substance as much as if its idea had from the beginning made a part of the compound one. The principle of union being regarded as the chief part of the complex idea, gives entrance to whatever quality afterwards occurs, and is equally comprehended by it, as are the others, which first presented themselves.

That this cannot take place in modes, is evident from considering their nature. The simple ideas of which modes are formed, either represent qualities, which are not united by contiguity and causation, but are dispers'd in different subjects; or if they be all united together, the uniting principle is not regrarded as the foundation of the complex idea. The idea of a dance is an instance of the first kind of modes; that of beauty of the second. The reason is obvious, why such complex ideas cannot receive any new idea, without changing the name, which distinguishes the mode. 


\section{PART II.}

OF THE IDEAS OF SPACE AND TIME.

$\begin{array}{llllll}* & * & * & * & * & * \\ * & * & * & * & * & *\end{array}$

\section{Section VI.}

Of the idea of cristence, and of external existence.

It may not be amiss, before we leave this subject, to explain the ideas of existence and of external existence; which have their difficulties, as well as the ideas of space and time. By this means we shall be the better prepar'd for the examination of knowledge and probability, when we understand perfectly all those particular ideas, which may enter into our reasoning.

There is no impression nor idea of any kind, of which we have any consciousness or memory, that is not conceiv'd as existent; and 'tis evident, that from this consciousness the most perfect idea and assurance of being is deriv'd. From hence we may form a dilemma, the most clear and conclusive that can be imarin'd, viz. that since we never remember any idea or impression without attributing existence to it, the idea of existence must either be deriv'd from a distinct impression, conjoin'd with every perception or object of our thought, or must be the very same with the idea of the perception or object.

As this dilemma is an evident consequence of the principle, that every idea arises from a similar impres- 
sion, so our decision betwixt the propositions of the dilemma is no more doubtful. So far from there being any distinct impression, attending every impression and every idea, that I do not think there are any two distinct impressions, which are inseparably conjoin'd. Tho' certain sensations may at one time be united, we quickly find they admit of a separation, and may be presented apart. And thus, tho' every impression and idea we remember be consider'd as existent, the idea of existence is not deriv'd from any particular impression.

The idea of existence, then, is the very same with the idea of what we conceive to be existent. To reflect on any thing simply, and to reflect on it as existent, are nothing different from each other. That idea, when conjoin'd with the idea of any object, makes no addition to it. Whatever we conceive, we conceive to be existent. Any idea we please to form is the idea of a being; and the idea of a being is any idea we please to form.

Whoever opposes this, must necessarily point out that distinct impression, from which the idea of entity is deriv'd, and must prove, that this impression is inseparable from every perception we believe to be existent. This we may without hesitation conclude to be impossible.

Our foregoing ${ }^{1}$ reasoning concerning the distinction of ideas without any real difference will not here serve us in any stead. That kind of distinction is founded on the different resemblances, which the same simple idea may have to several different ideas. But no object can be presented resembling some object with respect to its existence, and different from others

1 Part I., Sect. 7. 
in the same particular; since every object, that is presented, must necessarily be existent.

A like reasoning will account for the idea of external existence. We may observe, that 'tis universally allow'd by philosophers, and is besides pretty obvious of itself, that nothing is ever really present with the mind but its perceptions or impressions and ideas, and that external objects become known to us only by those perceptions they occasion. To hate, to love, to think, to feel, to see; all this is nothing but to perceive.

Now since nothing is ever present to the mind but perceptions, and since all ideas are deriv'd from something antecedently present to the mind; it follows, that 'tis impossible for us so much as to conceive or form an idea of any thing specifically different from ideas and impressions. Let us fix our attention out of ourselves as much as possible: Let us chace our imagination to the heavens, or to the utmost limits of the universe; we never really advance a step beyond ourselves, nor can conceive any kind of existence, but those perceptions, which have appear'd in that narrow compass. This is the universe of the imagination, nor have we any idea but what is there produc'd.

The farthest we can go towards a conception of external objects, when suppos'd specifically different from our perceptions, is to form a relative idea of them, without pretending to comprehend the related objects. Generally speaking we do not suppose them specifically different; but only attribute to them different relations, connexions and durations. But of this more fully hereafter. ${ }^{1}$

$\begin{array}{llllll}* & * & * & * & * & * \\ * & * & * & * & * & *\end{array}$

1 Yrart IV., Sect. 2. 


\section{PART IV.}

\section{OF THE SCEPTICAL AND OTHER SYSTEMS}

OF PHILOSOPHY.

$\begin{array}{cccccc}* & * & * & * & * & * \\ * & * & * & * & * & * \\ & & \text { Section } & \text { II. } & & \end{array}$

Of scepticism arith regard to the senses.

Thus the sceptic still continues to reason and believe, even tho' he asserts, that he cannot defend his reason by reason; and by the same rule he must assent to the principle concerning the existence of body, tho' he cannot pretend by any arguments of philosophy to maintain its veracity. Nature has not left this to his choice, and has doubtless esteem'd it an affair of too great importance to be trusted to our uncertain reasonings and speculations. We may well ask, What causes induce us to believe in the existence of body? but 'tis vain to ask, Whether there be body or not? That is a point, which we must take for granted in all our reasonings.

The subject, then, of our present enquiry is concerning the causes which induce us to believe in the existence of body; and my reasonings on this head I shall begin with a distinction, which at first sight may seem superfluous, but which will contribute very much to the perfect understanding of what follows. We cught to examine apart those two questions, which are commonly confounded together, viz. Why we attribute a CONTINU'D existence to objects, even when they are 
not present to the senses; and why we suppose them to have an existence DISTINCT from the mind and perception. Under this last head I comprehend their situation as well as relations, their external position as well as the independence of their existence and operation. These two questions concerning the continu'd and distinct existence of body are intimately connected together. For if the objects of our senses continue to exist, even when they are not perceiv'd, their existence is of course independent of and distinct from the perception; and vice versa, if their existence be independent of the perception and distinct from it, they must continue to exist, even tho' they be not perceiv'd. But tho' the decision of the one question decides the other; yet that we may the more easily discover the principles of human nature, from whence the decision arises, we shall carry along with us this distinction, and shall consider, whether it be the senses, reason, or the imagination, that produces the opinion of a continu d or of a distinct existence. These are the only questions, that are intelligible on the present subject. For as to the notion of external existence, when taken for something specifically different from our perceptions, ${ }^{1}$ we have already shewn its absurdity.

To begin with the sEnses, 'tis evident these faculties are incapable of giving rise to the notion of the continu'd existence of their objects, after they no longer appear to the senses. For that is a contradiction in terms, and supposes that the senses continue to operate, even after they have ceas'd all manner of operation. These faculties, therefore, if they have any influence in the present case, must produce the opinion

1 Part II., Sect. 6. 
of a distinct, not of a continu'd existence; and in order to that, must present their impressions either as images and representations, or as these very distinct and external existences.

That our senses offer not their impressions as the images of something distinct, or independent, and external, is evident; because they convey to us nothing but a single perception, and never give us the least intimation of any thing beyond. A single perception can never produce the idea of a double existence, but by some inference either of the reason or imagination. When the mind looks farther than what immediately appears to it, its conclusions can never be put to the account of the senses; and it certainly looks farther, when from a single perception it infers a double existence, and supposes the relations of resemblance and causation betwixt them.

2 $*$

$\approx$

But tho' we are led after this manner, by the natural propensity of the imagination, to ascribe a continu'd existence to those sensible objects or perceptions, which we find to resemble each other in their interrupted appearance; yet a very little reflection and philosophy is sufficient to make us perceive the fallacy of that opinion. I have already observ'd, that there is an intimate connexion betwixt those two principles, of a continu'd and of a distinct or independent existence, and that we no sooner establish the one than the other follows, as a necessary consequence. 'Tis the opinion of a continu'd existence, which first takes place, and without much study or reflection draws the other along with it, wherever the mind follows its first and 
most natural tendency. But when we compare experiments, and reason a little upon them, we quickly perceive, that the doctrine of the independent existence 'of our sensible perceptions is contrary to the plainest experience. This leads us backward upon our footsteps to perceive our error in attributing a continu'd existence to our perceptions, and is the origin of many very curious opinions, which we shall here endeavour to account for.

'Twill first be proper to observe a few of those experiments, which convince us, that our perceptions are not possest of any independent existence. When we press one eye with a finger, we immediately perceive all the objects to become double, and one half of them to be remov'd from their common and natural position. But as we do not attribute a continu'd existence to both these perceptions, and as they are both of the same nature, we clearly perceive, that all our perceptions are dependent on our organs, and the disposition of our nerves and animal spirits. This opinion is confirm'd by the seeming encrease and diminution of objects, according to their distance; by the apparent alterations in their figure; by the changes in their colour and other qualities from our sickness and distempers; and by an infinite number of other experiments of the same kind; from all which we learn, that our sensible perceptions are not possest of any distinct or independent existence.

The natural consequence of this reasoning shou'd be, that our perceptions have no more a continu'd than an independent existence; and indeed philosophers have so far run into this opinion, that they change their system, and distinguish, (as we shall do for the future) betwixt perceptions and objects, of which the 
former are suppos'd to be interrupted, and perishing, and different at every different return; the latter to be uninterrupted, and to preserve a continu'd existence and identity. But however philosophical this new system may be esteem'd, I assert that 'tis only a palliative remedy, and that it contains all the difficulties of the vulgar system, with some others, that are peculiar to itself. There are no principles either of the understanding or fancy, which lead us rirectly to embrace this opinion of the double existeno $;$ perceptions and objects, nor can we arrive at it ii t $t$ by passing thro' the common hypothesis of the identity and continuance of our interrupted perceptions. Were we not first perswaded, that our perceptions are our only objects, and continue to exist even when they no longer make their appearance to the senses, we shou'd never be led to think, that our perceptions and objects are different, and that our objects alone preserve a continu'd existence. 'The latter hypothesis has no primary recommendation either to reason or the imagination, but acquires all its influence on the imagination from the former.' This proposition contains two parts, which we shail endeavour to prove as distinctly and clearly, as such abstruse subjects will permit.

As to the first part of the proposition, that this philosophical hypothesis has no primary recommendat:on, either to reason or the imagination, we may soon satisfy ourselves with regard to reason by the following reflections. The only existences, of which we are certain, are perceptions, which being immediately present to us by consciousness, command our strongest assent, and are the first foundation of all our conclusions. The only conclusion we can draw from the existence of one thing to that of ancther, is by means 
of the relation of cause and effect, which shews, that there is a connexion betwixt them, and that the existence of one is dependent on that of the other. The idea of this relation is deriv'd from past experience, by which we find, that two beings are constantly conjoin'd together, and are always present at once to the mind. But as no beings are ever present to the mind but perceptions; it follows that we may observe a conjunction or a relation of cause and effect between different perceptions, but can never observe it between perceptions and objects. 'Tis impossible, therefore, that from the existence or any of the qualities of the former, we can ever form any conclusion concerning the existence of the latter, or ever satisfy our reason in this particular.

'Tis no less certain, that this philosophical system has no primary recommendation to the imagination, and that that faculty wou'd never, of itself, and by its original tendency, have fallen upon such a principle. i confess it will be somewhat difficult to prove this to the full satisfaction of the reader; because it implies a negative, which in many cases will not admit of any positive proof. If any one wou'd take the pains to examine this question, and wou'd invent a system, to account for the direct origin of this opinion from the imagination, we shou'd be able, by the examination of that system, to pronounce a certain judgment in the present sulject. Let it be taken for granted, that our perceptions are broken, and interrupted, and however like, are still different from each other; and let any one upon this supposition shew why the fancy, directly and immediately, proceeds to the belief of another existence, resembling these perceptions in their nature, but yet continu'd, and uninterrupted, and iden- 
tical; and after he has done this to my satisfaction, I promise to renounce my present opinion. Mean while I cannot forbear concluding, from the very abstractedness and difficulty of the first supposition, that 'tis an improper subject for the fancy to work upon. Whoever wou'd explain the origin of the common opinion concerning the continu'd and distinct existence of body, must take the mind in its common situation, and must proceed upon the supposition, that our perceptions are our only objects, and continue to exist even when they are not perceiv'd. Tho' this opinion be false, 'tis the most natural of any, and has alone any primary recommendation to the fancy.

As to the second part of the proposition, that the philosophical sy'stem acquires all its infuence on the inagination from the vulgar one; we may observe, that this is a natural and unavoidable consequence of the foregoing conclusion, that it has no primary recommendation to reason or the imagination. For as the philosophical system is found by experience to take hold of many minds, and in particular of all those, who reflect ever so little on this subject, it must derive all its authority from the vulgar system; since it has no original authority of its own. The manner, in which these two systems, tho' directly contrary, are connected together, may be explain'd, as follows.

The imagination naturally runs on in this train of thinking. Our perceptions are our only objects: Resembling perceptions are the same, however broken or uninterrupted in their appearance: This appearing interruption is contrary to the identity: The interruption consequently extends not beyond the appearance, and the perception or object really continues to exist, even when absent from us: Our sensible perceptions have, 
therefore, a continu'd and uninterrupted existence. But as a little reflection destroys this conclusion, that our perceptions have a continu'd existence, by shewing that they have a dependent one, 'twou'd naturally be expected, that we must altogether reject the opinion, that there is such a thing in nature as a continu'd existence, which is preserv'd even when it no longer appears to the senses. The case, however, is otherwise. Philosophers are so far from rejecting the opinion of a continu'd existence upon rejecting that of the independence and continuance of our sensible perceptions, that tho' all sects agree in the latter sentiment, the former, which is, in a manner, its necessary consequence, has been peculiar to a few extravagant sceptics; who after all maintain'd that opinion in words only, and were never able to bring themselves sincerely to believe it.

There is a great difference betwixt such opinions as we form after a calm and profound reflection, and such as we embrace by a kind of instinct or natural irnpulse, on account of their suitableness and conformity to the mind. If these opinions become contrary, 'tis not difficult to foresee which of them will have the advantage. As long as our attention is bent upon the subject, the philosophical and study'd principle may prevail; but the moment we relax our thoughts, nature will display herself, and draw us back to our former opinion. Nay she has sometimes such an influence, that she can stop our progress, even in the midst of our most profound reflections, and keep us from running on with all the consequences of any philosophical opinion. Thus tho' we clearly perceive the dependence and interruption of our perceptions, we stop short in our career, and never upon that account reject the 
notion of an independent and continu'd existence. That opinion has taken such deep root in the imagination, that 'tis impossib'e ever to eradicate it, nor will any strain'd metaphysical conviction of the dependence of our perceptions be sufficient for that purpose.

But tho' our natural and obvious principles here prevail above our study'd reflections, 'tis certain there must be some struggle and opposition in the case; at least so long as these reflections retain any force or vivacity. In order to set ourselves at ease in this particular, we contrive a new hypothesis, which seems to comprehend both these principles of reason and inagination. This hypothesis is the philosophical one of the double existence of perceptions and objects; which pleases our reason, in allowing, that our dependent perceptions are interrupted and different; and at the same time is agreeable to the imagination, in attributing a continu'd existence to something else, which we call objects. This philosophical system, therefore, is the monstrous offspring of two principles, which are contrary to each other, which are both at once embrac'd by the mind, and which are unable mutually to destroy each other. The imagination tells us, that our resembling perceptions have a continu'd and uninterrupted existence, and are not annihilated by their absence. Reflection tells us, that even our resembling perceptions are interrupted in their existence, and different from each other. The contradiction betwixt these opinions we elude by a new fiction, which is conformable to the hypotheses both of reflection and fancy, by ascribing these contrary qualities to different existences; the intcrupion to perceptions, and the contimuance to objects. Nature is obstinate, and will not quit the field, however strongly attacis'd by reason; 
and at the same time reason is so clear in the point, that there is no possibility of disguising her. Not being able to reconcile these two enemies, we endeavour to set ourselves at ease as much as possible, by successively granting to each whatever it demands, and by feigning a double existence, where each may find something, that has all the conditions it desires. Were we fully convinc'd, that our resembling perceptions are continu'd, and identical, and independent, we shou'd never run into this opinion of a double existence; since we shou'd find satisfaction in our first suppositio: 1 , and wou'd not look beyond. Again, were we fully convinc'd, that our perceptions are dependent, and interrupted, and different, we shou'd be as little inclin'd to embrace the opinion of a double existence; since in that case we shou'd clearly perceive the error of our first supposition of a continu'd existence, and wcu'd never regard it any farther. 'Tis therefore from the intermediate situation of the mind, that this opinion arises, and from such an adherence to these two contrary principles, as makes us seek some pretext 1 , justify our receiving both; which happily at last $i$ found in the system of a double existence.

Another advantage of this philosophical system is its similarity to the vulgar one; by which means we can humour our reason for a moment, when it becomes troublesome and sollicitous; and yet upon its least negligence or inattention, can easily return to our vulgar and natural notions. Accordingly we find, that philosophers neglect not this advantage; but immediately upon leaving their closets, mingle with the rest of mankind in those exploded opinions, that our perceptions are our only objects, and continue identically and unin 
terruptedly the same in all their interrupted appearances.

There are other particulars of this system, wherein we may remark its dependence on the Iancy, in a very conspicuous manner. Of these, I shali observe the two following. First, We suppose external objects to resemble internal perceptions. I have already shewn, that the relation of cause and effect can never afford us any just conclusion from the existence or qualities of our perceptions to the existence of external continu'd objects: And I shall farther add, that even tho' they cou'd afford such a conclusion, we shou'd never have any reason to infer, that our objects resemble our perceptions. That opinion, therefore, is deriv'd from nothing but the quality of the fancy above-explain'd, that it borrows all its ideas from some precedent perception. We never can conceive any thing but perceptions, and therefore must make every thing resemble them.

Secondly, As we suppose our objects in general to resemble our perceptions, so we take it for granted, that every particular object resembles that perception, which it causes. The relation of cause and effect determines us to join the other of resemblance; and the ideas of these existences being already united together in the fancy by the former relation, we naturally add the latter to compleat the union. We have a strong propensity to compleat every union by joining new relations to those which we have before observ'd betwixt any ideas, as we shall have occasion to observe presently. 1

Having thus given an account of all the systems both popular and philosophical, with regard to exter-

1 Sect. 5 
nal existences, I cannot forbear giving vent to a certain sentiment, which arises upon reviewing those systems. I begun this subject with premising, that we ought to have an implicit faith in our senses, and that this wou'd be the conclusion, I shou'd draw from the whole of my reasoning. But to be ingenuous, I feel myself at present of a quite contrary sentiment, and am more inclin'd to repose no faith at all in my senses, or rather imagination, than to place in it such an implicit confidence. I cannot conceive how such trivial qualities oi the fancy, conducted by such false suppositions, can ever lead to any solid and rational system. They are the coherence and constancy of our perceptions, which produce the opinion of their continu'd existence; tho' these qualities of perceptions have no perceivable connexion with such an existence. The constancy of our perceptions has the most considerable effect, and yet is attended with the greatest difficulties. 'Tis a gross illusion to suppose, that our resembling perceptions are numerically the same; and 'tis this illusion, which leads us into the opinion, that these perceptions are uninterrupted, and are still existent, even when they are not present to the senses. This is the case with our popular system. And as to our philosophical one, 'tis liable to the same difficulties; and is over-and-above loaded with this absurdity, that it at once denies and establishes the vulgar supposition. Philosophers deny our resembling perceptions to be identically the same, and uninterrupted; and yet nave so great a propensity to believe them such, that they arbitrarily invent a new set of perceptions, to which they attribute these qualities. I say, a new set of perceptions: For we may well suppose in general, but 'tis impossible for us distinctly to conceive, objects to be in their nature any 
thing but exactly the same with perceptions. What then can we look for from this confusion of ground. less and extraordinary opinions but error and falsehood? And how can we justify to ourselves any belief we repose in them?

This sceptical doubt, both with respect to reason and the senses, is a malady, which can never be radically cur'd, but must return upon us every moment, however we may chace it away, and sometimes may seem entirely free from it. 'Tis impossible upon any system to defend either our understanding or senses; and we but expose them farther when we endeavour to justify them in that manner. As the sceptical doubt arises naturally from a profound and intense reflection on those subjects, it always encreases, the farther we carry our reflections, whether in opposition or conformity to it. Carelessness and in-attention alone can afford us any remedy. For this reason I rely entirely upon them; and take it for granted, whatever may be the reader's opinion at this present moment, that an hour hence he will be persuaded there is both an external and internal world; and going upon that supposition, I intend to examine some general systems both ancient and modern, which have been propos'd of both, before I proceed to a more particular enquiry concerning our impressions. This will not, perhaps, in the end be found foreign to our present purpose. 


\section{Section VI.}

\section{Of personal identity.}

There are some philosophers, who imagine we are every moment intimately conscious of what we call our SELF; that we feel its existence and its continuance in existence; and are certain, beyond the evidence of demonstration, both of its perfect identity and simplicity. The strongest sensation, the most violent passion, say they, instead of distracting us from this view, -only fix it the more intensely, and make us consider their influence on self either by their pain or pleasure. To atrempt a farther proof of this were to weaken its evidence; since no proof can be deriv'd from any fact, of which we are so intimately conscious; nor is there any thing, of which we can be certain, if we doubt of this.

Unluckily all these positive assertions are contrary to that very experience, which is pleaded for them, nor have we any idea of self, after the manner it is here explain'd. For from what impression cou'd this idea be deriv'd? This question 'tis impossible to answer without a manifest contradiction and absurdity; and yet 'tis a question, which must necessarily be answer'd. if we wou'd have the idea of self pass for clear and intelligible. It must be some one impression, that gives rise to every real idea. But self or person is not any one impression, but that to which our several impressions and ideas are suppos'd to have a reference. If any impression gives rise to the idea of self, that im.

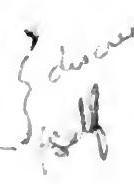


pression must continue invariably the same, thro' the whole course of our lives; since self is suppos'd to exist after that manner. *But there is no impression constant and invariable. Pain and pleasure, grief and joy, passions and sensations succeed each other, and never all exist at the same time. It cannot, therefore, be from any of these impressions, or from any other, that the idea of self is deriv'd; and consequently there is no such idea.

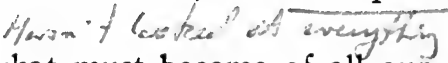

But farther, what must become of all our particular perceptions upon this hypothesis? All these are different, and distinguishable, and separable from each other, and may be separately consider'd, and may exist separately, and have no need of any thing to support their existence. After what manner, therefore, do they belong to self; and how are they connected with it? For my part, when I enter most intimately into what I call myself, I always stumble on some particular perception or other, of heat or cold, light or shade, love or hatred, pain or pleasure. I never can catch myself at any time without a perception, and never can observe any thing but the perception. When my perceptions are remov'd for any time, as by sound sleep; so long am I insensible of myself, and may truly be said not to exist. And were all my perceptions remov'd by death, and cou'd I neither think, nor feel, nor see, nor love, nor hate after the dissolution of my body, I shou'd be entirely annihilated, nor do I conceive what is farther requisite to make me a perfect non-entity. If any one upon serious and unprejudic'd reflexion, thinks he has a different notion of himself, I must confess I can reason no longer with him. All I can allow him is, that he may be in the right as well as I, and that we are essentially different in this par- 
ticular. He may, perhaps, perceive something simple and continu'd, which he calls himself; tho' I am certain there is no such principle in me. Tom chentuty.

But setting aside some metaphysicians of this kind, I may venture to affirm of the rest of mankind, that they are nothing but a bundle or collection of different perceptions, which succeed each other with an inconceivable rapidity, and are in a perpetual flux and movement. Our eyes cannot turn in their sockets without varying our perceptions. Our thought is still more variable than our sight; and all our other senses and faculties contribute to this change; nor is there any single power of the soul, which remains unalterably the same, perhaps for one moment. The mind is a kind of theatre, where several perceptions successively make their appearance; pass, re-pass, glide away, and mingle in an infinite variety of postures and situations. There is properly no simplicity in it at one time, nor identity in different; whatever natural propension we may have to imagine that simplicity and identity. The comparison of the theatre must not mislead us. They are the successive perceptions only, that constitute the mind; nor have we the most distant notion of the place, where these scenes are represented, or of the materials, of which it is compos'd.

What then gives us so great a propension to ascribe an identity to these successive perceptions, and to suppose ourselves possest of an invariable and uninterrupted existence thro' the whole course of our lives? In order to answer this question, we must distinguish betwixt personal identity, as it regards our thought of imagination, and as it regards our passions or the con cern we take in ourselves. The first is our present subject; and to expiain it perfectly we must take the 
matter pretty deep, and account for that identity, which we attribute to plants and animals; there being a great analogy betwixt it, and the identity of a self or person.

We have a distinct idea of an object, that remains invariable and tminterrupted thro' a suppos'd variation of time; and this idea we call that of identity or sameness. We have also a distinct idea of several different objects existing in succession, and connected together by a close relation; and this to an accurate view affords as perfect a notion of diversity, as if there was no manner of relation among the objects. But tho' these two ideas of identity, and a succession of related objects be in themselves perfectly distinct, and even contrary, yet 'tis certain, that in our common way of thinking they are generally confounded with each other. That action of the imagination, by which we consider the uninterrupted and invariable object, and that by which we reflect on the succession of related objects, are almost the same to the feeling, nor is there Smuch more effort of thought requir'd in the latter case than in the former. The relation facilitates the transition of the mind from one object to another, and renders its passage as smooth as if it contemplated one continu'd object. This resemblance is the cause of the confusion and mistake, and makes us substitute the notion of identity, instead of that of related objects. However at one instant we may consider the related succession as variable or interrupted, we are sure the next to ascribe to it a perfect identity, and regard it as invariable and uninterrupted. Our propensity to this mistake is so great from the resemblance abovemention'd, that we fall into it before we are aware; and tho' we incessantly correct ourselves by reflexion, and return to a more accurate method of thinking, 
yet we cannot long sustain our philosophy, or take off this biass from the imagination. Our last resource is to yield to it, and boldly assert that these different related objects are in effect the same, however interrupted and variable. In order to justify to ourselves this absurdity, we often feign some new and unintelligible principle, that connects the objects together, and prevents their interruption or variation. Thus we feign the continu'd existence of the perceptions of our senses, to remove the interruption; and run into the notion of a soul, and self, and substance, to disguise the variation. But we may farther observe, that where we do not give rise to such a fiction, our propension to confound identity with relation is so great, that we are apt to imagine ${ }^{1}$ something unknown and mysterious, connecting the parts, beside their relation; and this I take to be the case with regard to the identity we ascribe to plants and vegetables. And even when this does not take place, we still feel a propensity to confound these ideas, tho' we are not able fully to satisfy ourselves in that particular, nor find any thing invariable and uninterrupted to justify our notion of identity.

Thus the controversy concerning identity is not merely a dispute of words. For when we attribute identity, in an improper sense, to variable or interrupted objects, our mistake is not confin'd to the expression, but is commonly attended with a fiction, either of something invariable and uninterrupted, or

1 If the reader is desirous to see how a great genius may be influenc'd by these seemingly trivial principles of the imagination, as well as the mere vulgar, let him read my Lord Shaftsbury's reasonings concerning the uniting principle of the universe, and the identity of plants and animals. See his Moralists: or, Philosophical rhapsody. 
of something mysterious and inexplicable, or at least with a propensity to such fictions. What will suffice to prove this hypothesis to the satisfaction of every fair enquirer, is to shew from daily experience and observation, that the objects, which are variable or interrupted, and yet are suppos'd to continue the same, are such only as consist of a succession of parts, connected together by resemblance, contiguity, or causation. For as such a succession answers evidently to our notion of diversity, it can only be by mistake we ascribe to it an identity; and as the relation of parts, which leads us into this mistake, is really nothing but a quality, which produces an association of ideas, and an easy transition of the imagination from one to another, it can only be from the resemblance, which this act of the mind bears to that, by which we contemplate one continu'd object, that the error arises. Our chief business, then, must be to prove, that all objects, to which we ascribe identity, without observ. ing their invariableness and uninterruptedness, are such as consist of a succession of related objects.

In order to this, suppose any mass of matter, of which the parts are contiguous and connected, to be plac'd before us; 'tis plain we must attribute a perfect identity to this mass, provided all the parts continue uninterruptedly and invariably the same, whatever motion or change of place we may observe either in the whole or in any of the parts. But supposing some very small or inconsiderable part to be added to the mass, or substracted from it; tho' this absolutely destroys the identity of the whole, strictly speaking; yet as we seldom think so accurately, we scruple not to pronounce a mass of matter the same, where we find so trivial an alteration. The passage of the thought 
from the object before the change to the object after it, is so smooth and easy, that we scarce perceive the transition, and are apt to imagine, that 'tis nothing but a continu'd survey of the same object.

There is a very remarkable circumstance, that attends this experiment; which is, that tho' the change of any considerable part in a mass of matter destroys. the identity of the whole, yet we must measure the greatness of the part, not absolutely, but by its proportion to the whole. The addition or diminution of a mountain wou'd not be sufficient to produce a diversity in a planet; tho' the change of a very few inches wou'd be able to destroy the identity of some bodies. 'Twill be impossible to account for this, but by reflecting that objects operate upon the mind, and break or interrupt the continuity of its actions not according to their real greatness, but according to their proportion to each other: And therefore, since this interruption makes an object cease to appear the same, it must be the uninterrupted progress of the thought, which constitutes the imperfect identity.

This may be confirm'd by another phæroumenon. A change in any considerable part of a body destroys its identity; but 'tis remarkable, that where the change is produc'd gradually and insensibly we are less apt to ascribe to it the same effect. The reason can plainly be no other, than that the mind, in following the successive changes of the body, feels an easy passage from the surveying its condition in one moment to the viewing of it in another, and at no particular time perceives any interruption in its actions. From which continu'd perception, it ascribes a continu'd existence and identity to the object.

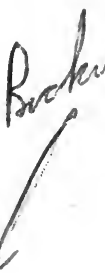

11
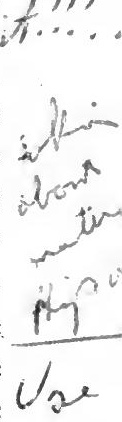

\section{Whax} of ar 
But whatever precaution we may use in introducing the changes gradually, and making them proportionable to the whole, 'tis certain, that where the changes are at last observ'd to become considerable, we make a scruple of ascribing identity to such different objects. There is, however, another artifice, by which we may induce the imagination to advance a step farther; and that is, by producing a reference of the parts to each other, and a combination to some common end or purpose. A ship, of which a considerable part has been chang'd by frequent reparations, is still consider'd as the same; nor does the difference of the materials hinder us from ascribing an identity to it. The common end, in which the parts conspire, is the same under all their variations, and affords an easy transition of the imagination from one situation of the body to another.

But this is still more remarkable, when we add a sympathy of parts to their common end, and suppose that they bear to each other, the reciprocal relation of cause and effect in all their actions and operations. This is the case with all animals and vegetables; where not only the several parts have a reference to some general purpose, but also a mutual dependence on, and connexion with each other. The effect of so strong a relation is, that tho' every one must allow, that in a very few years both vegetables and animals endure a total change, yet we still attribute identity to them, while their form, size, and substance are entirely alter'd. An oak, that grows from a small plant to a. large tree, is still the same oak; tho' there be not one particle of matter, or figure of its parts the same. An infant becomes a man, and is sometimes fat, sometimes lean, without any change in his identity. 
We may also consider the two following phænomena, which are remarkable in their kind. The first is, that tho' we commonly be able to distinguish pretty exactly betwixt numerical and specific identity, yet it sometimes happens, that we confound them, and in our thinking and reasoning employ the one for the other. Thus a man, who hears a noise, that is frequently interrupted and renew'd, says, it is still the same noise; tho' 'tis evident the sounds have only a specific identity or resemblance, and there is nothing numerically the same, but the cause, which produc'd them. In like manner it may be said without breach of the propriety of language, that such a church, which was formerly of brick, fell to ruin, and that the parish rebuilt the same church of free-stone, and according to modern architecture. Here neither the form nor materials are the same, nor is there any thing common to the two objects, but their relation to the inhabitants of the parish; and yet this alone is sufficient to make us denominate them the same. But we must observe, that in these cases the first object is in a manner annihilated before the second comes into existence; by which means, we are never presented in any one point of time with the idea of difference and multiplicity; and for that reason are less scrupulous in calling them the same.

Secondly, We may remark, that tho' in a succession of related objects, it be in a manner requisite, that the change of parts be not sudden nor entire, in order to preserve the identity, yet where the objects are in their nature changeable and inconstant, we admit of a more sudden transition, than wou'd otherwise be consistent with that relation. Thus as the nature of a river consists in the motion and change of 
parts; tho' in less than four and twenty hours these be totally alter'd; this hinders not the river from continuing the same during several ages. What is natural and essential to any thing is, in a manner, expected; and what is expected makes less impression, and appears of less moment, than what is unusual and extraordinary. A considerable change of the former kind seems really less to the imagination, than the most trivial alteration of the latter; and by breaking less the continuity of the thought, has less influence in destroying the identity.

We now proceed to explain the nature of personal identity, which has become so great a question in philosophy, especially of late years in England, where all the abstruser sciences are study'd with a peculiar ardour and application. And here 'tis evident, the same method of reasoning must be continu'd, which has so successfully explain'd the identity of plants, and animals, and ships, and houses, and of all the compounded and changeable productions either of art or nature. The identity, which we ascribe to the mind of man, is only a fictitious one, and of a like kind with that which we ascribe to vegetables and animal bodies. It cannot, therefore, have a different origin, but must proceed from a like operation of the imagination upon like objects.

But lest this argument shou'd not convince the reader; tho' in my opinion perfectly decisive; let him weigh the following reasoning, which is still closer and more immediate. 'Tis evident, that the identity, which we attribute to the human mind, however perfect we may imagine it to be, is not able to run the several different perceptions into one, and make them lose their characters of distinction and difference, 
which are essential to them. 'Tis still true, that every distinct perception, which enters into the composition of the mind, is a distinct existence, and is different, and distinguishable, and separable from every other perception, either contemporary or successive. But, as, notwithstanding this distinction and separability, we suppose the whole train of perceptions to be united by identity, a question naturally arises concerning this relation of identity; whether it be something that really binds our several perceptions together, or only associates their ideas in the imagination. That is, in other words, whether in pronouncing concerning the identity of a person, we observe some real bond among his perceptions, or only feel one among the ideas we form of them. This question we might easily decide, if we wou'd recollect what has been already prov'd at large, that the understanding never observes any real connexion among objects, and that even the union of cause and effect, when strictly examin'd, resolves itself into a customary association of ideas. For from thence it evidently follows, that identity is nothing really belonging to these different perceptions, and uniting them together; but is merely a quality, which we attribute to them, because of the union of their ideas in the imagination, when we reflect upon them. Now the only qualities, which can give ideas an union in the imagination, are these three relations above-mention'd. These are the uniting principles in the ideal world, and without them every distinct object is separable by the mind, and may be separately consider'd, and appears not to have any more connexion with any other object, than if disjoin'd by the greatest difference and remoteness. 'Tis therefore, on some of these three relations of resemblance, contiguity and caus- 
ation, that identity depends; and as the very essence of these relations consists in their producing an easy transition of ideas; it follows, that our notions of personal identity, proceed entirely from the smooth and uninterrupted progress of the thought along a train of connected ideas, according to the principles above explain'd.

The only question, therefore, which remains, is, by what relations this uninterrupted progress of our thought is produc'd, when we consider the successive existence of a mind or thinking person. And here' tis evident we must confine ourselves to resemblance and causation, and must drop contiguity, which has little or no influence in the present case.

To begin with resemblance; suppose we cou'd see clearly into the breast of another; and observe that succession of perceptions, which constitutes his mind or thinking principle, and suppose that he always preserves the memory of a considerable part of past perceptions; 'tis evident that nothing cou'd more contribute to the bestowing a relation on this succession amidst all its variations. For what is the memory but a faculty, by which we raise up the images of past perceptions? And as an image necessarily resembles its object, must not the frequent placing of these tesembling perceptions in the chain of thought, convey the imagination more easily from one link to another, and make the whole seem like the continuance of one object? In this particular, then, the memory not only discovers the identity, but also contributes to its production, by producing the relation of resemblance among the perceptions. The case is the same whether we consider ourselves or others. 
As to causation; we may observe, that the true idea of the human mind, is to consider it as a system of different perceptions or different existences, which are link'd together by the relation of cause and effect, and mutually produce, destroy, influence, and modify each other. Our impressions give rise to their correspondent ideas; and these ideas in their turn produce other impressions. One thought chaces another, and draws after it a third, by which it is expell'd in its turn. In this respect, I cannot compare the soul more properly to any thing than to a republic or commonwealth, in which the several members are united by the reciprocal ties of government and subordination, and give rise to other persons, who propagate the same republic in the incessant changes of its parts. And as the same individual republic may not only change its members, but also its laws and constitutions; in like manner the same person may vary his character and disposition, as well as his impressions and ideas, without losing his identity. Whatever changes he endures, his several parts are still connected by the relation of causation. And in this view our identity with regard to the passions serves to corroborate that with regard to the imagination, by the making our distant perceptions influence each other, and by giving us a present concern for our past or future pains or pleasures.

As memory alone acquaints us with the continuance and extent of this succession of perceptions, 'tis to be consicler'd, upon that account chiefly, as the source of personal identity. Had we no memory, we never shou'd have any notion of causation, nor consequently of that chain of causes and effects, which constitute our self or person. But having once acquir'd t duremit? 
this notion of causation from the memory, we can cxtend the same chain of causes, and consequently the identity of our persons beyond our memory, and can comprehend times, and circumstances, and actions, which we have entirely forgot, but suppose in general to have existed. For how few of our past actions are there, of which we have any memory? Who can tell me, for instance, what were his thoughts and actions on the first of January I7 I5, the IIth of March 1719, and the 3d of August 1733? Or will he affirm because he has entirely forgot the incidents of these days, that the present self is not the same person with the self of that time; and by that means overturn all the most establish'd notions of personal identity? In this view, therefore, memory does not so much produce as discover personal identity, by shewing us the relation of cause and effect-among our different perceptions. 'Twill be incumbent on those, who affirm that memory produces entirely our personal identity, to give a reason why we can thus extend our identity beyond our memory.

The whole of this doctrine leads us to a conclusion, which is of great importance in the present affair, viz. that all the nice and subtile questions concerning personal identity can never possibly be decided, and are to be regarded rather as grammatical than as philesophical difficulties. Identity depends on the relation of ideas; and these relations produce identity, by means of that easy transition they occasion. But as the relations, and the easiness of the transition may diminish by insensible degrees, we have no just standard, by which we can decide any dispute concerning the time, when they acquire or lose a title to the name of identity. All the disputes concerning the identity 
of connected objects are merely verbal, except so far as the relation of parts gives rise to some fiction or imaginary principle of union, as we have already observ'd.

What I have said concerning the first origin and uncertainty of our notion of identity, as apply'd to the human mind, may be extended with little or no variation to that of simplicity. An object, whose different co-existent parts are bound together by a close relation, operates upon the imagination after much the same manner as one perfectly simple and indivisible, and requires not a much greater stretch of thought in order to its conception. From this similarity of operation we attribute a simplicity to it, and feign a principle of union as the support of this simplicity, and the center of all the different parts and qualities of the object.

Thus we have finish'd our examination of the several systems of philosophy, both of the intellectual and moral world; and in our miscellaneous way of reasoning have been led into several topics; which will either illustrate and confirm some preceding part of this discourse, or prepare the way for our following opinions. 'Tis now time to return to a more close examination of our subject, and to proceed in the accurate anatomy of human nature, having fully explain'd the nature of our judgment and understanding.

$\begin{array}{llllll}* & * & * & * & * & * \\ * & * & * & * & * & *\end{array}$




\section{APPENDIX.}

\section{* * * * * * * * *}

I had entertain'd some hopes, that however deficient our theory of the intellectual world might be, it wou'd be free from those contradictions, and absurdities, which seem to attend every explication, that human reason can give of the material world. But upon a more strict review of the section concerning personal identity, I find myself involv'd in such a labyrinth, that, I must confess, I neither know how to correct my former opinions, nor how to render them consistent. If this be not a good general reason for scepticism, 'tis at least a sufficient one (if I were not already abundantly supplied) for me to entertain a diffidence and modesty in all my decisions. I shall propose the arguments on both sides, beginning with those that induc'd me to deny the strict and proper identity and simplicity of a self or thinking being.

When we talk of self or substance, we must have an idea annex'd to these terms, otherwise they are aitogether unintelligible. Every idea is deriv'd from preceding impressions; and we have no impression of self or substance, as something simple and individual. We have, therefore, no idea of them in that sense.

Whatever is distinct, is distinguishable; and whatever is distinguishable, is separable by the thought or imagination. All perceptions are distinct. They are, therefore, distinguishable, and separable, and may be conceiv'd as separately existent, and may exist separately, without any contradiction or absurdity. 
When I view this table and that chimney, nothing is present to me but particular perceptions, which are of a like nature with all the other perceptions. This is the doctrine of philosophers. But this table, which is present to me, and that chimney, may and do exist separately. This is the doctrine of the vulgar, and implies no contradiction. There is no contradiction, therefore, in extending the same doctrine to all the perceptions.

In general, the following reasoning seems satisfactory. All ideas are borrow'd from preceding perceptions. Our ideas of objects, therefore, are deriv'd from that source. Consequently no proposition can be intelligible or consistent with regard to objects, which is not so with regard to perceptions. But 'tis intelligible and consistent to say, that objects exist distinct and independent, without any common simple substance or subject of inhesion. This proposition, therefore, can rever be absurd with regard to perceptions.

When I turn my reflexion on myself, I never can perceive this self without some one or more perceptions; nor can I ever perceive any thing but the perceptions. 'Tis the composition of these, therefore, which forms the self.

We can conceive a thinking being to have either many or few perceptions. Suppose the mind to be reduc'd even below the life of an oyster. Suppose it to have only one perception, as of thirst or hunger. - Consider it in that situation. Do you conceive any thing but merely that perception? Have you any notion of self or substance? If not, the addition of other perceptions can never give you that notion. 
The annihilation, which some people suppose to follow upon death, and which entirely destroys this self, is nothing but an extinction of all particular perceptions; love and hatred, pain and pleasure, thought and sensation. These therefore must be the same with self; since the one cannot survive the other.

Is self the same with substance? If it be, how can that question have place, concerning the subsistence of self, under a change of substance? If they be distinct, what is the difference betwixt them? For my part, I have a notion of neither, when conceiv'd distinct from particular perceptions.

Philosophers begin to be reconcil'd to the principle, that we have no idea of external substance, distinct from the ideas of particular qualities. This must pave the way for a like principle with regard to the mind, that we have no notion of it, distinct from the particular perceptions.

So far I seem to be attended with sufficient evidence. But having thus loosen'd all our particular perceptions, when ${ }^{1}$ I proceed to explain the principle of connexion, which binds them together, and makes us attribute to them a real simplicity and identity; I am sensible, that my account is very defective, and that nothing but the seeming evidence of the precedent reasonings cou'd have induc'd me to receive it. If perceptions are distinct existences, they form a whole only by being connected together. But no connexions among distinct existences are ever discoverable by human understanding. We only feel a connexion or determination of the thought, to pass from one object to another. It follows, therefore, that the thought alone finds personal identity, when reflecting on the train of past perceptions, that compose a mind, the 
ideas of them are felt to be connected together, and naturally introduce each other. However extraordinary this conclusion may seem, it need not surprize us. Most philosophers seem inclin'd to think, that personal identity arises from consciousness; and consciousness is nothing but a reflected thought or perception. The present philosophy, therefore, has su far a promising aspect. But all my hopes vanish, when I come to explain the principles, that unite our successive perceptions in our thought or consciousness. I cannot discover any theory, which gives me satisfaction on this head.

In short there are two principles, which I cannot render consistent; nor is it in my power to renounce either of them, viz. that all our distinct perceptions are distinct existences, and that the mind never perceives any real connexion among distinct existences. Did our perceptions either inhere in something simple and individual, or did the mind perceive some real connexion among them, there wou'd be no difficulty in the case. For my part, I must plead the privilege of a sceptic, and confess, that this difficulty is too hard for my understanding. I pretend not, however, to pronounce it absolutely insuperable. Others, perhaps, or myself, upon more mature reflexions, may discover some hypothesis, that will reconcile those contradictions. 


\section{INDEX}

Abstraction, 164 .

Abstract sciences, 167, 173 .

Academic philosophy, $4 \mathrm{I}$ et seq.

Accuracy, 6.

Addison, 3.

Alchemy, 136 .

Alexander, 87 .

Alexander, the false prophet, 126 . slgebra, 187.

Ambiguous expressions, 83 .

Analogy, reasoning by, so9.

Animals, reason of, 109 et seq.

Annihilation, 22.

A priori, 25, 26, 34, 44 .

Aqua regia, 228.

Arguments, demonstrative, 57; probable, 57; mutual destruction of, $12 \mathrm{I}$.

Arithmetic, 187.

Aristotle, 3, 86.

Association of ideas, 21 et seq., 51 et seq., 255.

Assurance, degrees of, 115 .

Astronomy, 175 .

Atheists, 159.

Athens, 139, 141.

Aurelius, Marcus, 126.

Bacon, I 36.

Bayle, 164 .

Dede, 132.

Belief, 47 et seq., 50 et seq., 60 , I1 $2,196$.

Perkeley, 164 .

Bible, I 37.

Billiard-ball, 27, 48, 64, 72, 78, 81 .

Bodies, operation of, 76,84 et seq., 95.

Body, existence of, 232 et seq.

Cæsar, 174.

Cartesians, 207 et seg.
Cartesian doubt, 159.

Catastroplies, I 35 .

Cato, 119.

Causation, 77 et seq., 185 et seq. 257.

Cause and effect, 22 et seq., 42 et seq,. 84 et seq., 143 et seq., 169, 198, et seq., 255 .

Causes, ultimate, 29 et seq.; similar, 35 et seq.; final, 56 ; probability of, 58 ; invisible, 71 ; occasional, 72; definition, 219.

Chance, 57 et seq., 99, 221 .

Chemistry, 175 .

Child, burnt, 38 .

Christian religion, $114,137,138$.

Chronology, 175.

Cicero, 3, 53, 124.

Clarke, 76, 199.

Climates, 59.

Color-sensation, 18.

Conduct, human, determinism and liberty in, 85 et seq.

Conjecture, 154 .

Conjunction, 72 et seq., 76 et seq., 85 , 169; customary, 47, 50; constant, 96, 231 .

Connexion, 25 et seq., 32, 36, $5 \mathrm{I}$ et seq., 72 et seq.; necessary, 61 et seq., 64,76 et seq., 99 , 196,202 et seq.

Constraint, roo.

Contiguity, 22 et seq., 53 et seq., 192, et seq.

Continued existence of objects, 232 et seq.

Contrariety, 22, 185 .

Contrast, 22.

Copies of impressions, ideas, 16 et seq., 63 et seq., 80, 189, 208, $211,222,227$. 
Creator, responsibility of, 104.

Criticism, 175.

Cudworth, 76 .

Curtius, Quintus, 87.

Custom, 43 et seq., 55, 112 .

Customary, connexion, 80 et seq.; transition, 79 et seq., 95 .

Definitions, exact, 82 .

Deity, 207 et seq.

Demetrius, I 29.

Demonstration, proper objects of, I 73.

Demonstrative, arguments, 57; reasoning, 34 .

Demosthenes, 124 .

Descartes, 76, 158 .

Design, 151 .

Determination of the mind, 203, 213 et seq.

Determinism, $8_{3}$ et seq.

Distance, 235 .

Distinctness, 23 I et seq., 260 et seq.

l)ivine existence, argument for, 143.

I)ivinity, 175 .

I)ivisibility, infinite, 166 .

I)oubt, Cartesian, I 59.

1)reams, 162 .

I)ye, 57 .

Effect. See Cause.

Elizabeth, Queen, I35.

Eloquence, 124.

End, common, 252.

Endeavour, 69.

Energy, 63, 80; of causes, 205 See Force.

E.picurus, I 39 et seq., I4 I et seq., $155,170$.

Ethics, 148 et seq.

Euclid, 23, 62.

Evidence, 24; natural, 93 et seq.; for the truth of Christian re. ligion, 114; contrariety of, II8; of sense, 160 et seq.; objections to moral, 168 et seq.

Evil, 105 et seq.

Existence, idea of, 229 et seq.; continued, of objects, 232 et seq.; distinct, of objects, 233 ef seq.

Experience, 26 et seq., 134, 162, 174; foundation of conclusions from, 3 I et seq.; reasonings from, 35,41 ; inferences from, 44; the foundation of evidence, i1 5 et seq., 186 et seq., 201 .

Experiments, I16, 235.

Extension, idea of, 164 .

External objects, belief of, 161 et seq.

Extraordinary, the, is 8 et seq.

Fact, matters of, 23 et seq.

Faith, 137, 138.

Fiction, 48.

Final causes, 56.

Force, 63, 80, 204 et seq., 299 et seq., $23 \mathrm{r}$.

Free will, 83 et seq.

Future state, 139 et seq.

Gabriel, I74.

General ideas, 164, 168, 209.

Geography, I75; mental, Io.

Geometry, 29, $6 \mathrm{I}, 168,187$.

God, 73, 74, 104, 107, 136, I53, $156,163$.

Gods, the, 144 et seq.

Gravity, 59.

Habit, 43 et seq.

Harmony, pre-established, 55 .

Heredotus, 132 .

Hippocrates, 86.

History, 93, 175.

Hobbes, 198.

Human body, 90 .

Human nature, science of, $r$ et seq.; principles and operations of, 85 et seq.

Human mind, 254.

Hypothesis, 149.

Ideas, origin of, I4 et seq.; association of, 21 et seq.; relations of, 23 et seq.; complex, $0_{3}$; copies of our impressions, 63 et seq., $80,189,208,211,222,227$, general, $164,168$. 
Identity, I85, 190.

Identity, personal, 245 et seq.

Identity, of objects, 250 et scq.

Images, sensible, 52 .

Imagination, 47 et seq., 49, 172, 234 et seq.

Impostures, 126.

Impressions, 15 et seq.; original, 63 ; of power, 213 .

Indeterminism, 83 et seq.

Indian prince, I 9 .

Infinite divisibility, 166 .

Innate, 19; ideas, 208.

Instincts, 113 .

Invisible causes, 71 .

Jansenist miracles, I3I.

Jesuits, 131 .

Jupiter, 145, 146.

justice, distributive, I49.

La Bruyère, 3 .

Liberty; 83 et seq.; defined, 99.

Limbs, use of our, 56 .

Livy, $128,136$.

Locke, 4, 20, 57, 65, 76, 200, 204.

Lucian, 126, $139,140$.

Lucretius, 132.

Magic, 136.

Mahomet, 128.

Malebranche, 3, 76, 205.

Mankind, the same in all times and places, 86 et seq.

Mariana, 132.

Marvellous, the, 118 et seq.; propensity to the, 124 et seq.

Mathematics, 23, 30, 61, 174, 187 .

Matters of fact, 23 et seq., 176 .

Medicine, 90.

Mental, geography, Io; research, II.

Metaphysics, 5 et seq., 62, 176 .

Mind, command of, over the body, 70.

Miracles, I14 et seq.; defined, 121; reasons for discrediting, 122 et seq.

Mode, 227 et seq.

Moral evidence, 93 et seq.; objections to, 168 et seq.
Morality, doctrines of necessity and of liberty consistent with, roo.

Moral, philosophy, I et seq.; reasoning, 34, 175 .

Morals, 93, 175 .

Motion, 27.

Motives and voluntary actions, conjunction between, 85 et seq.

Muscovy, II 9 .

Myself. See Self.

Natural evidence, 93 et seq.

Natural philosophy, 175 .

Nature, course of, 150 ; violations of the course of, 134 .

Necessary connexion, $64,196,202$ et seq.

Necessity, 83 et seq., 98 et sec/ as an inference, 85; define 1 , 100,197 et seq., 216 ; in tie mind, 214.

Newton, 75 .

Number, $173,176,185$ et seq.

Occasions, 72 et seq.

Objects, sensible, 52, 232 et seq ; external, 242.

Paphlagonia, 126.

Paris, Abbé, 131.

Pentateuch, 137.

Perceptions, 14.

Pharsalia, battle of, 131 .

Philippi, battle of, 131 .

Philosophers, fame of, 3 .

Philosophy, 139 et ser.; nature of, I et seq.; natural, 175 .

Physic, 175 .

Plutarch, 128, 132.

Points, mathematical, 166.

Politics, 93.

Polybius, 86.

Possibility, 149.

Power, 63, 64, 68 et seq., 8o, 204 et seq.; impression of, 213 . See Force.

Pre-estabilished harmony, 55 .

Pre-ordination, 103.

Priority, 193. 
Probability, 57 et seq., 116 et seq., $120,134$.

Prodigies, reasons for discrediting, 122 et seq.

Proofs, 57, 116 et seq., I20, 134 .

Prophecies, 138.

Prophet, Alexander the false, 126.

Protagoras, 139.

Providence, a particular, 139 et seq.; divine, 148.

Public good, questions of, 142.

Punishments, ror.

Purpose, 252.

Pyrrhonism, 168, 170, 172.

Qualities, sensible, 65; secondary and primary, 164 .

Quantity, 173, 176; science of, 168.

Reason, 26 et seq.; of animals, 109 et seq.; attempt to destroy, 165,234 et seq.

Reasoning, two kinds of, 34 ; concerning matter of fact, nature of, 31 et seq.; $a$ priori, 34; demonstrative, 34; moral, 34, 62, 175; from experience, 41; comparison, 190.

Regular succession, 56.

Relations of ideas, 23 et seq.

Relations, philosophical, $185,219$.

Religion, 123, 127.

Religious doctrines and life, 155 .

Resemblance, 22 et seq.; $5^{1}$ et seq., $185,256$.

Retz, Cardinal de, 130.

Rewards, ror.

Roman Catholic religion, 52.

Roman emperors, 140.

Saragossa, miracle of, 130.

Sceptical philosophy, $4^{\text {I }}$ et seq., 158 et seq., 244 .

Scepticism, mitigated, 17I; with regard to senses, 232 et seq.

Science, proper subjects of, 173 .

Sciences, abstract, 167, 173 .

Self, idea of, 245 et seq., 260 et sea
Senses, 32; evidence of, 160 et seq.; perceptions of the, 162 et seq.

Sensible, images, 52; objects, 52; qualities, 65.

Serapis, 129.

Shaftsbury, Lord, 349 .

Similar, causes, 35 et seq.; effects, 35 et seq.; instances, 81 ; ob jects, 61,79 .

Simplicity of mind, 247 .

Socrates, 139.

Soul, 249.

Soul with body, union of, 66 et seq.

Space, ideas of, 165 et seq.

Stoics, 40, 105, 170.

Substance, 227, 249, 260 .

Succession, régular, 56 .

Suetonius, 129.

Sumatra, 119.

Supreme Being, 208.

Surprise, 123 et seq.

Tacitus, $86, \quad 128$.

Terms, meaning of, 82 .

Testimony, human, ir 6 et seq.; circumstances requisite to give full assurance to, 122.

Theoiogy, 175.

Thoughts, I5 et seq.

Tillotson, Dr., 114.

Time, ideas of, 165 et seq.; re lations of, 185 .

Transition of the mind, 220 .

Truth, criteria of, 160.

Ultimate causes, 29 et seq.

Uniformity in nature, 84 et seq. 87 et seq.

Velleity, 98.

Vespasian, 128 .

$V$ is inertiae, 75.

Volition, 66 et seq., 83 et seq.

Will, 66 et seq., 83 et seq.

Witnesses, 118 .

Wonder, 123 et seq.

Zeuxis, I44. 
s: 


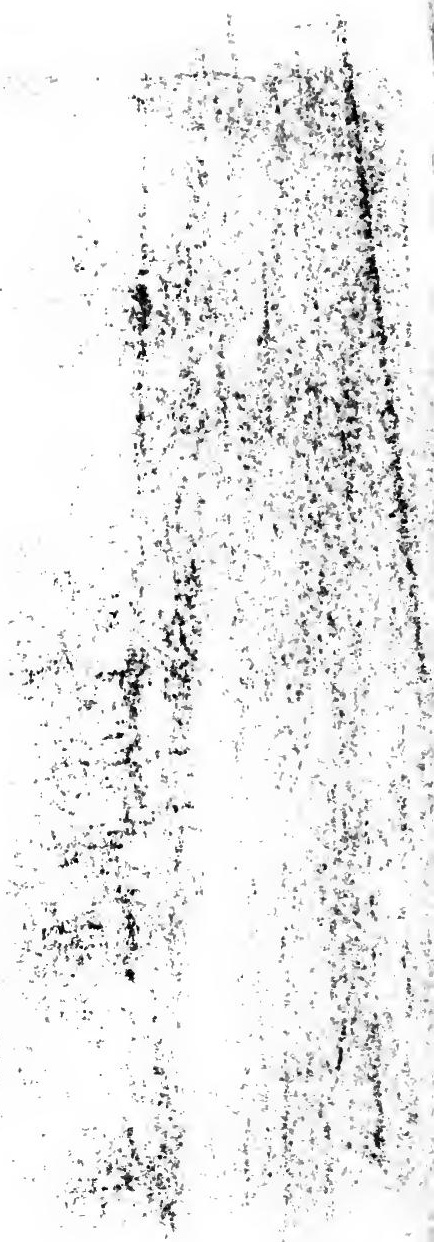


s 000301417005

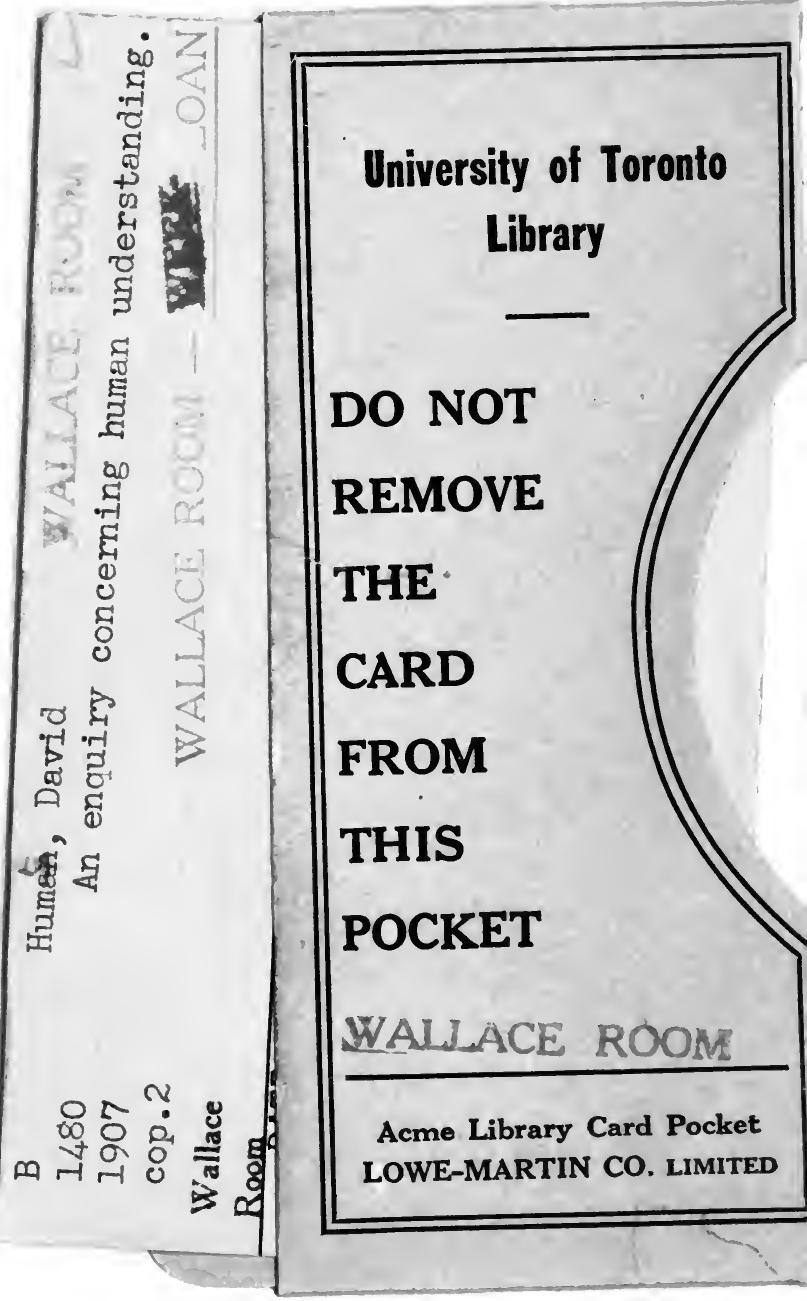




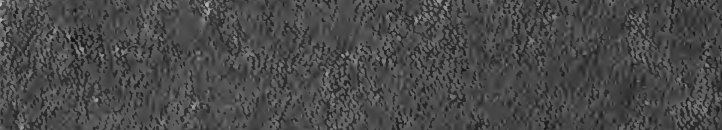

3.

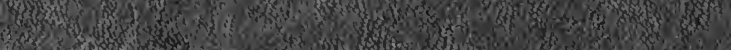

W.

of

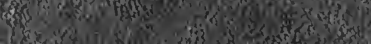

4.

(1)

is $0^{2}$,

2.

4.

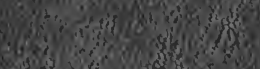

we hentivi

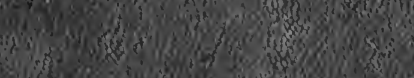

ir rowish

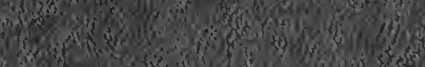

(19) 3 (h)

is 230

of

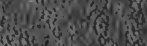

Hom

and

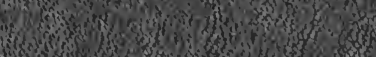

Whom

3
3

W. W

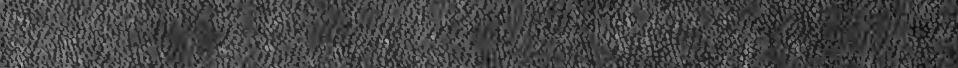

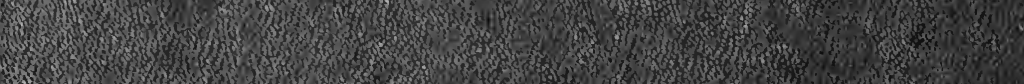

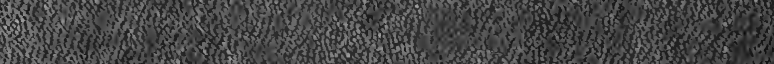

H.m.

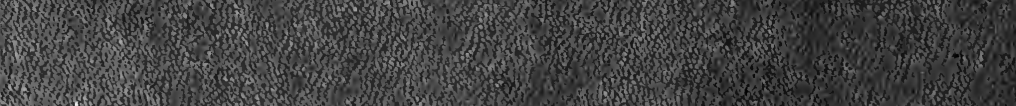
H.

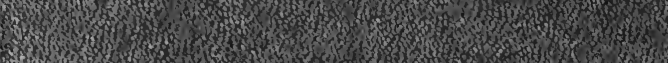
Mr.m.

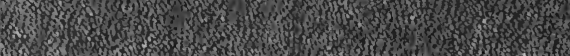

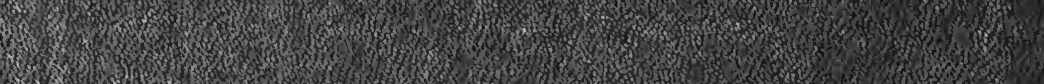

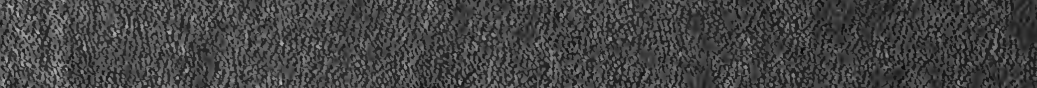
Whom H.w. (1) Whom 